\title{
دور الإحساس بالمكان في صناعة الأماكن والحفاظ الحضري لمواقع التراث : دراسة حالة المدينة المنورة فينة
}

\author{
د.حنان سليمان عيسى محمد

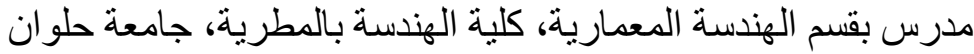

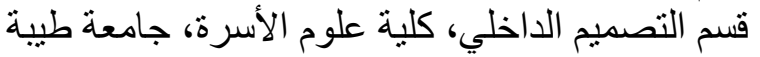 \\ hanan_mohamed01@m-eng.helwan.edu.eg
}

الملخه المدن التاريخية في ظل التطور الحضري السريع والعولمة تحديات عديدة من أهمها، إفتقاد فراغاتها

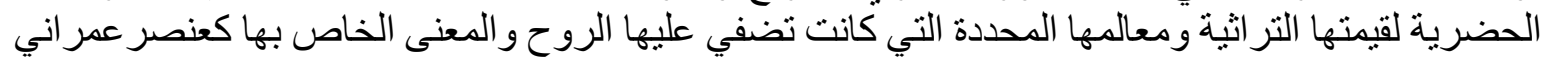

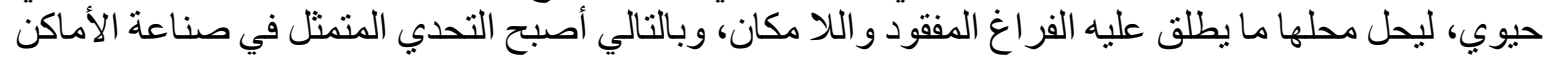

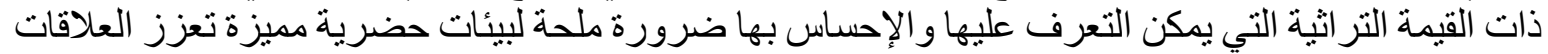

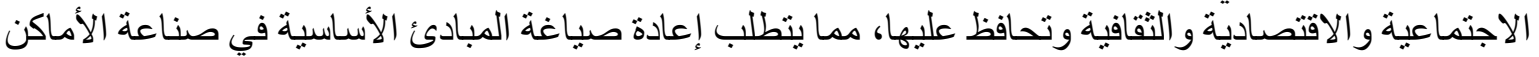

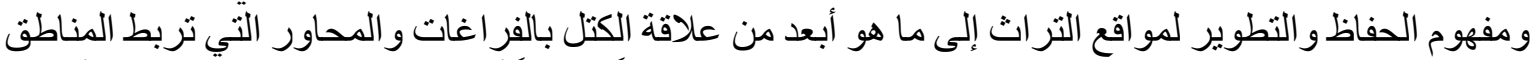

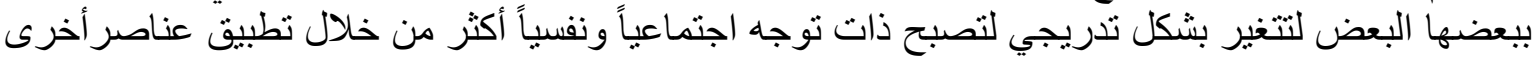

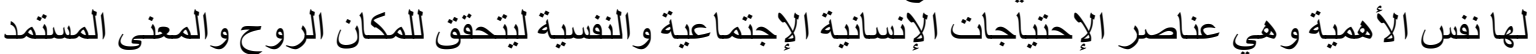

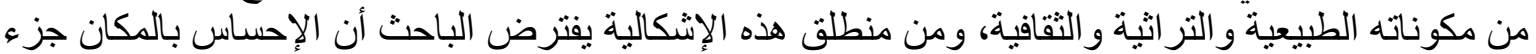

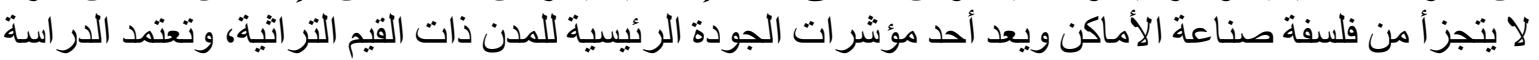

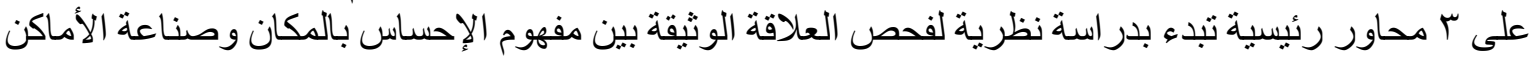

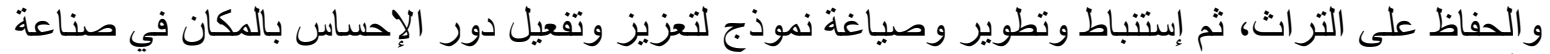

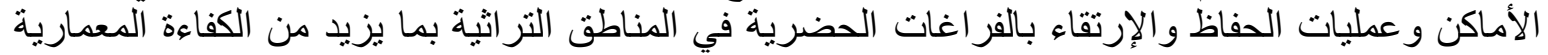

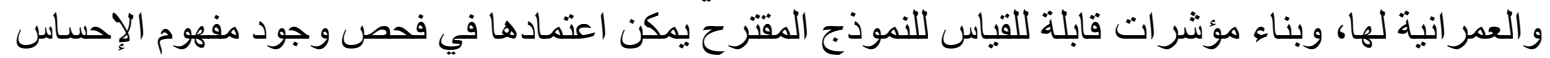

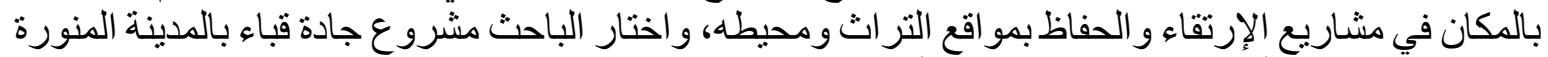

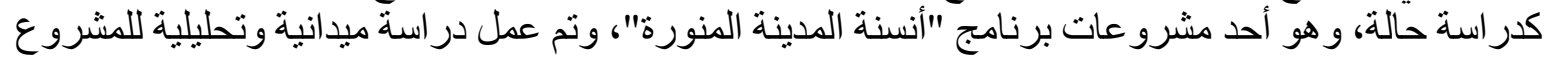

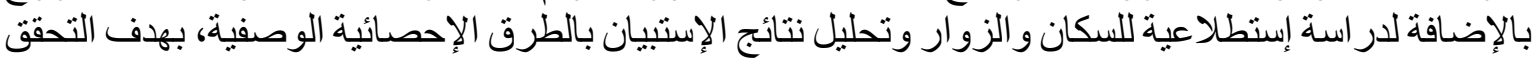

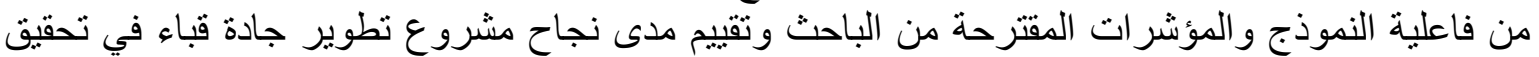

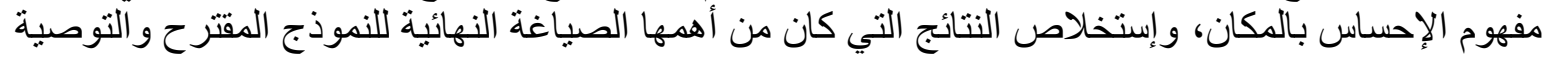

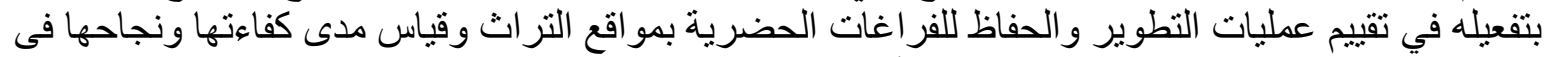

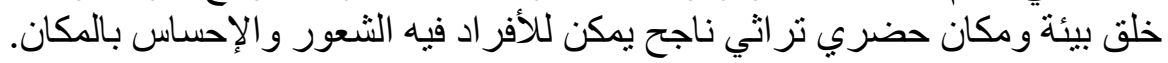

الكلمات الدالة: الإحساس بالمكان - صناعة الأماكن - الحفاظ الحضري - مو اقع التراث

مقدمة

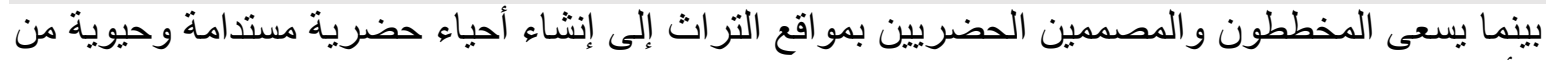

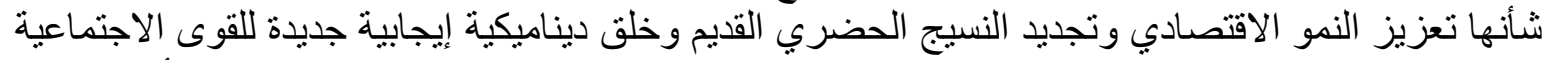

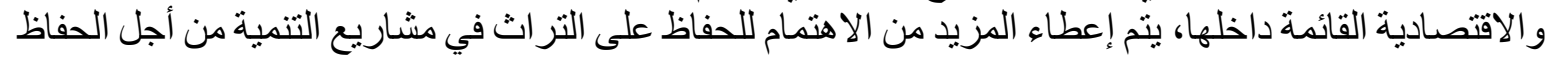

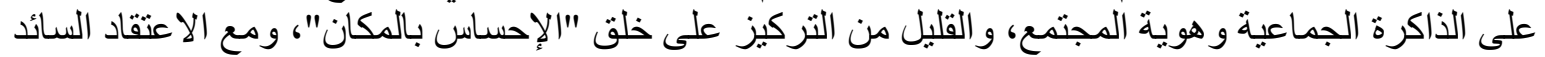

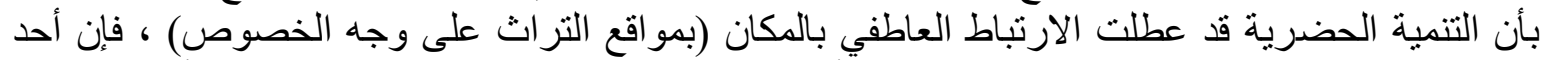

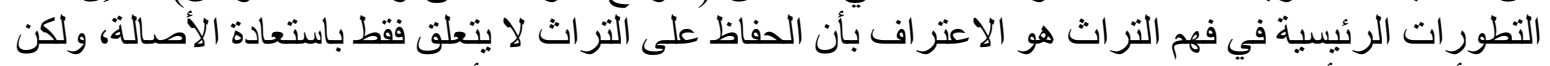

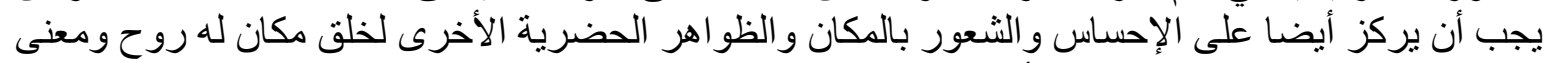

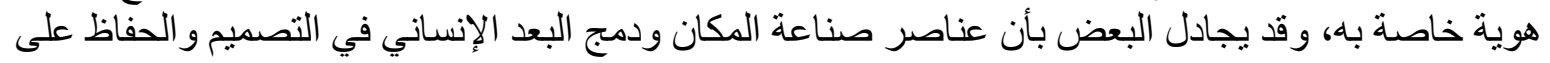




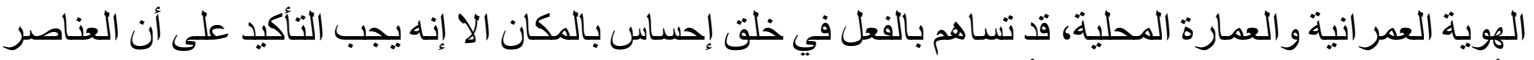

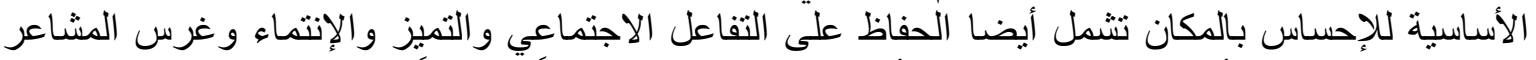

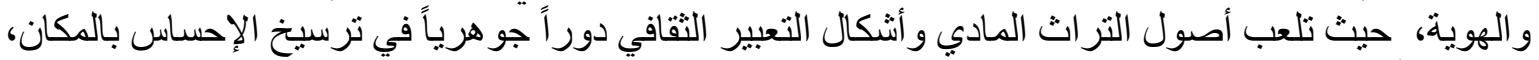

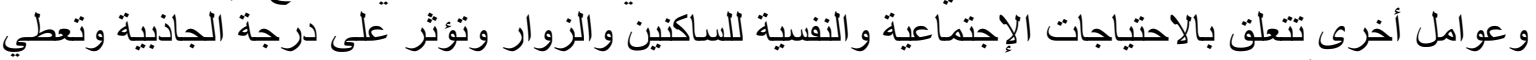

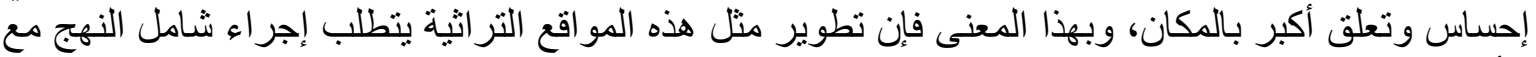

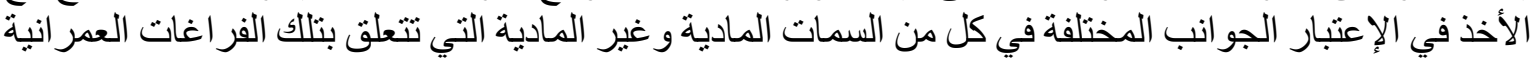

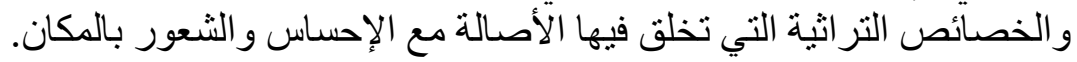

\section{مشكلة البحث أمثن}

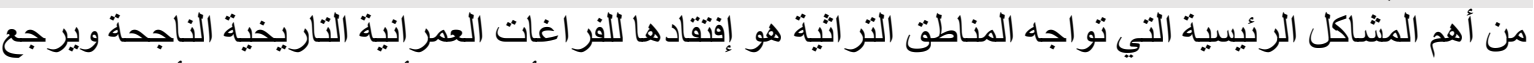

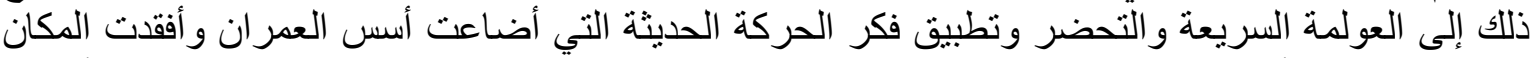

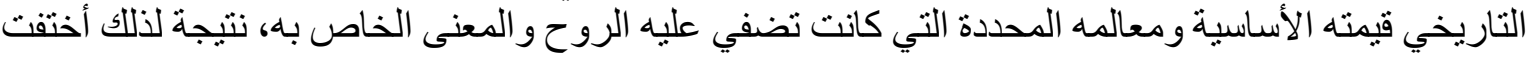

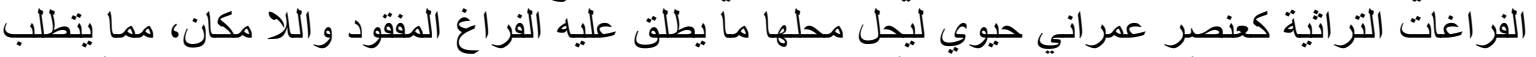

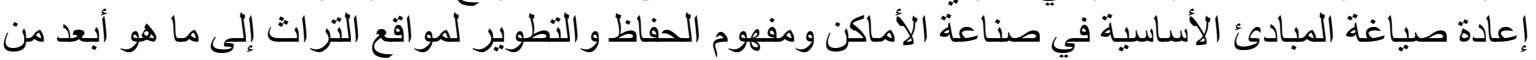

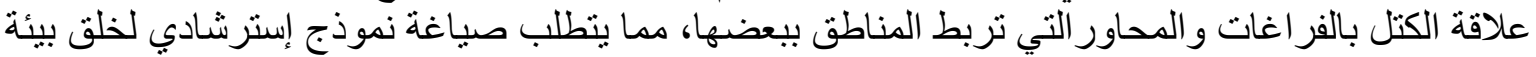

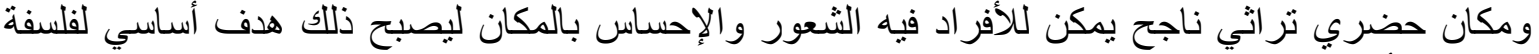

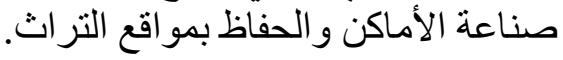

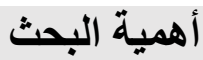

تتمثل أهمية هذه الدر اسة في مساعدة المصممين و المخططين على فهم أفضل لكيفية أن يصبح الإحساس بالمكان المكان

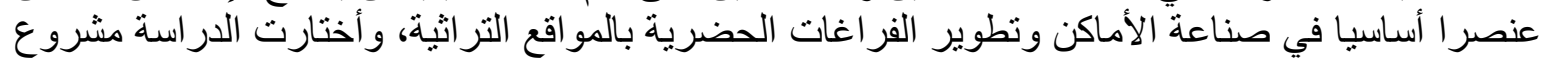

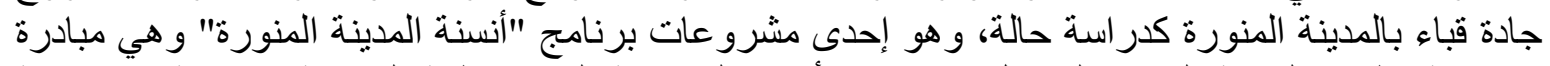

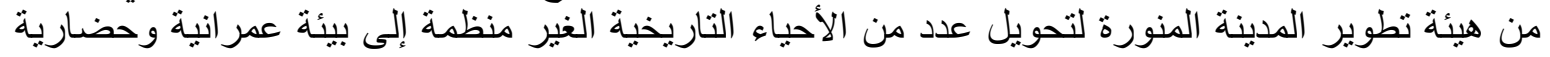

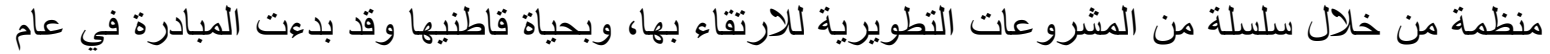

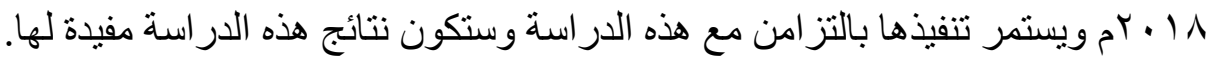

أهداف البحث

الهذف الرئيسي للبحث صياغة نموذج لتفعيل دور الإحساس بالمكان في صناعة الأماكن و عمليات الحفاظ والإرتقاء

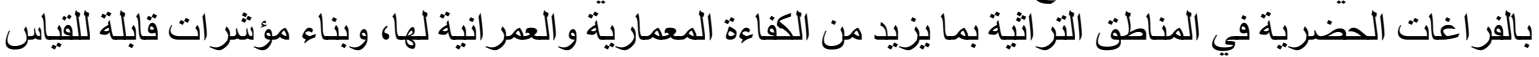

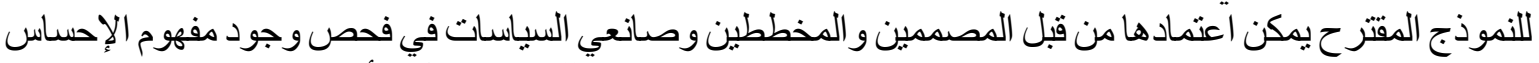

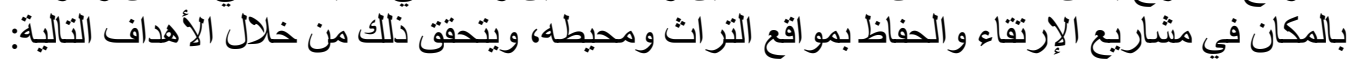

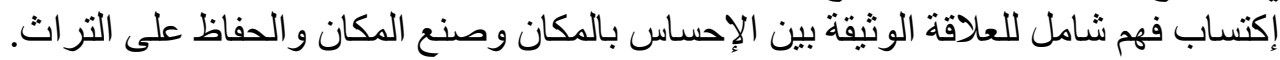

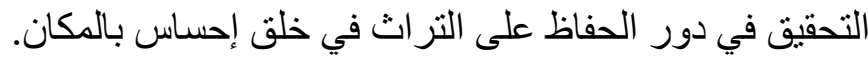

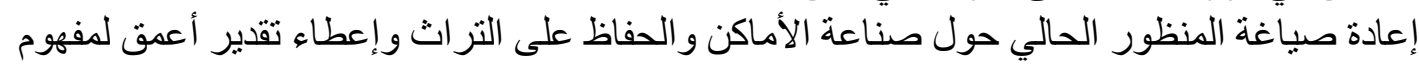

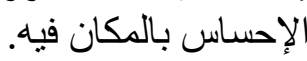
تحديد المكونات و السمات الأساسية التي تساهم في خلق الإحساس بالمكان في عملية الحفاظ على التراث

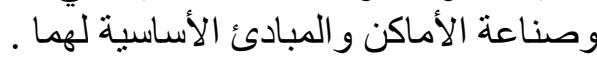

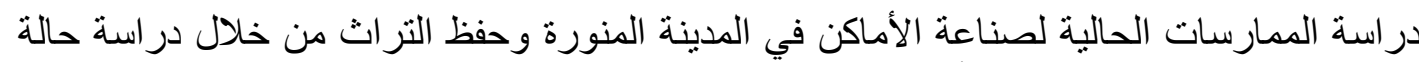

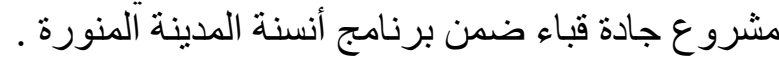

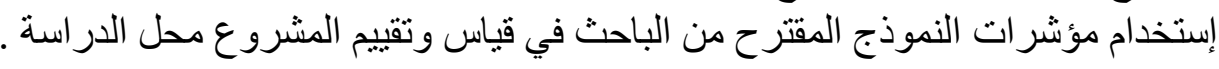

الإحساس بالمكان جز ء لا يتجز أ من فلسفة صناعة الأماكن ويعد أحد مؤشر ات الجودة الرئيسية للمدن

دمج مفهوم الإحساس بالمكان في ممارسات صناعة التهة الأماكن و الحفاظ على التر اث يصنع تجربة عمر انية 
منهجبة البحث

تتكون الدر اسة من ب مر احل رئيسية يتم فيها إستخدام المناهج التالية:

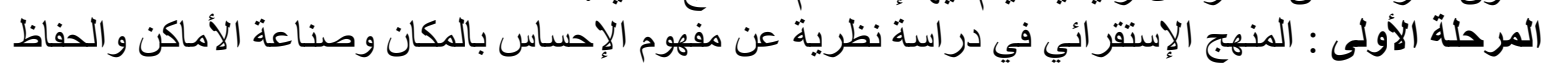

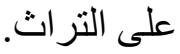
المرحلة الثانية : المنهج الإستنباطي صياغة نموذج لتفعيل مفهوم الإحساس بالمكان في الحفاظ والإنة الإرتقاء

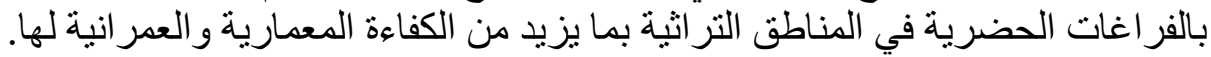

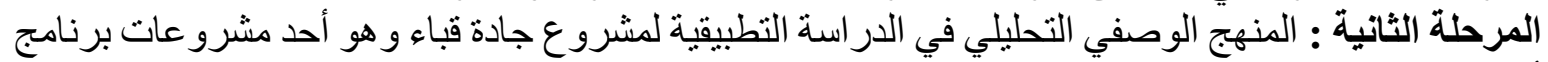

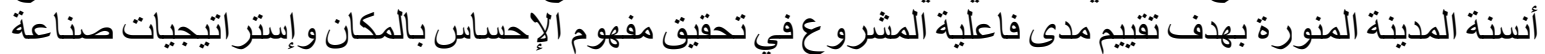

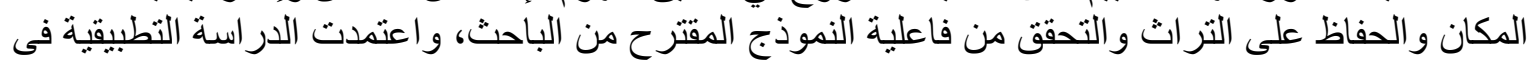

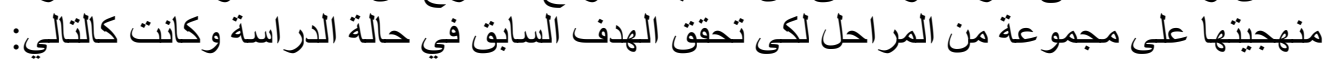

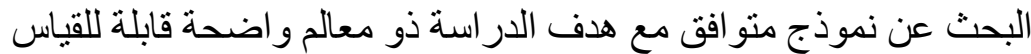

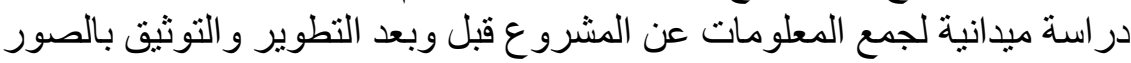

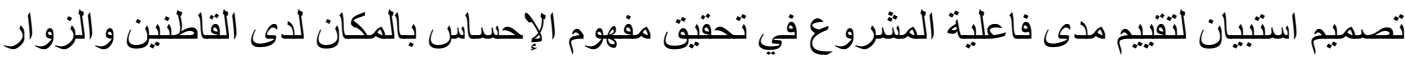

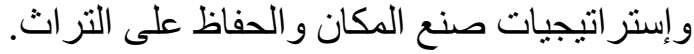
توزيع الإستبيان بإستخدام وسائل التو اصل الإجتماعي و المقابلات التخصية مع السكان و الزوار لملء

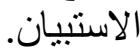

تفريغ الإستبيان و الدر اسة الإحصائية بإستخدام برنامج (SPSS)

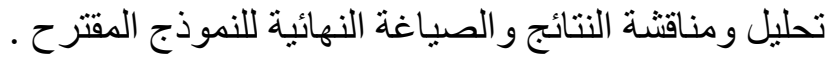

\section{PLACEMAKING إعناعة المكان الحضري}

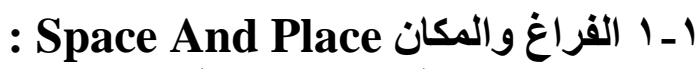

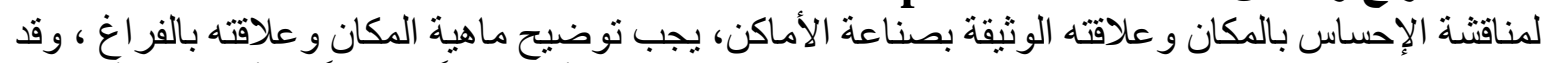

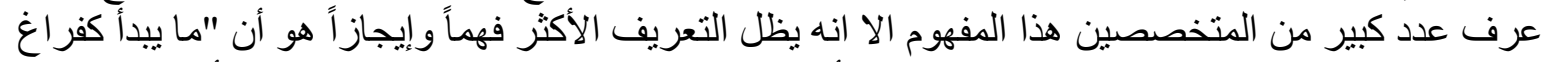

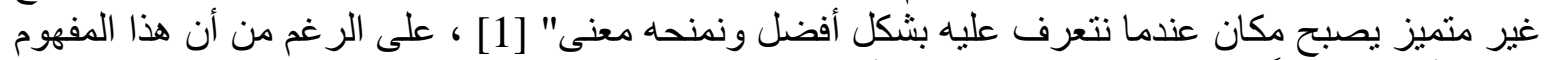

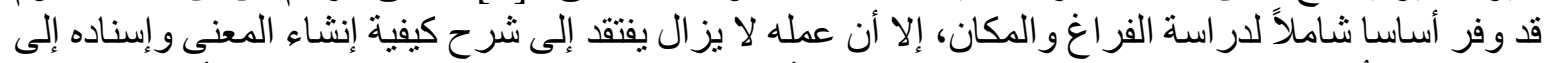

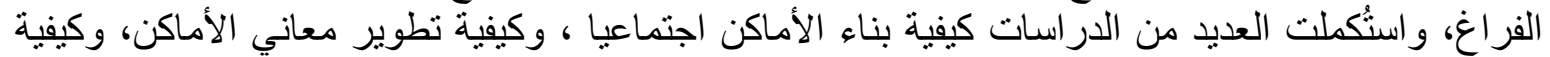

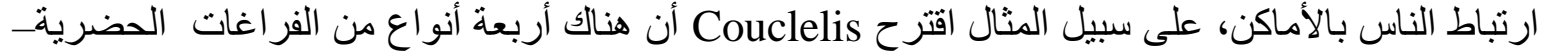

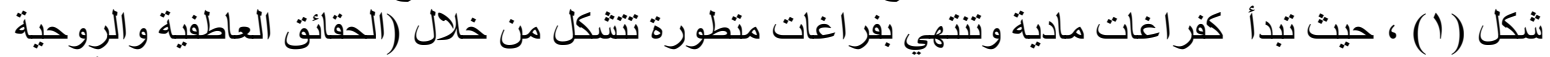

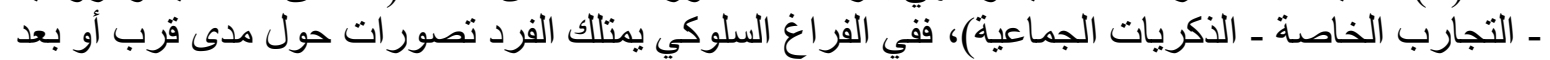

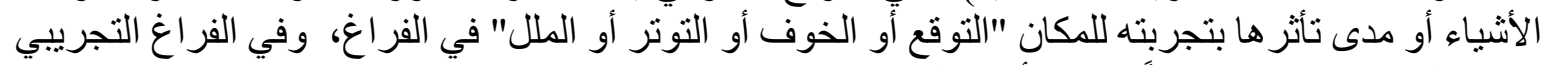

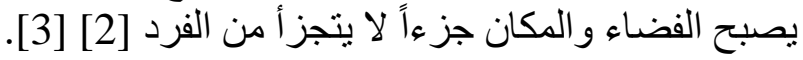

\section{فراغ سلوكي \\ Behavioura \\ I Space}

\section{فراغ مادي \\ Mathematical \\ Space}

\section{فراغ تجريبي \\ Experiential \\ Space}

○

○

\section{فراغ اجتماعي إقتصادي \\ Socio-economic \\ Space}

[2] Couclelis شكل(1) : أنو اع الفر اغات الحضرية في تصنيف

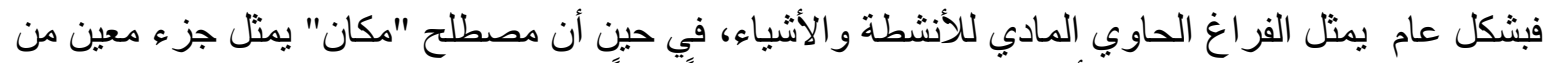

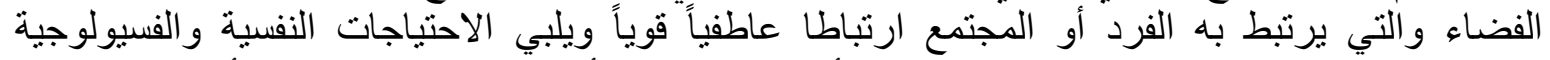
و الاجتماعية لَّم [4]، ببساطة تصبح الفراغات "أماكن" عندما تبدأ في تطوير العديد من الأسباب والمعاني الفاني 
المعرفية مما يتطلب فهم الأفر اد للفراغ وتجاربهم داخله بحيث يمكن اعتبار كل نقطة في الفر اغ بمثنابة معلماً،

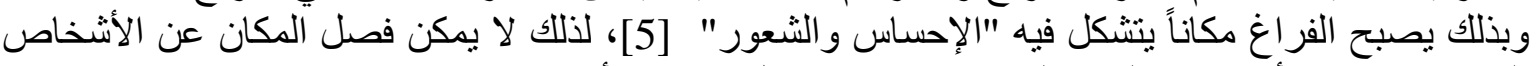

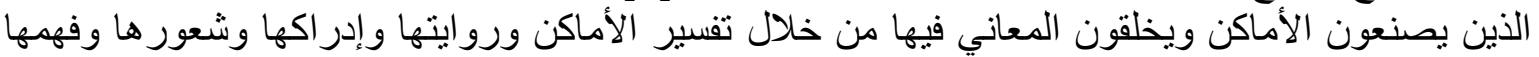

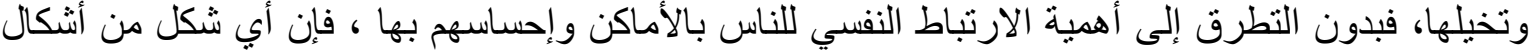

صناعة الأماكن وتقييم جودتها سيكون غيرن الفير كاف [6.

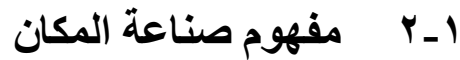

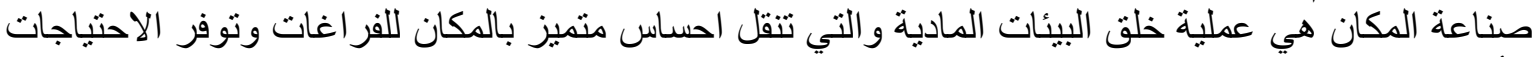

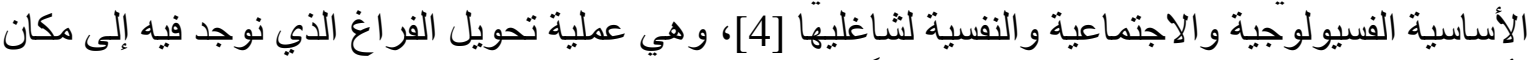

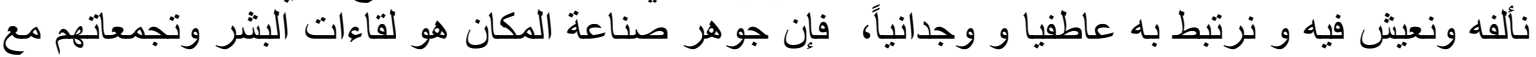

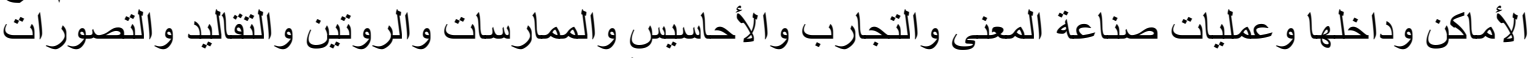

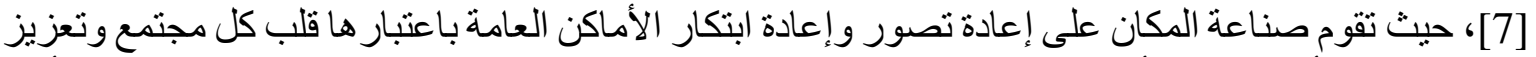

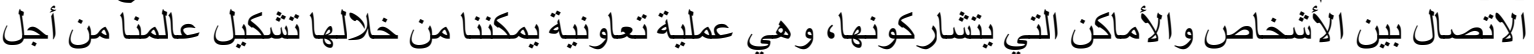

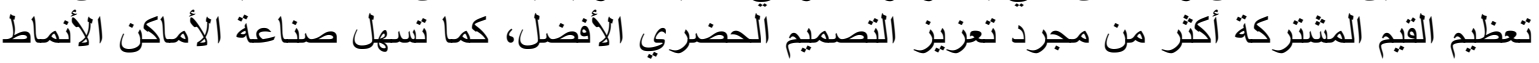

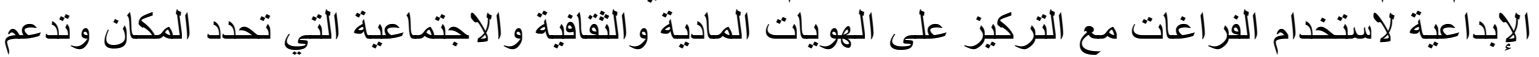

تطوره المستمر [8]

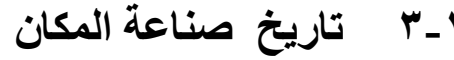

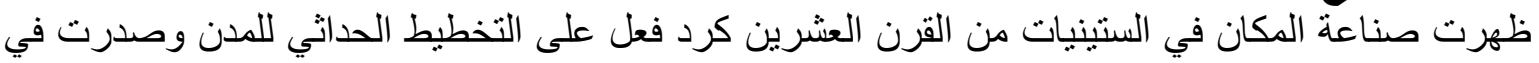
هذه الفترة الكثير من الكتابات التي مهدت لظهور مفهوم صناعة المكان دون إستعمال المصطلح فئح بشكل صريح

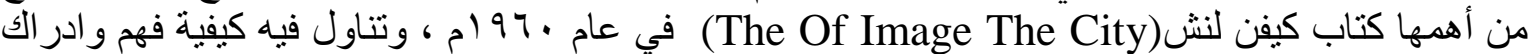

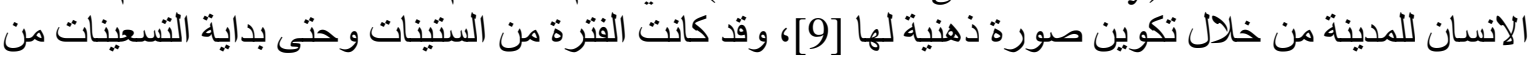

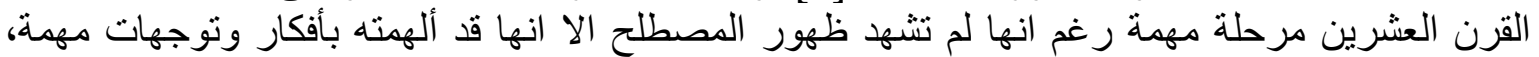

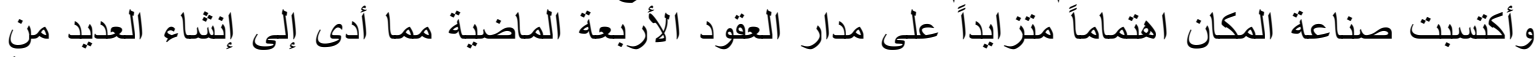

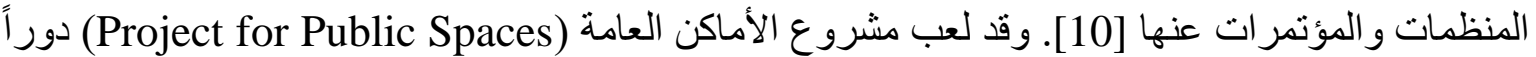

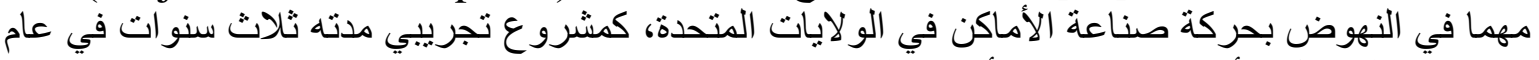

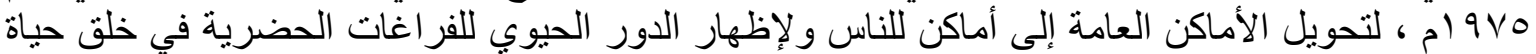

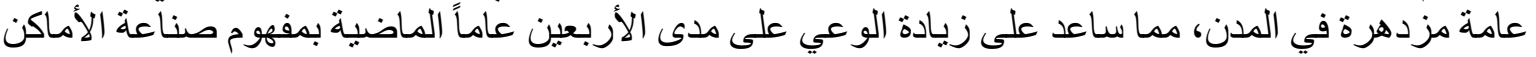

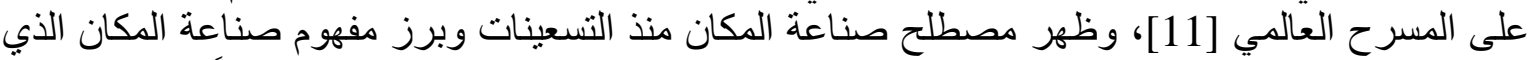

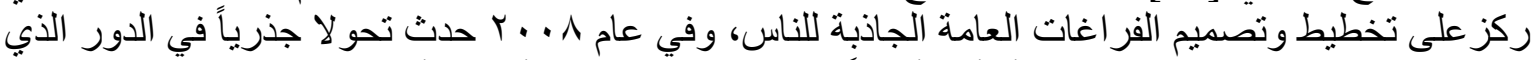

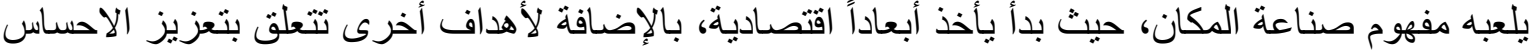

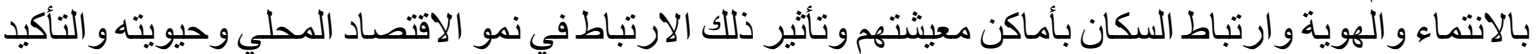

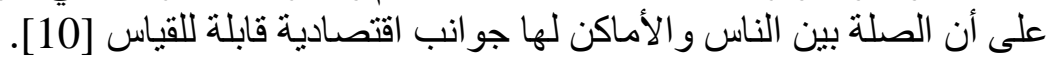

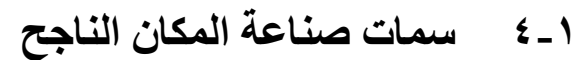

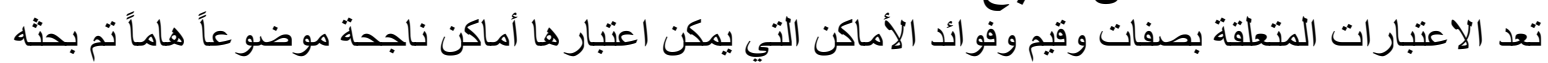

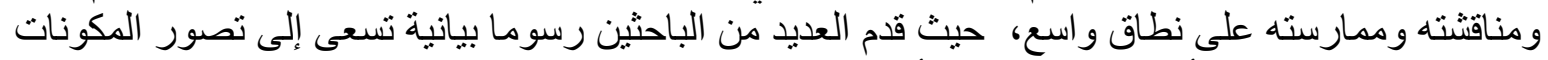

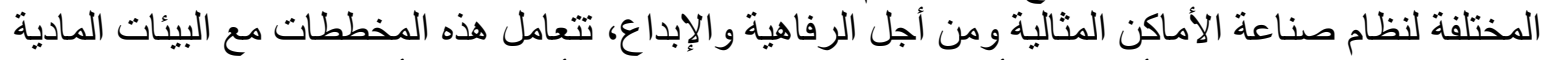

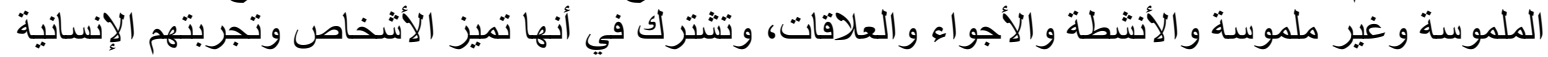
كمحرك مركزي لمفاهيم المكان المثالي [11]، على سبيل المثال يقترح

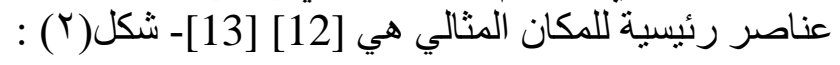

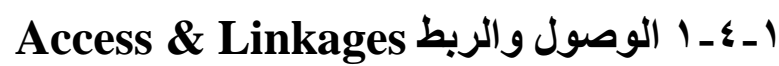

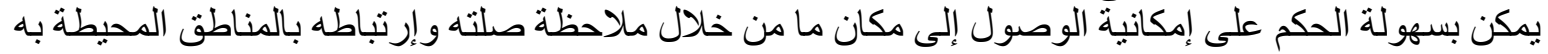

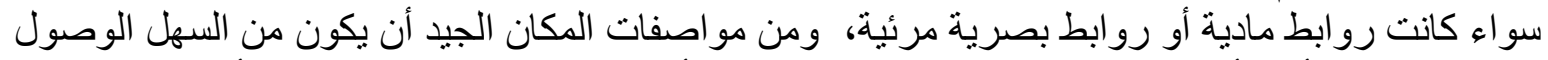

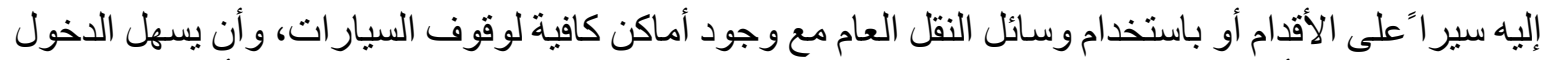

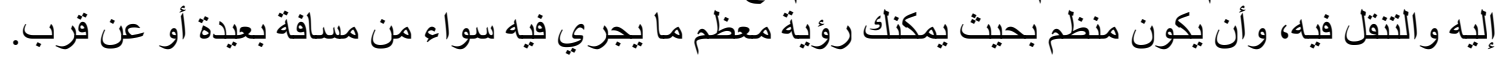




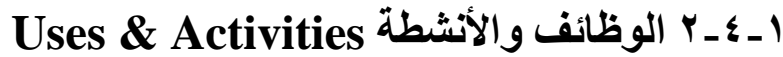

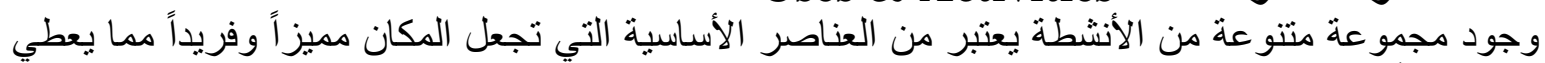

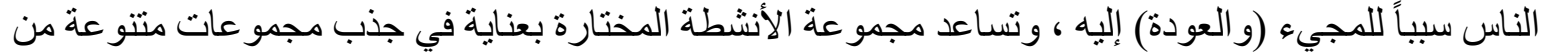

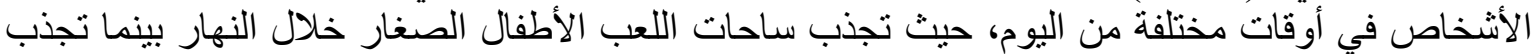

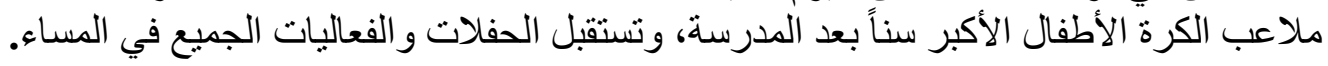

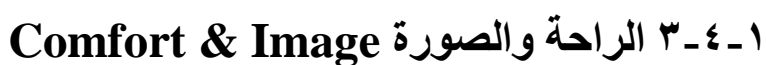

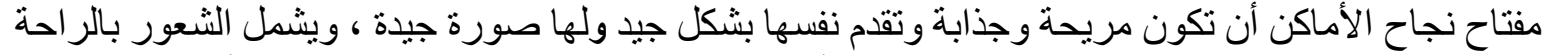

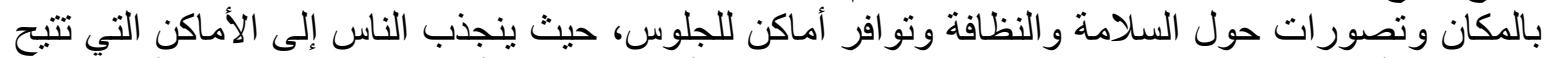

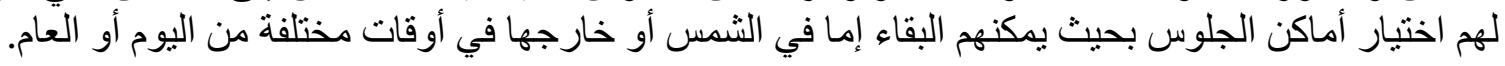

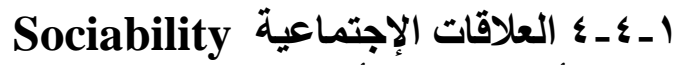

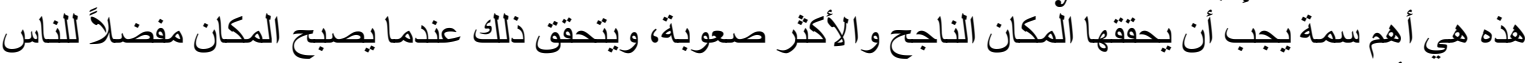

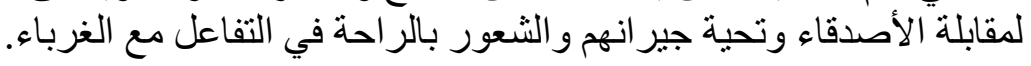

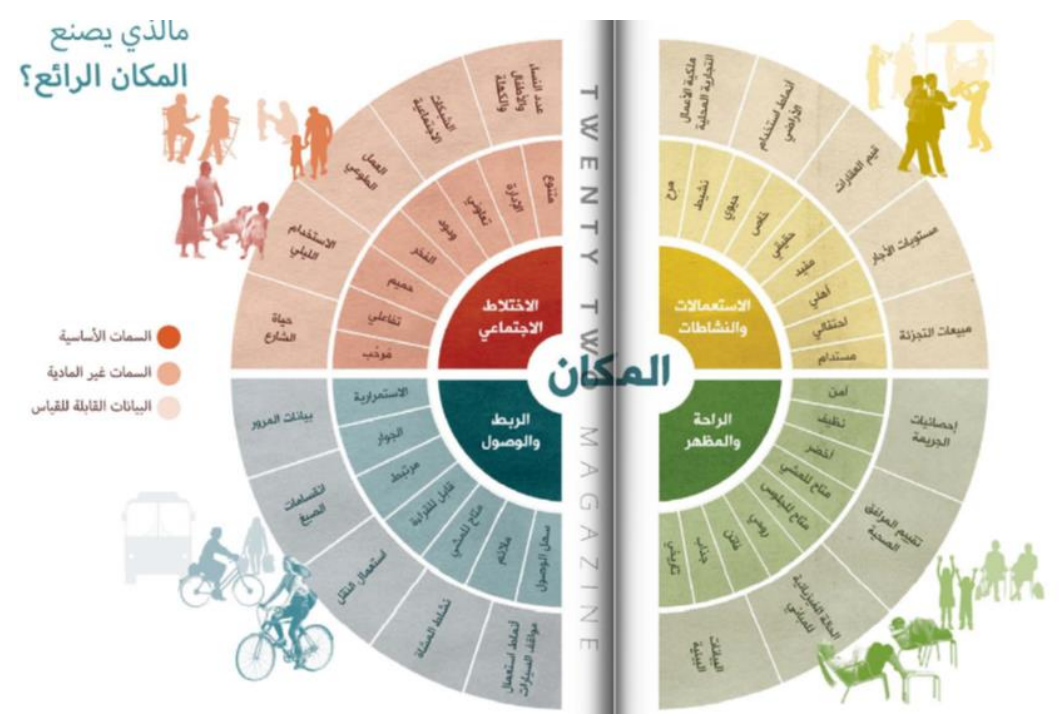

[13] Project for Public Spaces شكل (Y): مخطط بياني لتقييم الأماكن- مشروع الأماكن العامة

إلا أن هذا النموذج يفتقد التركيز على خلق إحساس بالمكان ولم بر اعي الاختلاف الذي يمكن أن يحدث من مكان

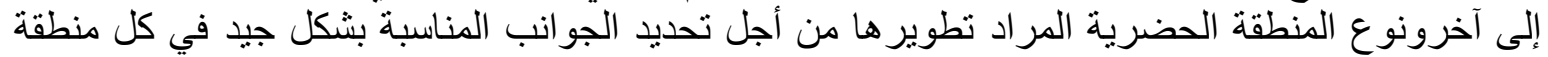
معينة وخاصة المناطق الحضرية التراثية.

\section{The Sense Of Place الإحساس بالمكان}

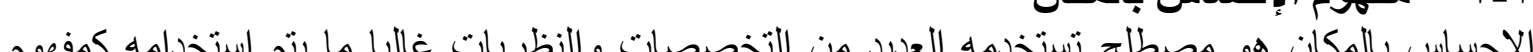
الإحساس بالمكان هوم الإحساس بالمكان

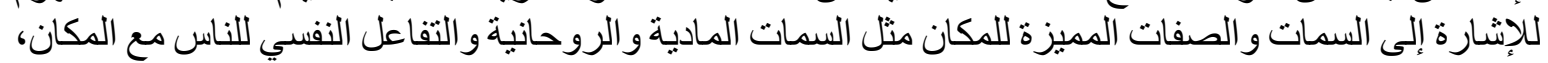

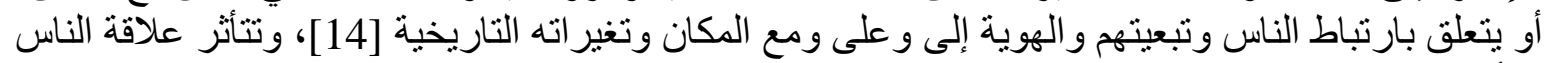

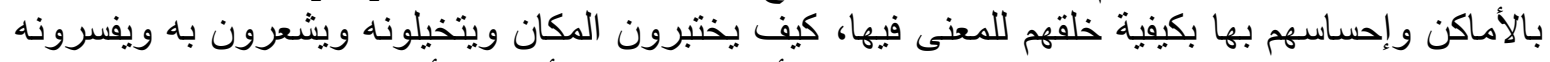

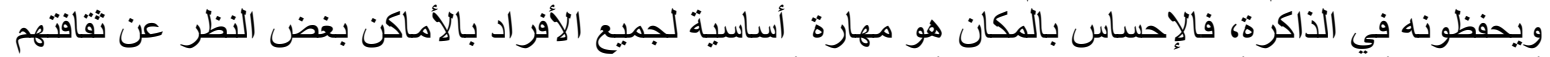

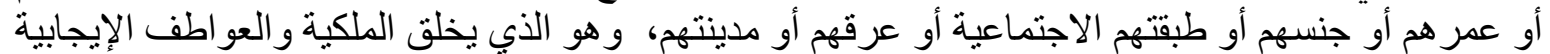

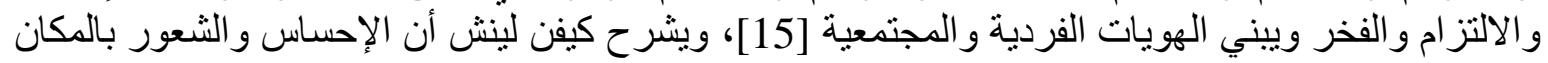

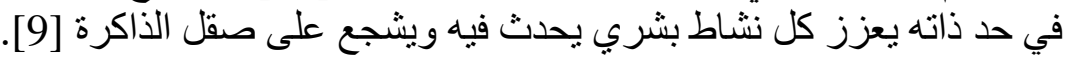


وقد تم تعريف "الإحساس بالمكان": على أنه إرتباطات عاطفية ووظيفية بالأماكن [16]، وهو المعاني التي

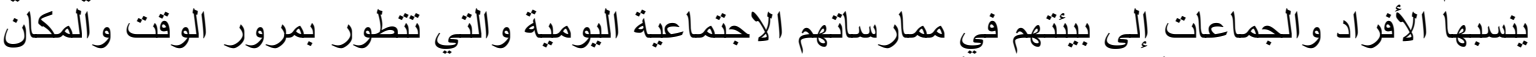

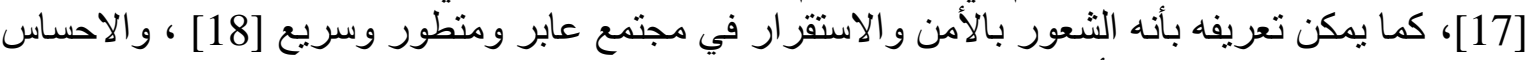

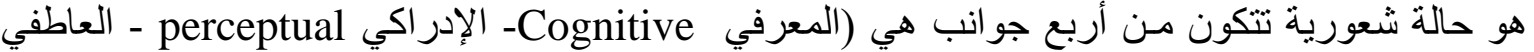

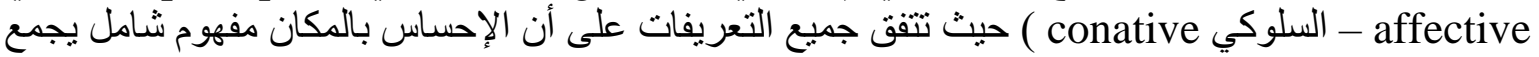

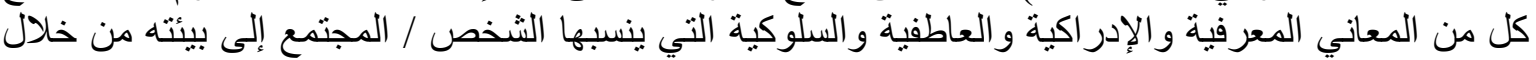

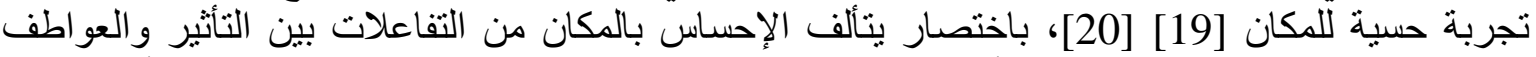

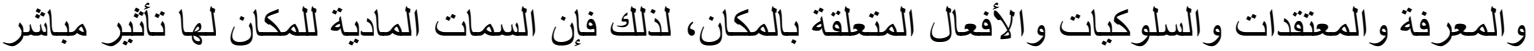

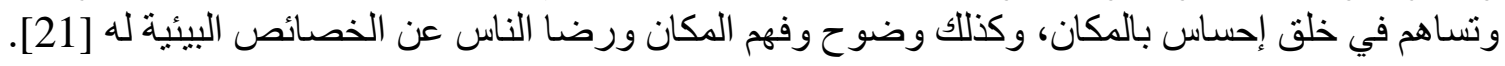

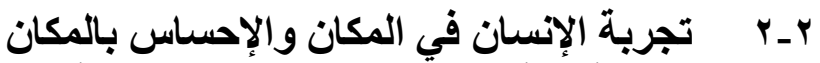

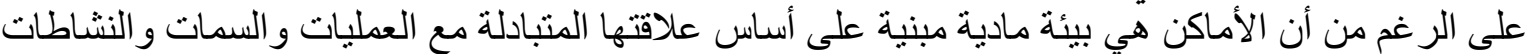

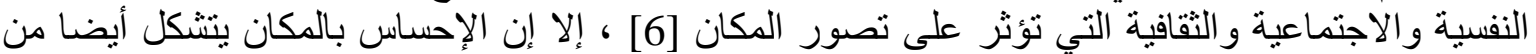

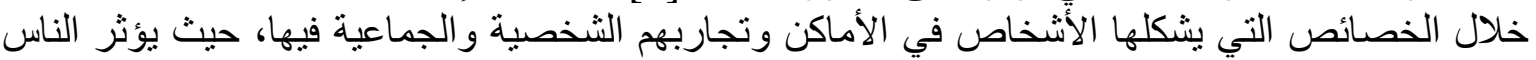

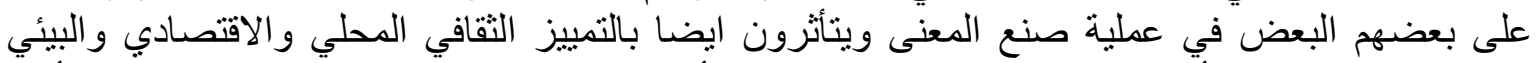

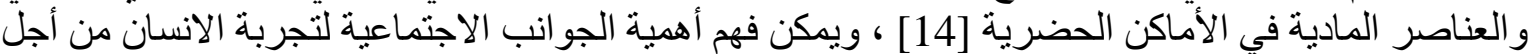

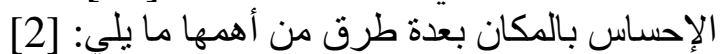

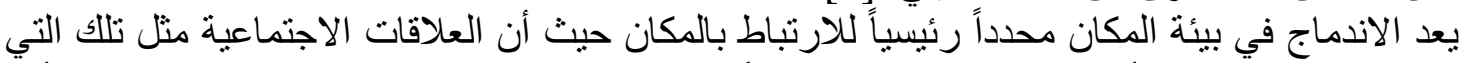

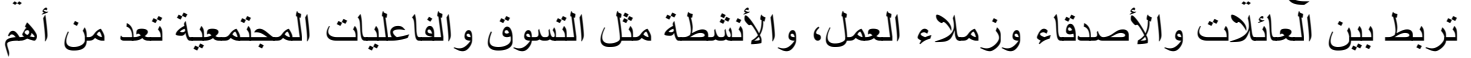
مصادر الروابط العاطفية بالأماكن في البيئة المحلية.

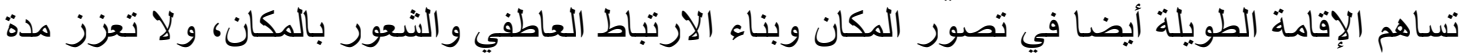

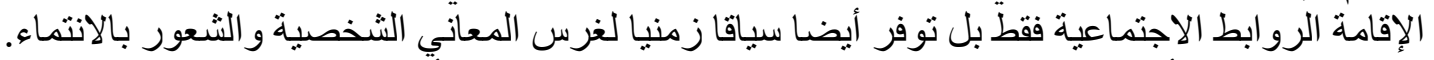

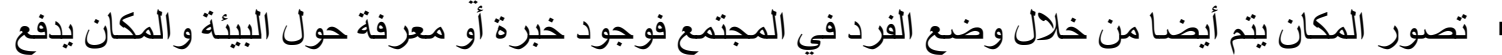

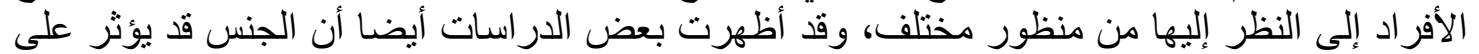

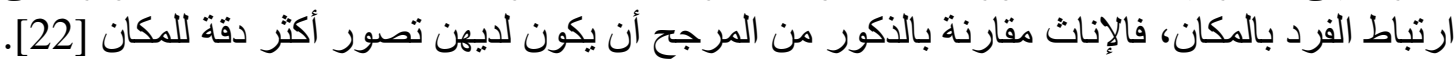

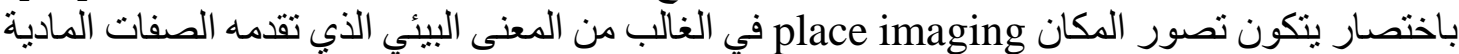
للمكان، بينما الأحساس بالمكان Sense of place هو نتاج كلا من صفات وخصائص النص الأماكن و علاقات

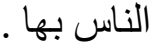

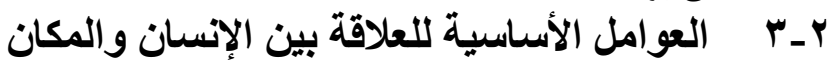

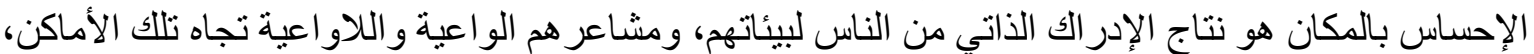

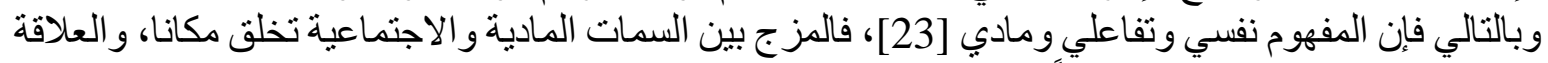

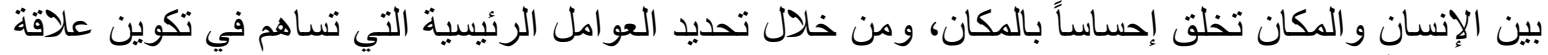

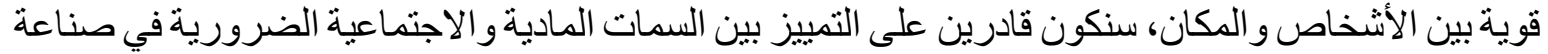

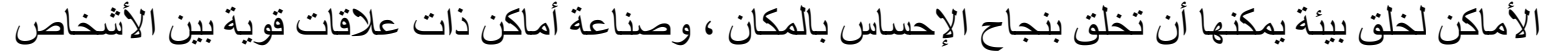

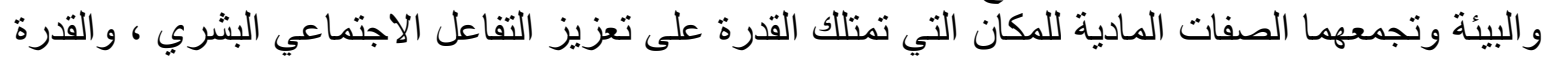

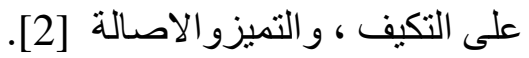
• التفاعل الاجتماعي :لا تتعلق الصفة الأساسية للمكان فقط بإمكانياته الجمالية أو السلوكية بل نثمل أيضا قدرته في تعزيز التفاعل بين الأفر ادوتتجيع تنمية الهويات الثخصية والتهية المجتمعية وتعزيز المعاني الاجتماعية

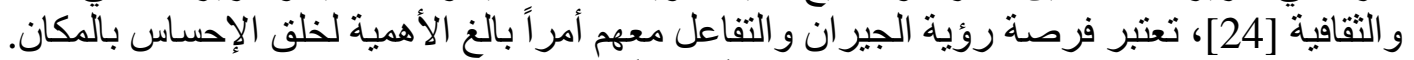

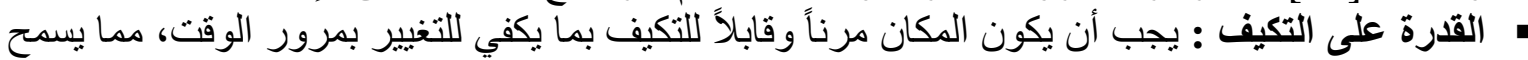

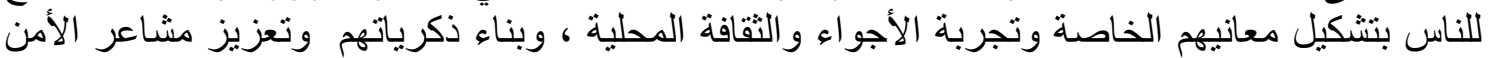
و الر احة و الملكية.

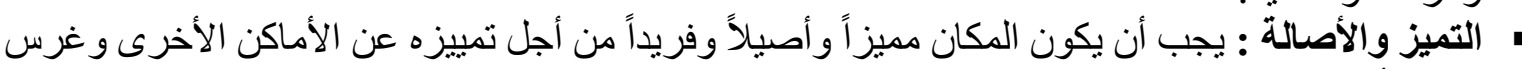
شعور أقوى بالإنتماء والهوية ولتعزيز قيم المجتمع المتميزة والخصائ الخصائص المحلية للمكان. 


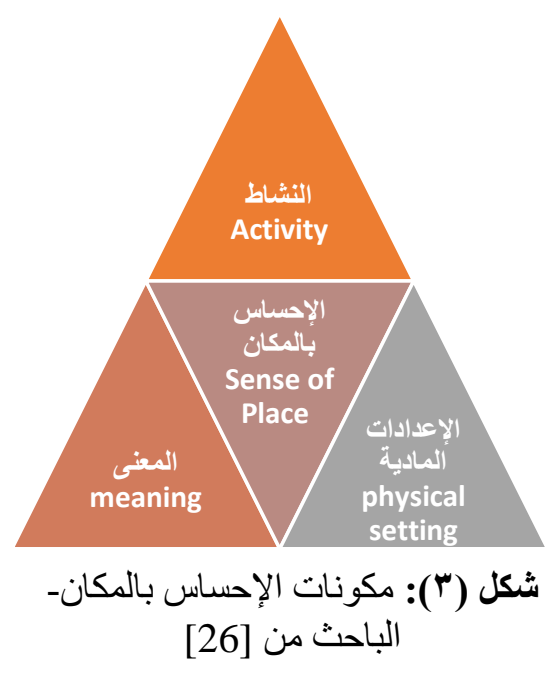

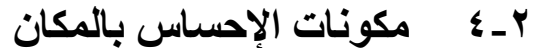

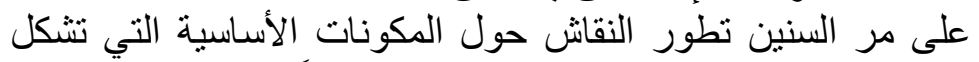

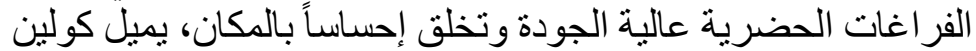
Cullen

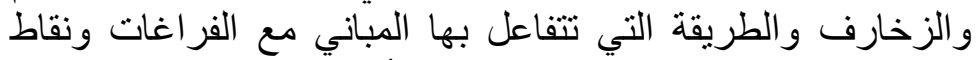

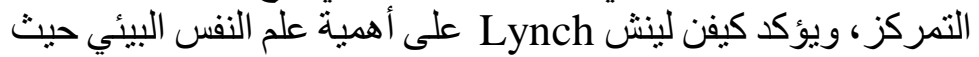

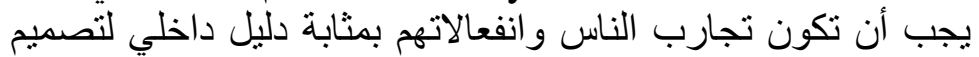

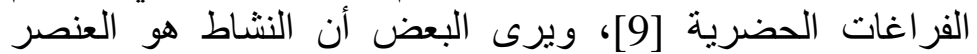

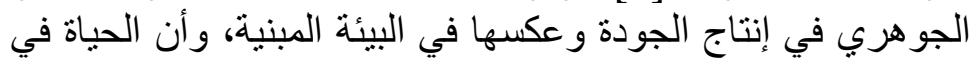

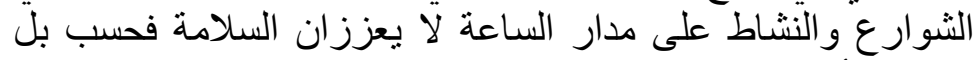

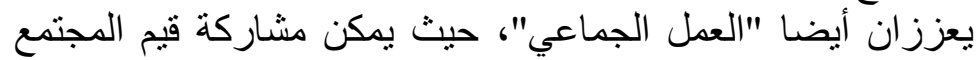

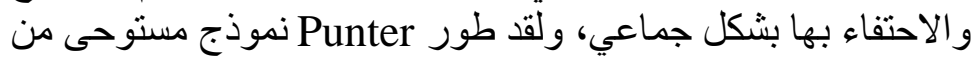

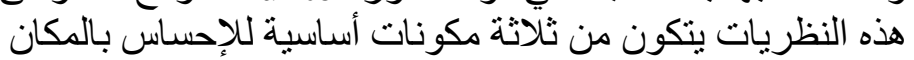

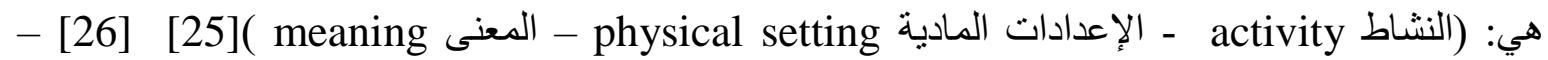

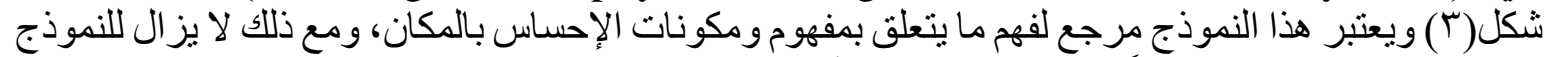

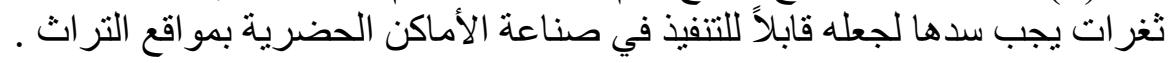

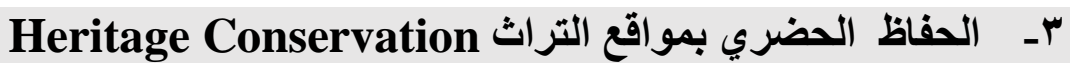

r- إ مفهوم الحفاظ الحضري

لقد تغيرت عمليات الحفاظ الحضري لمو اقع التراث على مدار العقود الأخيرة بشكل جذري من حيث نظريتها

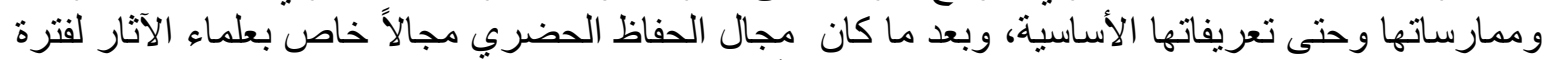

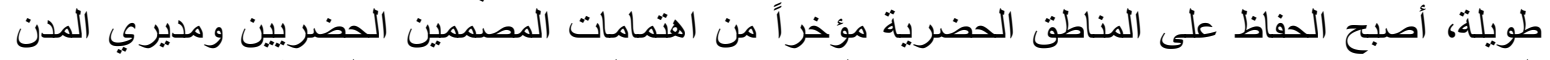

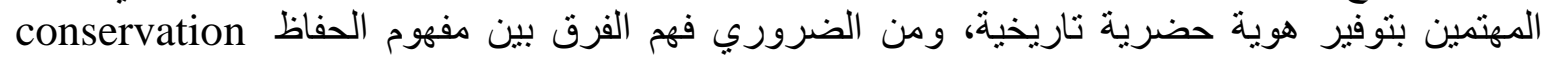
concept ومنهجية الحفاظ conservation methodology فالمنهجية هي الإجر اءات العملية المتبعة للحفاظ

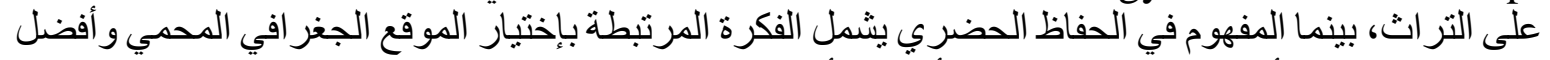

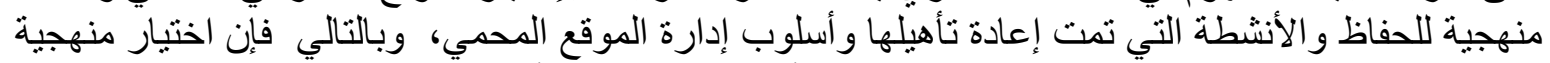

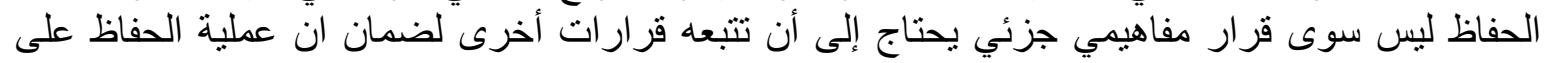

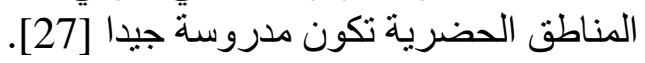

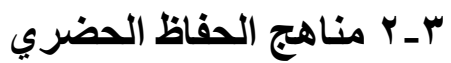

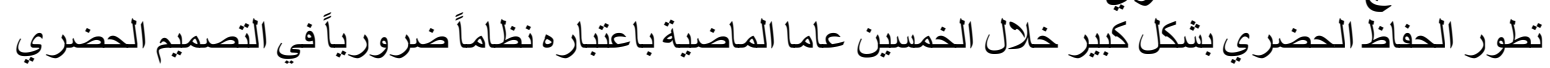

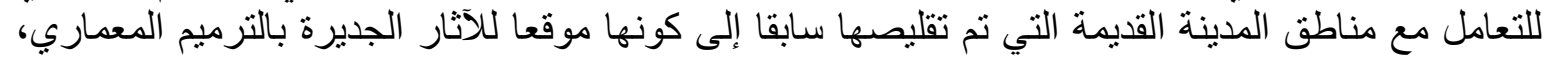

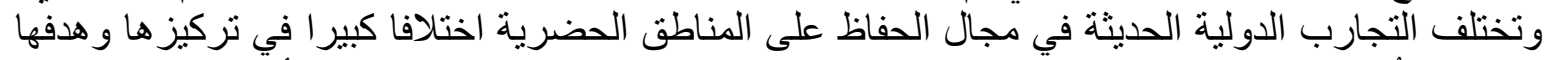

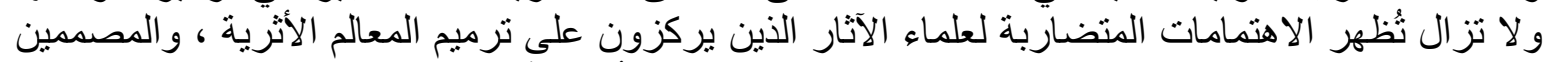

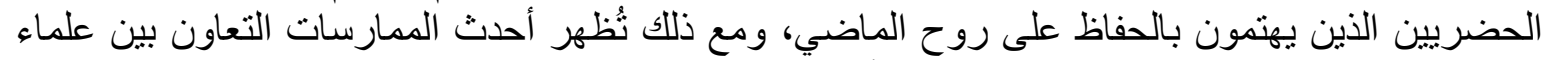

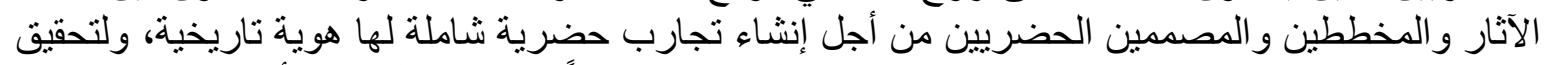

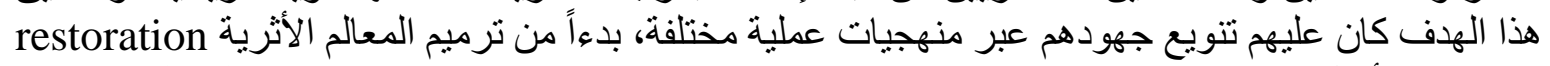

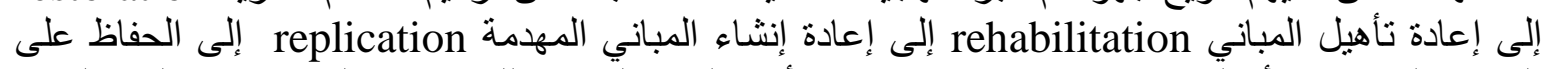

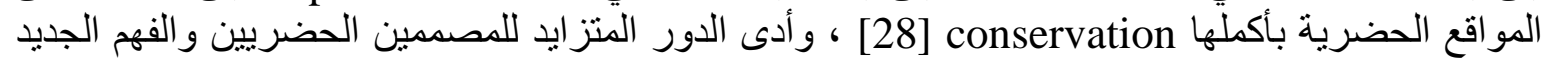

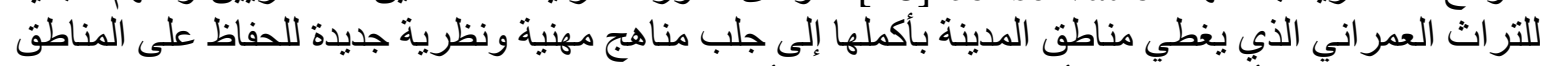
الحضرية، وتهذف أحدث هذه الأساليب إلى صناعة أماكن حضرية ممتعة وليس مجرد الاحتفاظ الحئ بالتاريخ

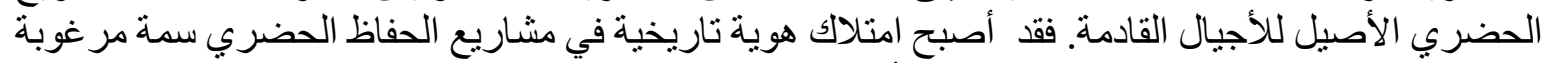

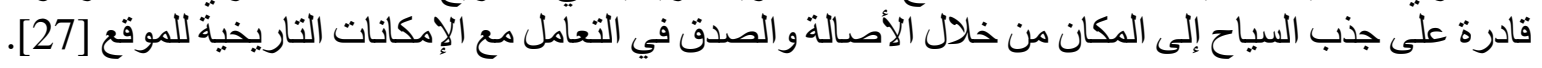




\section{r-r الحفاظ وصناعة المكان بمواقع التراث}

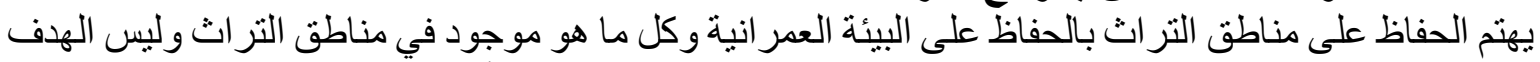

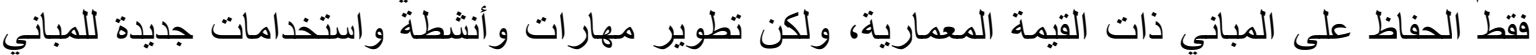

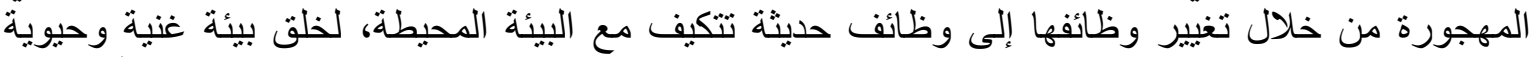

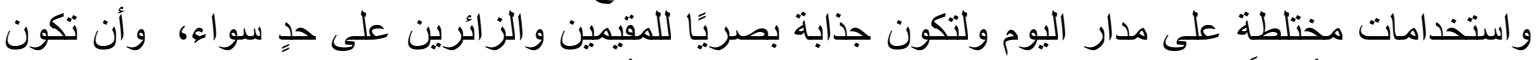

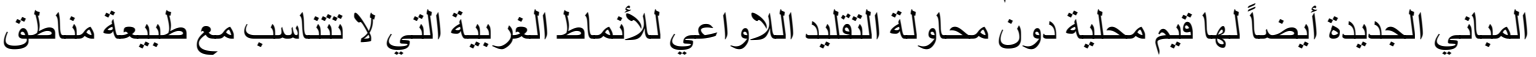

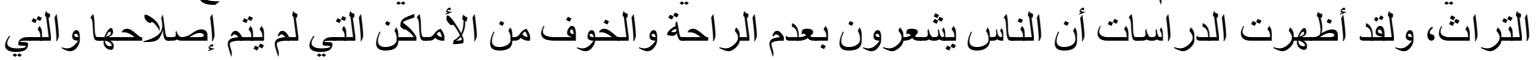

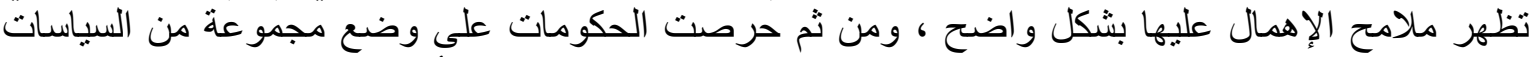

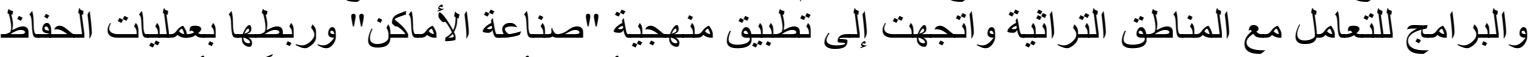

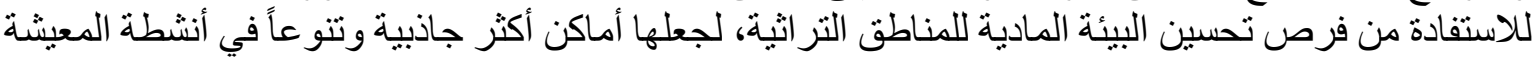

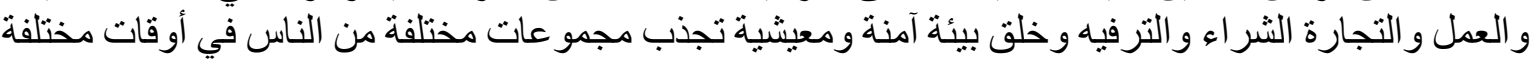

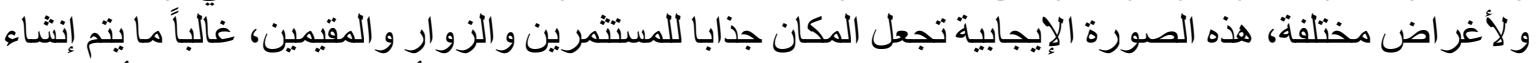

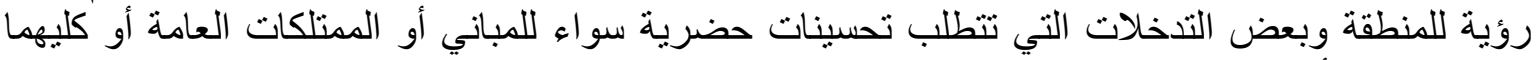

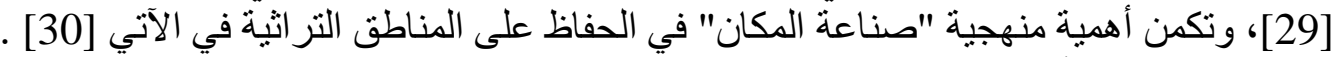

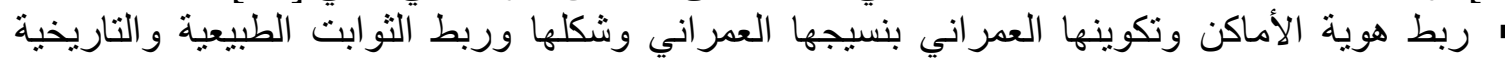
و الثقافية لحياة المنطقة وسكانها.

• التعرف على الخصائص العمر انية الجديدة للمناطق التراثية وكيفية التحليل العمر اني و المادي من خلال الترل

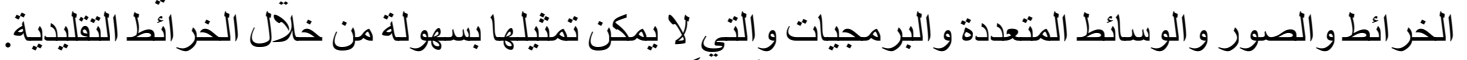

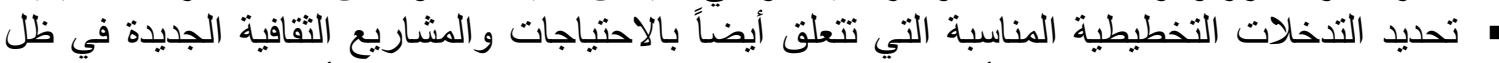

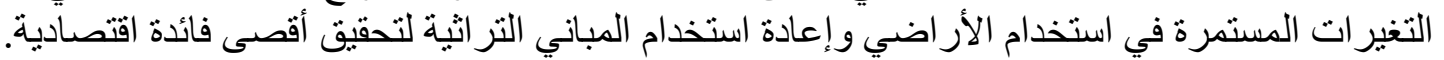

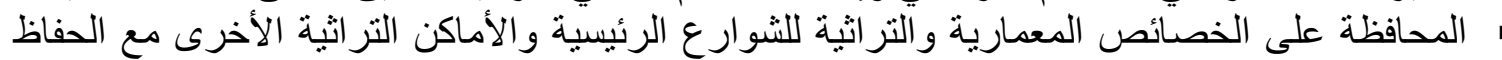

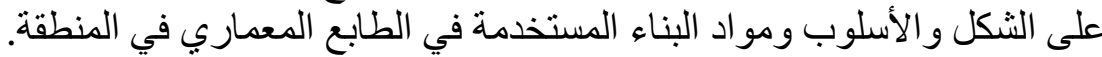

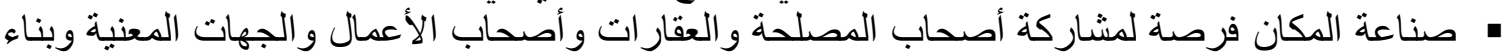

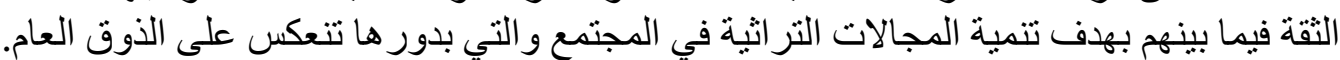

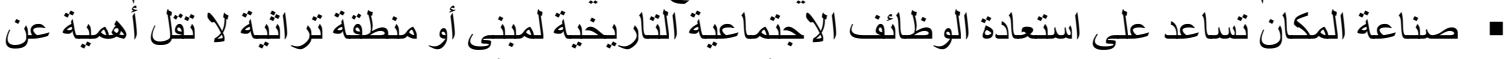
الوظائف المدنية والتجارية، كما تساعد صناعة الأماكن على توسيع تأثير مشاريع التهاعيع الحفاظ.

\section{بـ ـ الحفاظ الحضري والإحساس بالمكان}

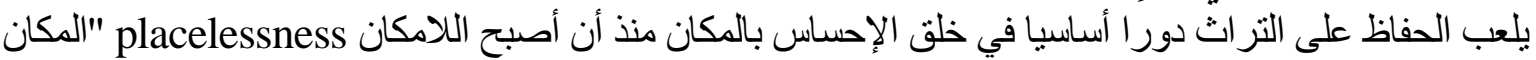

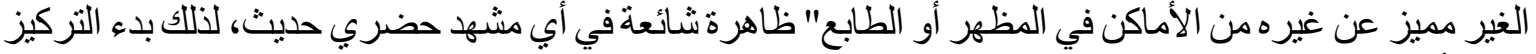

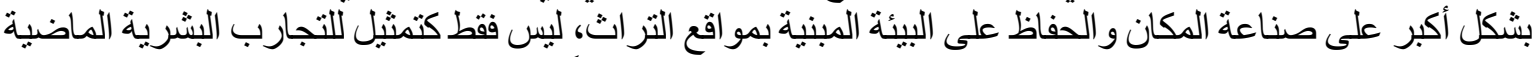

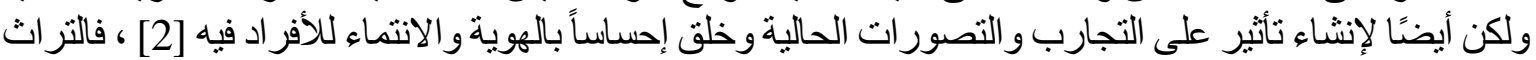

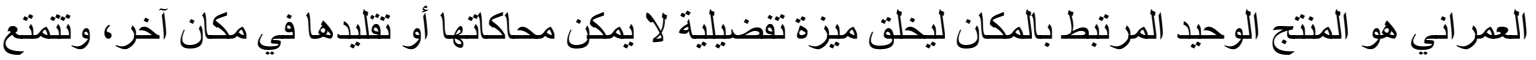

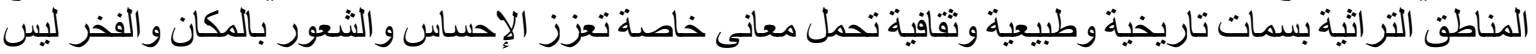

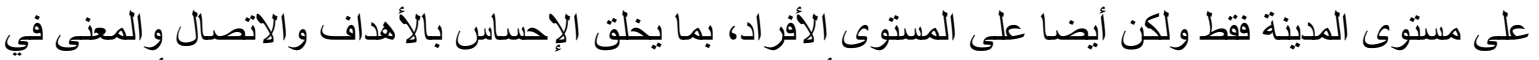

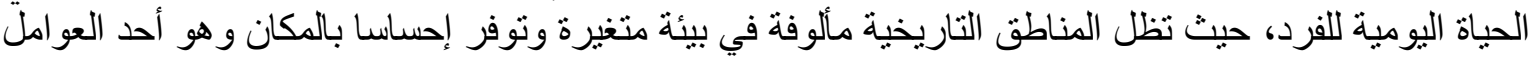

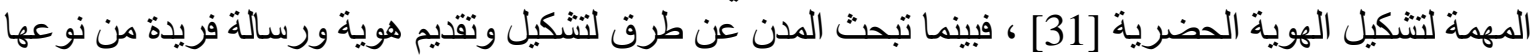

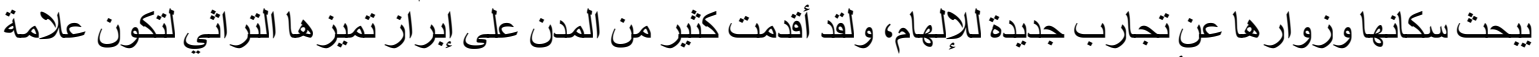

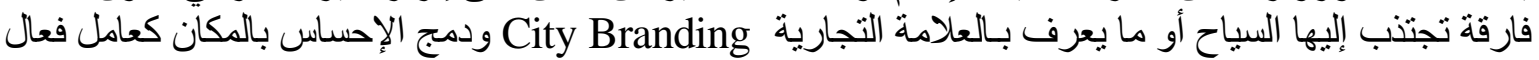

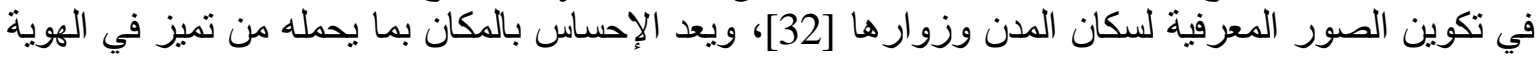

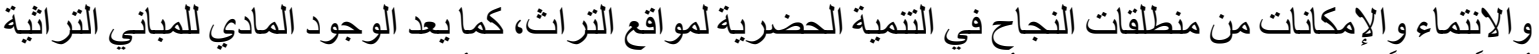

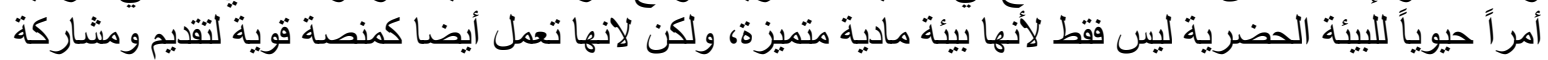

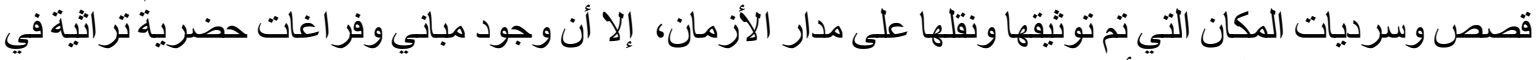

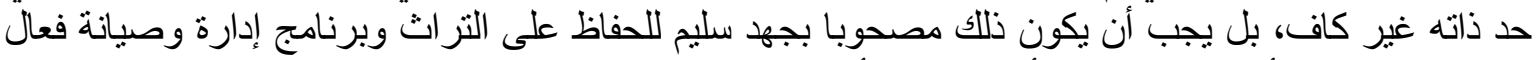
لضمان استمر ارية أصالته وحيويته وأن يكون له تأثير ات طويلة ذان المدى على محيطه [27]. 


\section{ع - صياغة نموذج لتفعيل الإحساس بالمكان في صناعة الأماكن والحفاظ الحضري بمواقع التراثية}

جميع الأماكن الناجحة لها هو يات وخصائص مميزة و التي غالبا ما تكون نتيجة لإنشاء و الحفاظ على الإنى نقاط محددة

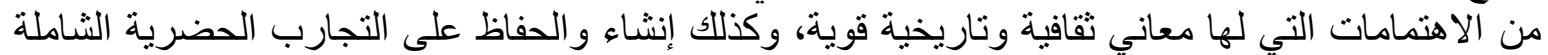

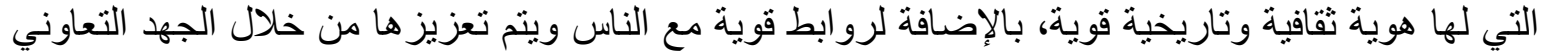

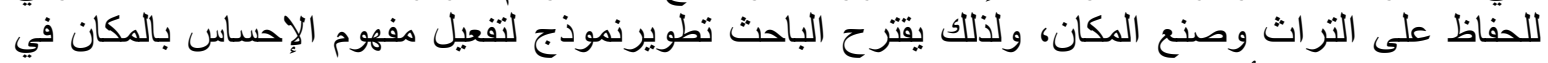

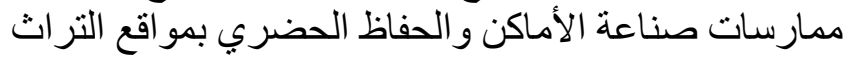

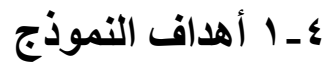

يعهدف النموذج المقتر ح لتفعيل الإحساس بالمكان في صناعة المدأ الأماكن و الحفاظ الحضري بمو اقع التر اث إلى إنشاء

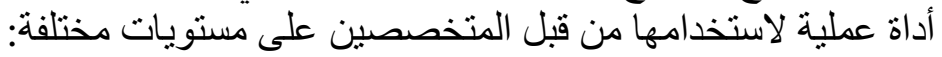

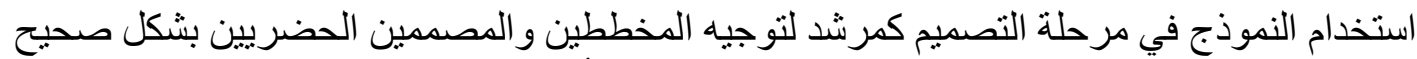

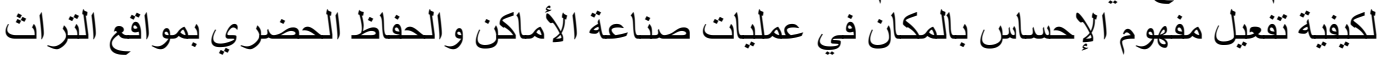

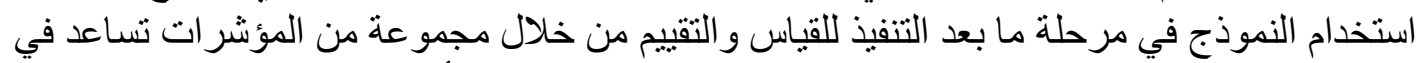

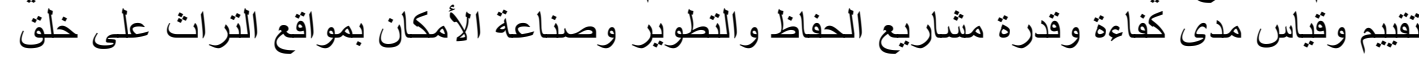

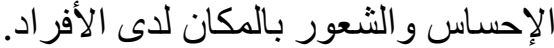
تقديم إرشادات واضحة لصنانعي القرار لاتخان لإناذ الإجر اءات حسب الأولوية والأهمية.

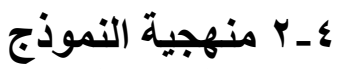

النموذج المقترح لصناعة المكان بمو اقع التراث العمر اني يركز على الجو انب المعنية بمثل هذه المو اقع العمر انية

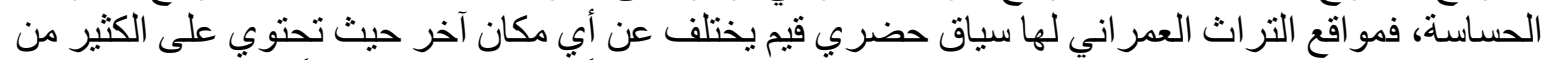

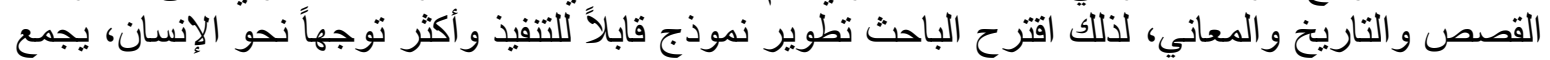

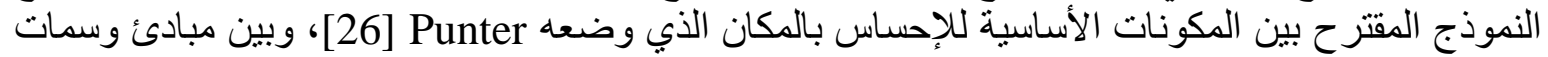

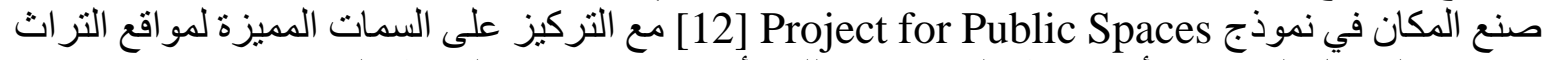

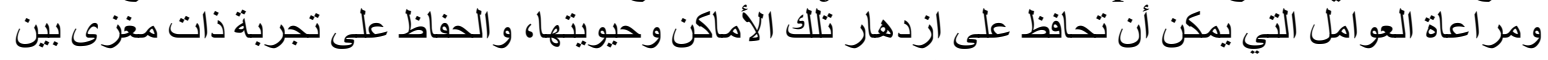
الإنسان و المكان ومن ثم تحقيق الإحساس بالـ المكان.

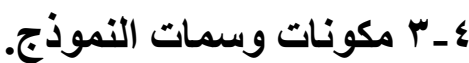

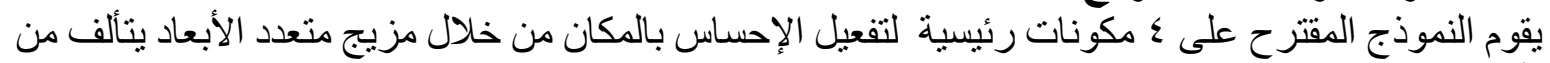

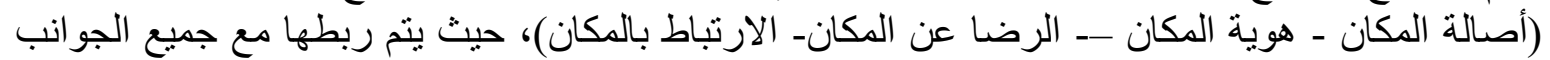

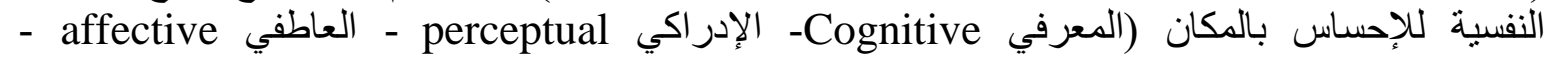

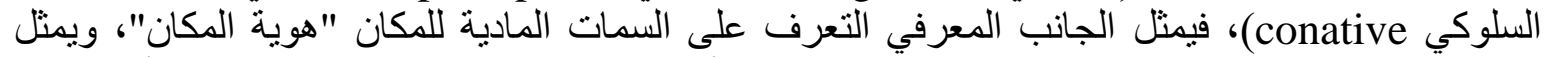

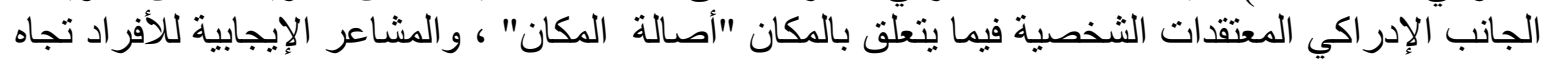

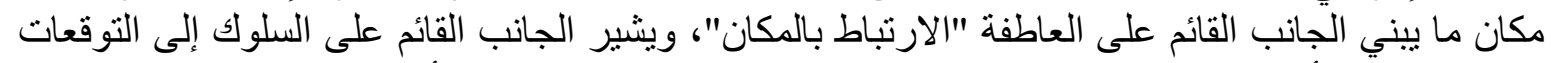

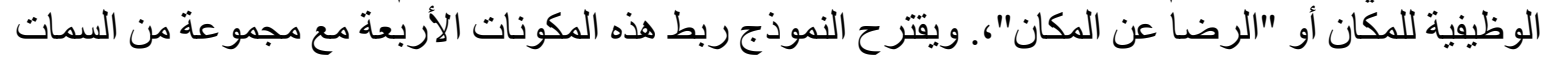

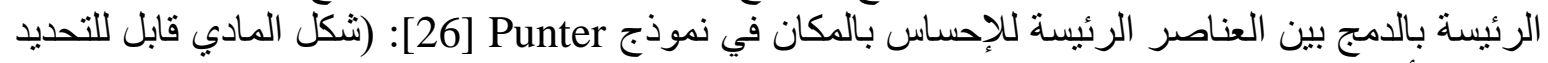

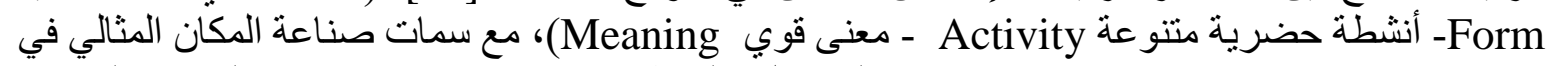

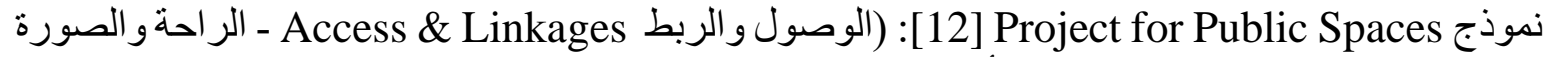

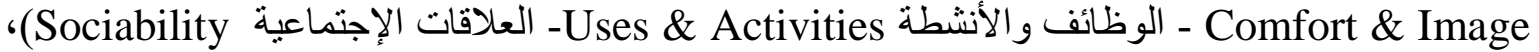

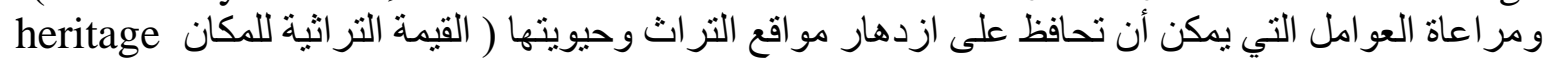

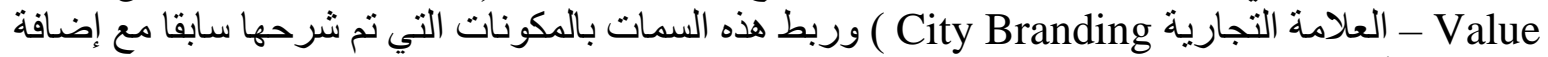
المزيد من أبعاد التخطيط و التصميم لسهولة التنفيذ و التقييم.

فيما يلي المكونات الرئيسية والسمات التي يتكون منها النموذج المقترح لتعزيزوخلق الإحساس بالمكان،

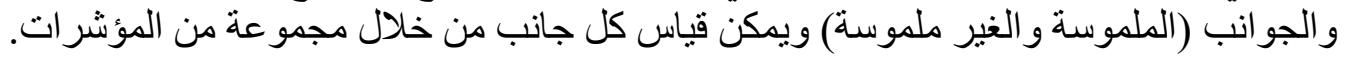


ع ـ بـ أصالة المكان :(القيمة التراثية ـ العلامة التجارية)

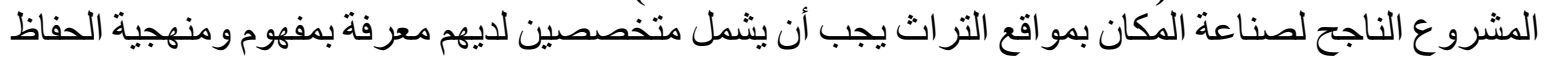

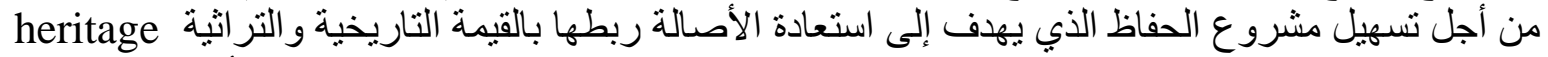

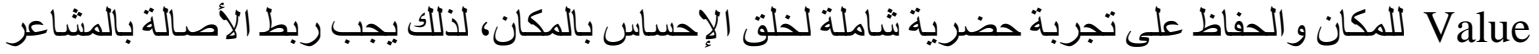

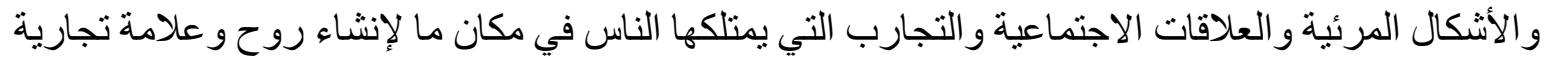

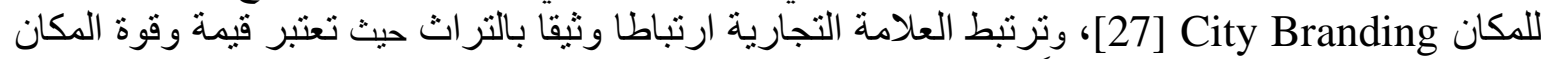

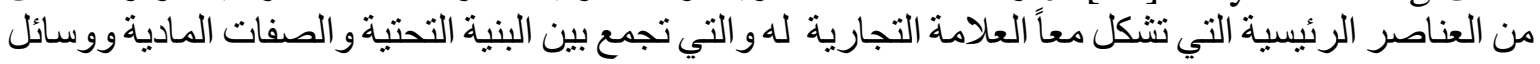
الر احة و السمات التاريخية و الثقافية [33]

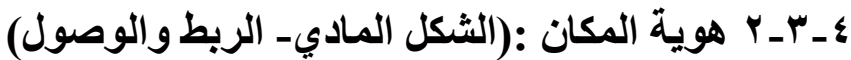

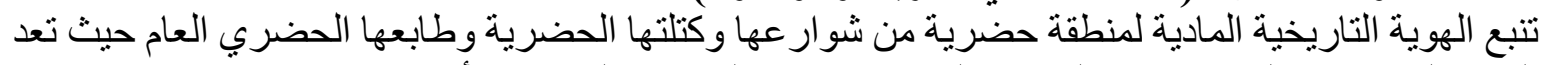

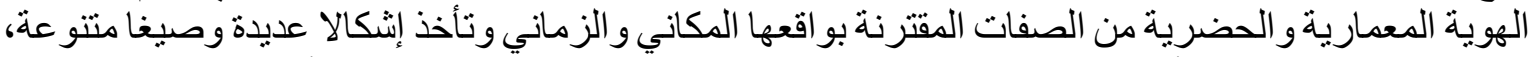

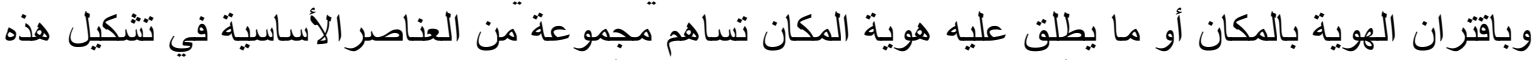

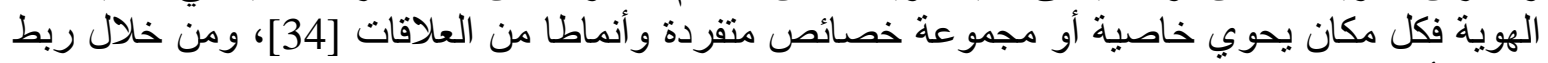

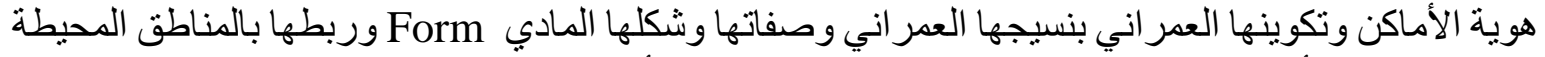

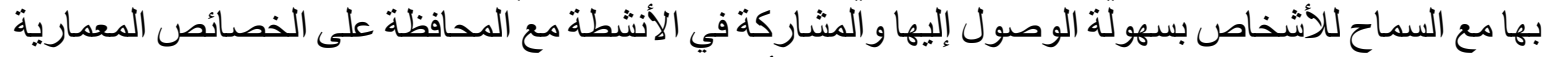

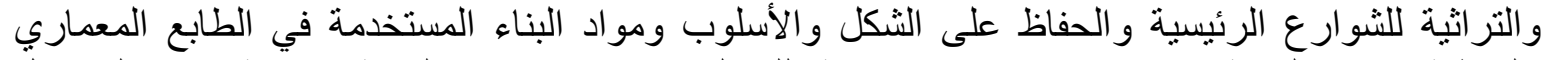

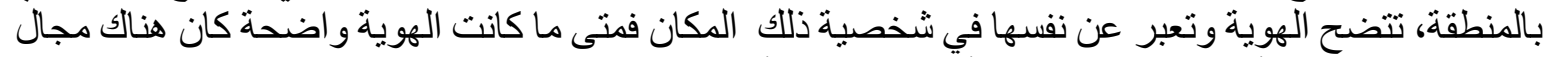

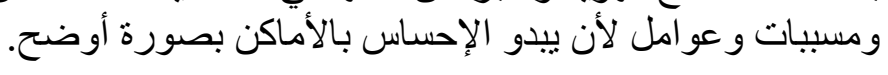

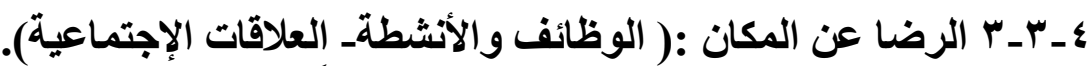

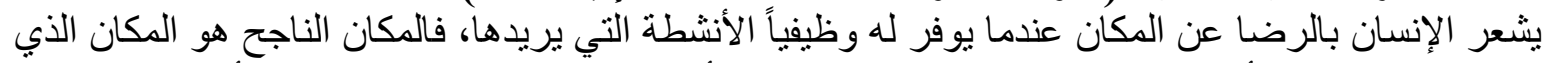

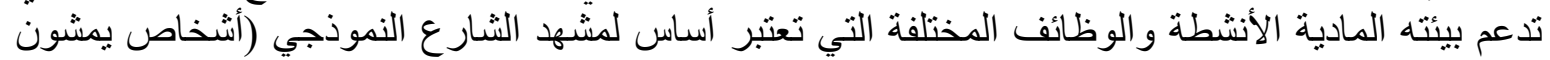

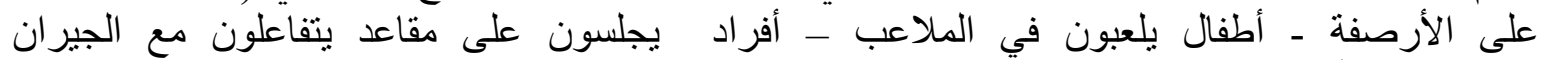

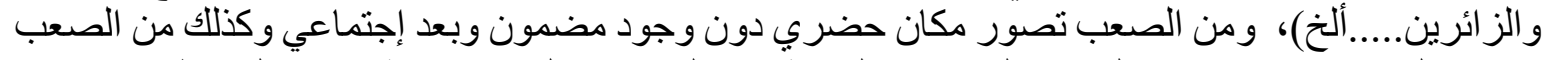

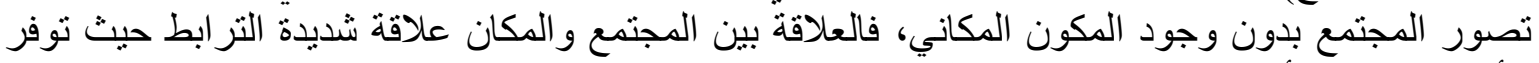

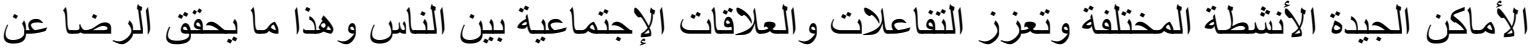

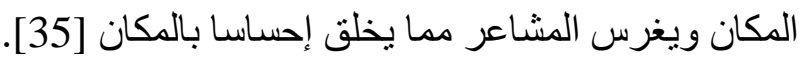

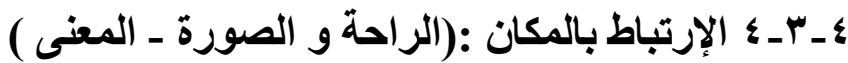

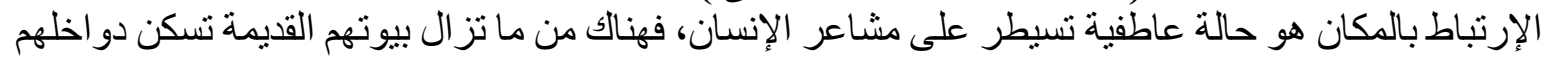

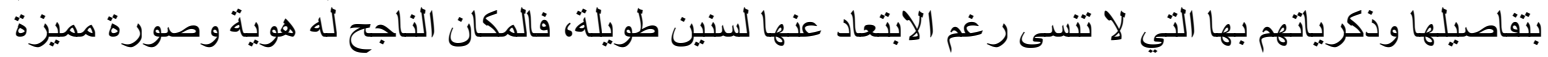

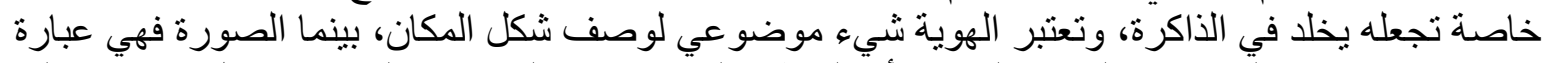

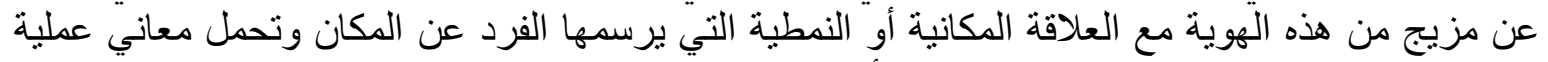

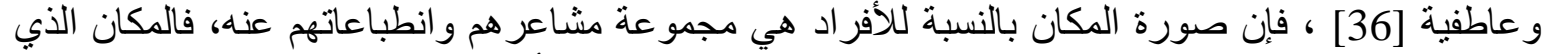

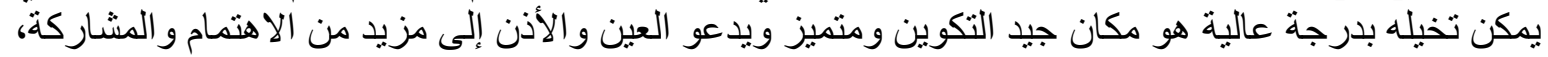

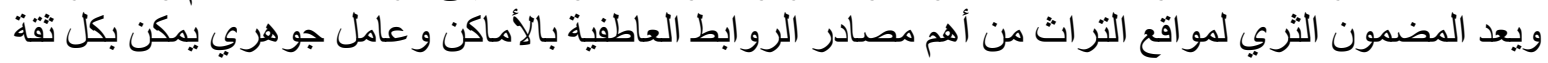

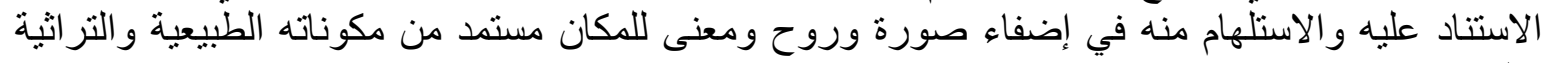

و الثقافية.

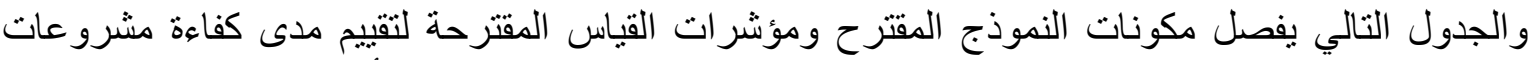

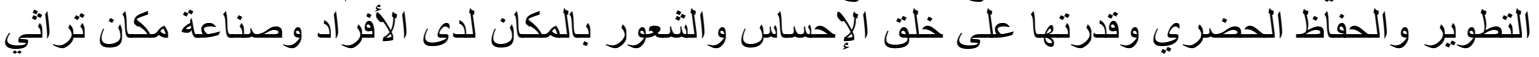

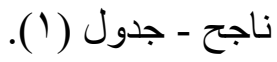


جدول ( ) ): المكونات والسمات و المؤشر ات للنموذج المقترح ـ المصدر : الباحث

\begin{tabular}{|c|c|c|}
\hline 4 & \multicolumn{2}{|l|}{ ت و السمات الأسساسية } \\
\hline \multirow{2}{*}{ 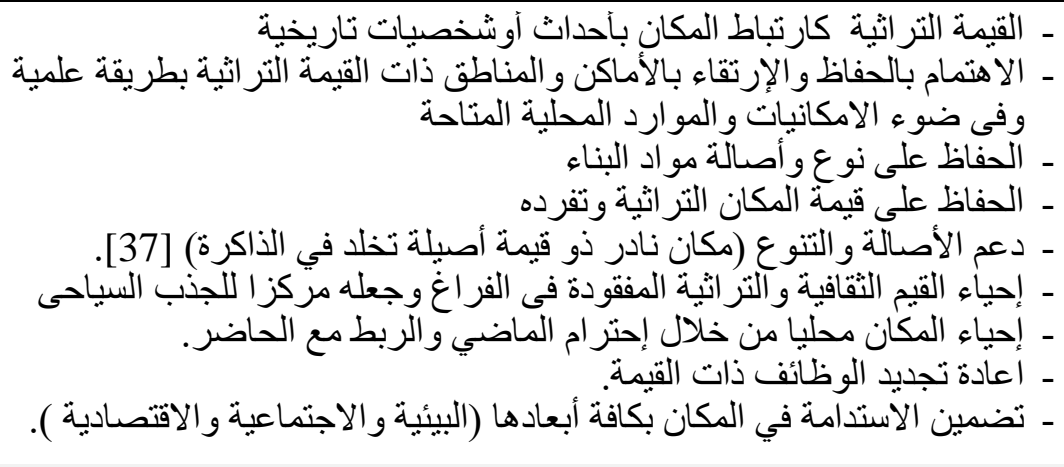 } & $\begin{array}{c}\text { القيمة التراثية } \\
\text { heritage Value }\end{array}$ & \\
\hline & الصميانة & \\
\hline \multirow[b]{2}{*}{ 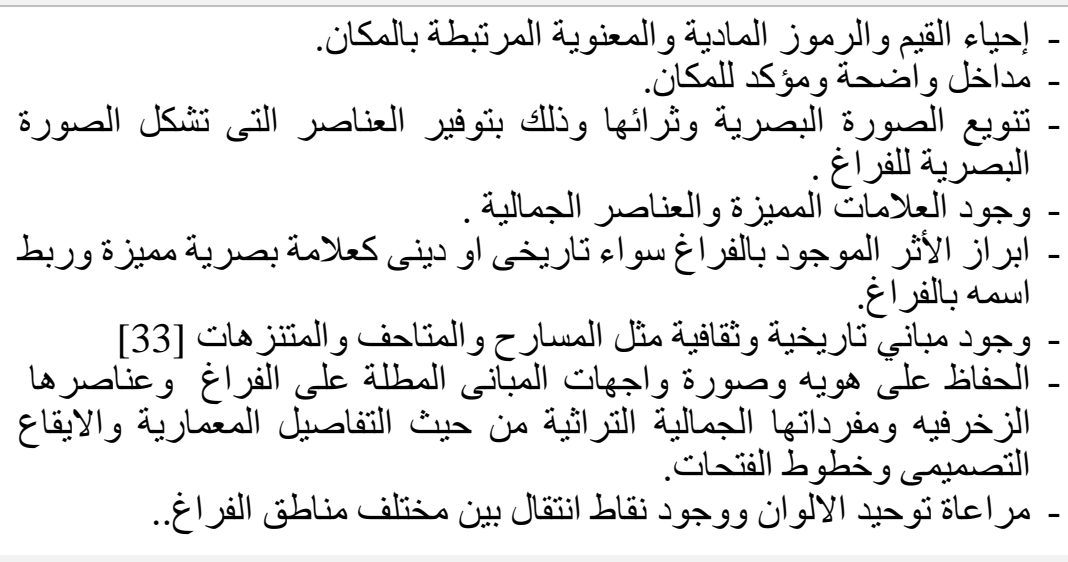 } & $\begin{array}{c}\text { العلامة التجارية } \\
\text { City Branding }\end{array}$ & \\
\hline & معلامة $\quad$ واضيح ومؤكدية & \\
\hline \multirow[b]{2}{*}{ 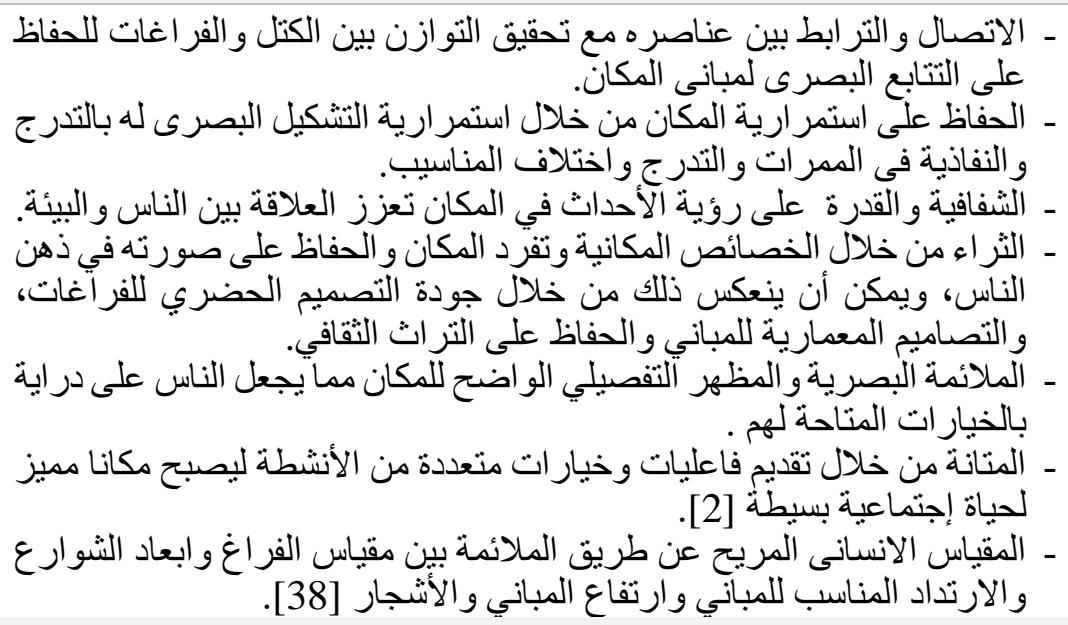 } & Form الشكل المادي & \multirow{4}{*}{$\frac{c}{\underline{E}}$} \\
\hline & النفاذية الإلت و التر ابط & \\
\hline \multirow{2}{*}{ 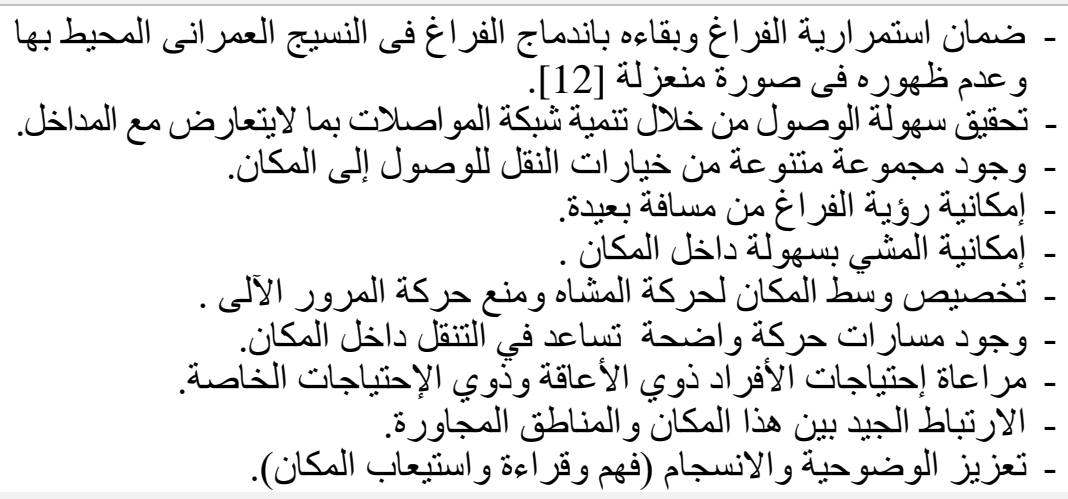 } & $\begin{array}{c}\text { الوصول والربط } \\
\text { Access\&Linkage }\end{array}$ & \\
\hline & " & \\
\hline
\end{tabular}


- وجود أماكن مخصصة للانشطة السلبية و النشطة ، سو اء أجريت على مستوى

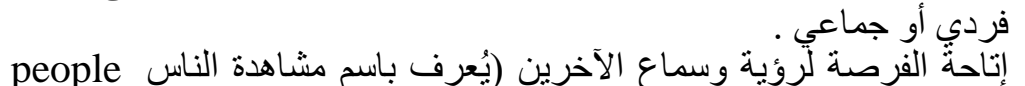
- watching ) و الأنشطة التفاعلية الأخرى [39] (39). - يحفز الاطفال على الانطلاق و الحركة. - يلبي إحتياجات الأفر اد الحالية و المستقبلية.

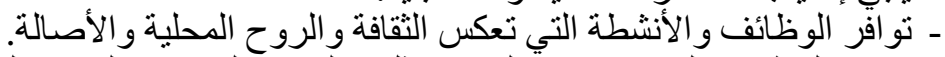

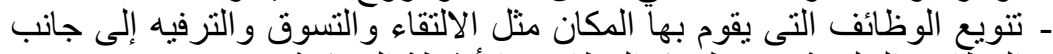

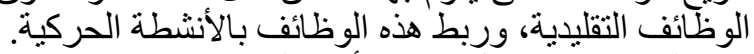

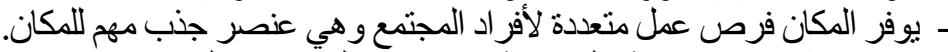

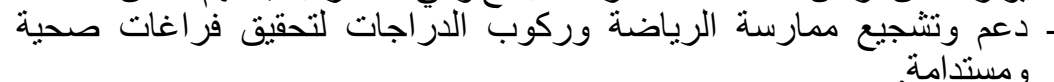

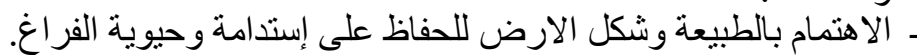

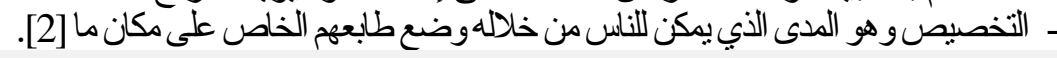

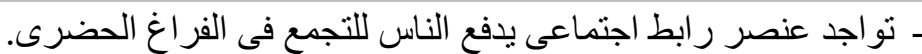

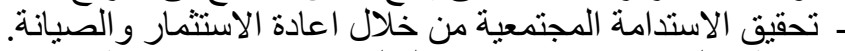

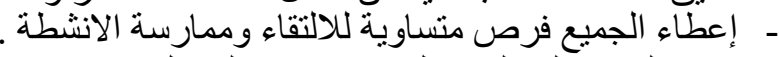
ـ ـ تحفيز الناس على التواصل العل و الإندماج و التفاعل.

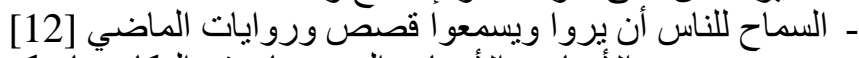

\section{الوظائف والآنشطة \\ Uses \& Activities}

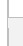

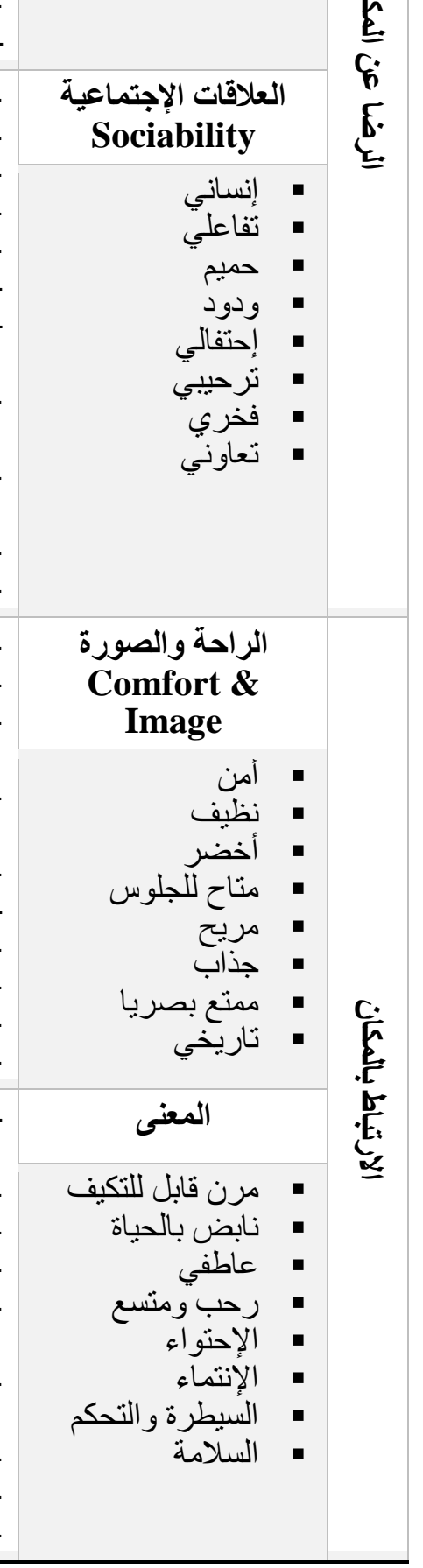


ع ـ ع الصياغة الأولية للنموذج المقترح.

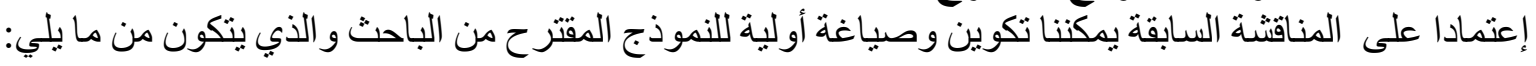
ـ مخطط النموذج المقترح من الباحث لتفعيل الإحساس بالمكان و الذي يتكون من أربعة مكونات أساسية وكل

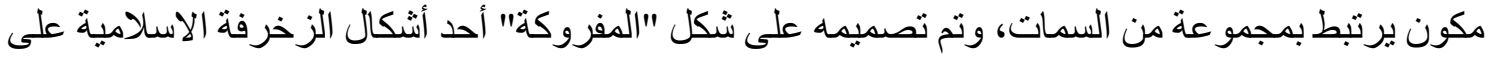

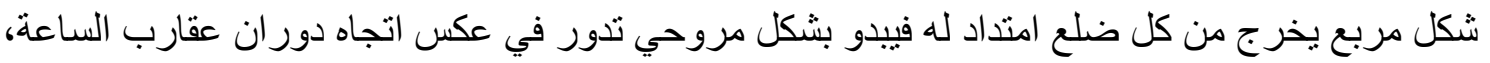

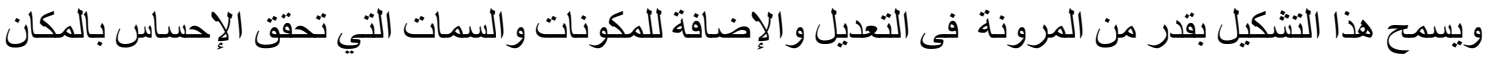

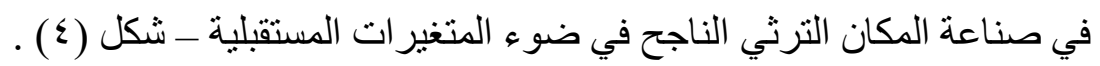

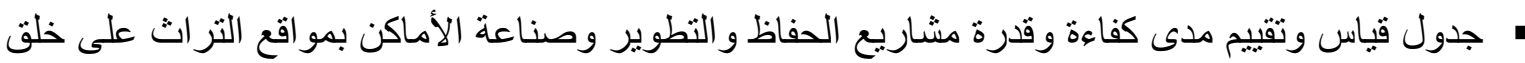

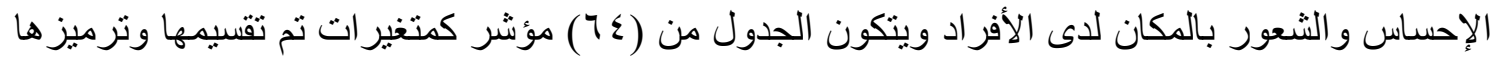

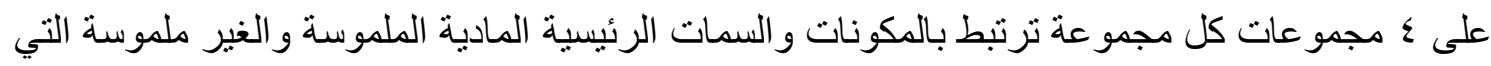

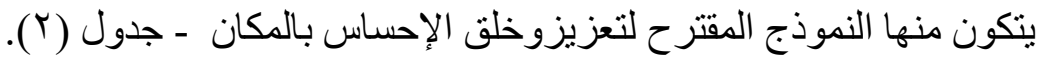

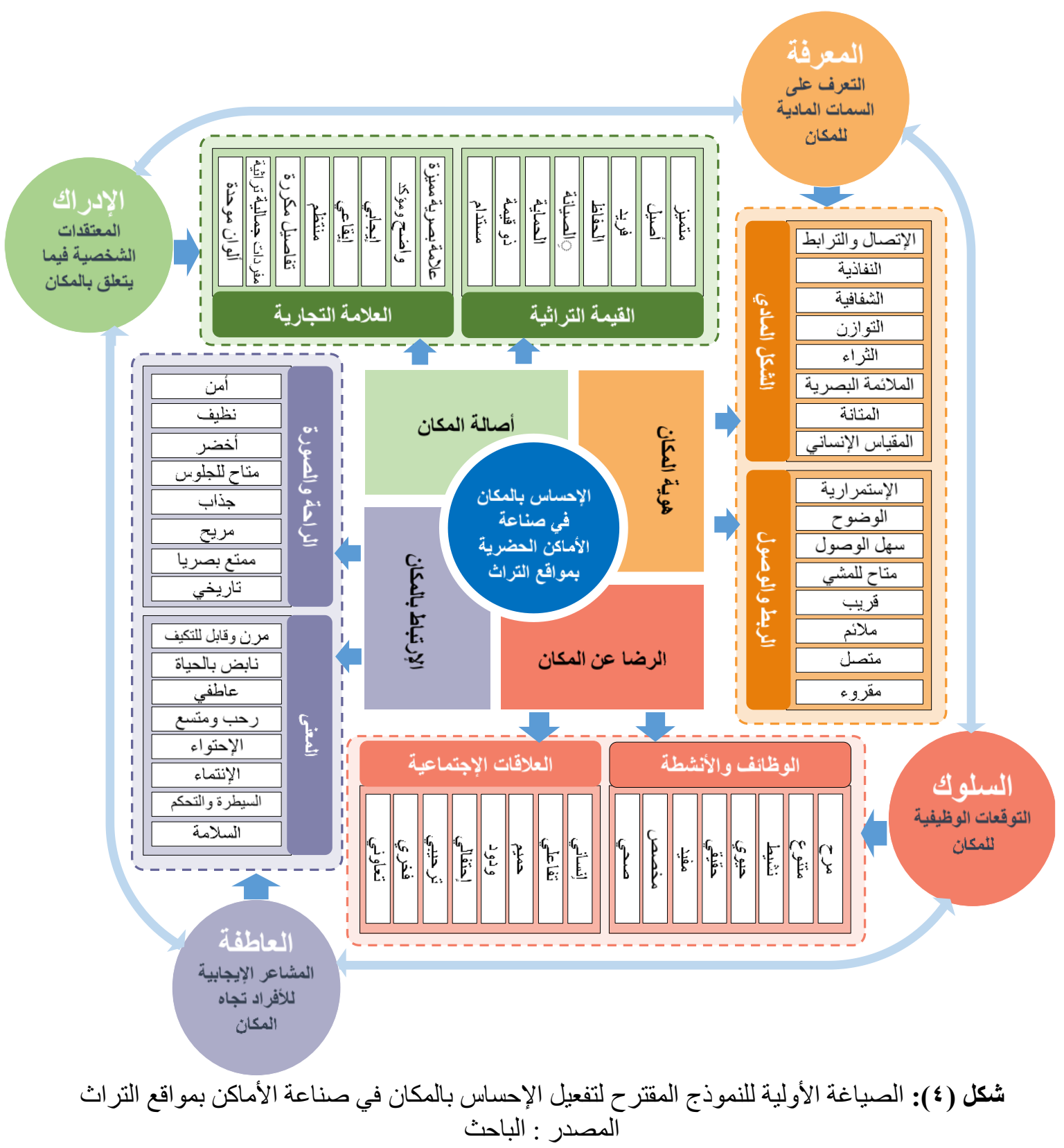


جدول (ץ): جدول مقترح لقياس وتقييم مدى كفاءة مشاريع الحفاظ وصناعة الأماكن بمو اقع التر اث في خلق الإق الإحساس و الثُعور بالمكان ـ المصدر : الباحث

\begin{tabular}{|c|c|c|c|}
\hline الإحساس بمهويـة المكان & & \multicolumn{2}{|l|}{ الإحساس بأصالة المكان } \\
\hline C الثفافية و القدرة على رؤية الأحداث & \multirow{8}{*}{$: 6$} & A ا. يحقق المشروع صناعة مكان تر اثي ناجح & \\
\hline rC & & 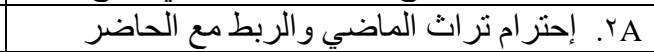 & \\
\hline ClC & & 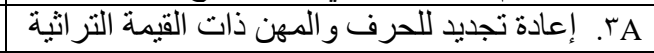 & C. \\
\hline C؛. نفاذية الممر ات وحيويتها & & A. يحقق إحياء المكان محليا & 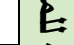 \\
\hline C.C. التدرج و اختلاف المناسيب & & A A . . الحفاظ على قيمة المكان التر اثية & $E:$ \\
\hline CIC المالائمة البصرية والمظهر التفصيلي & & AT، المكان المشروع الحفاظ على أصالة واستدامة & $\underline{E}$ \\
\hline 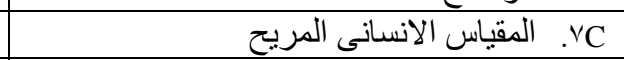 & & VA يحقق المشروع صناعة مكان فريد ونادر & 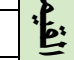 \\
\hline مC مكان ثري ذو خصائص و هوية مكانية & & AA الذاكرة المشروع صناعة مكان أصبل يخلا في & \\
\hline ID . يرتبط بالمناطق المجاورة لها بشكل جيد. & & 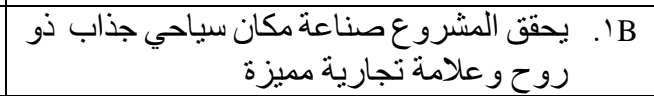 & \\
\hline ID . يحقق المشروع مكان سهل الوصول إليه & F & 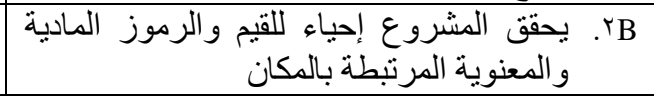 & $L^{*}$ \\
\hline DD م يمكن الوصول إليه بخيارات نقل متتوعة & $\underline{\underline{E}}$ & rB & $\bar{E}$ \\
\hline DS يتميز بإمكانية رؤيته من مسافة بعيدة & 6 & B. يتميز بوجود هوية بصرية مميزة & \\
\hline DD D . يمكن المشي فيه بسهولة ويسر & $\xi$ & 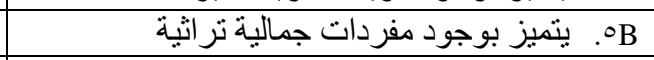 & 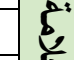 \\
\hline Dי. مسار ات حركة و اضحة للتنقل داخل المكان & $\underline{\underline{e}}$ & آTB ت تدعيم الإحساس بالإيجابية & $\underline{\underline{E}}$ \\
\hline VDD إلإحتياجات التصيم الأفر اد ذوي الأعاقة وذوي & & 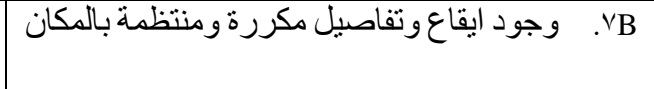 & \\
\hline 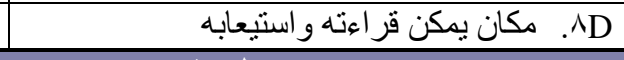 & & 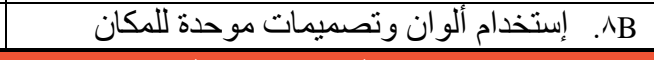 & \\
\hline الإحساس بالإرثباط بإلمكان & & الإعساس بالرضا عن المكان & \\
\hline أ. . . . صناعة مكان يعطي انطباع أولي جيد. & & le . وظائف و أنشطة تعكس الثقافة والروح المحلية. & \\
\hline rG & & EE ب. يتو افر أماكن للأنثطة الفردية و الجماعية & \\
\hline rG . يتو افر فيه مساحات نظيفة ومناطق خضر اء & $\xi$ & 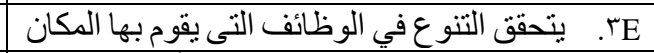 & $E$ \\
\hline Gك & $\underline{\underline{E}}$ & E. ئ. يوفر المكان فرص عمل متعددة لأفر اد المجتمع & $\frac{1}{6}$ \\
\hline 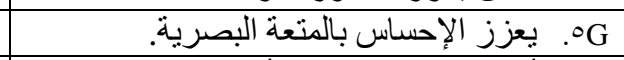 & 6 & Eْ. يحفز المكان الاطفال على الانطلاق والحركة & E. \\
\hline TG. أماكن جذابة ومتاحة لأخذ الصور التذكارية & 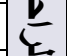 & 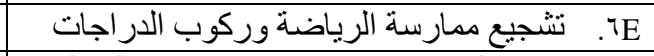 & "艹 \\
\hline 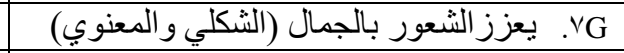 & & rE يحقق المشروع مكان صحي يحافظ على البيئة & \\
\hline 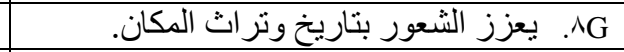 & & 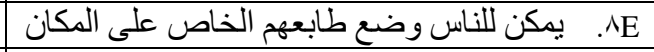 & \\
\hline ال. مكان مرن قابل للتكييف مع التغيير & & F أ. . مكان إنساني إجتماعي ناجح & \\
\hline 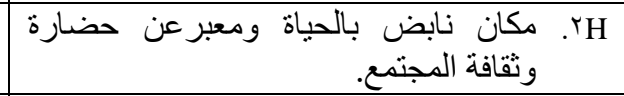 & & rF ئ. يحفز الناس على التواصل و الإندماج و التفاعل. & \\
\hline rH مكان يعزز المعاني و العو اطف الإيجايية & & 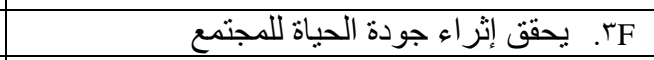 & \\
\hline H & & F. يدعم الشعور بالتماسك والتجانس الاجتماعي & 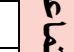 \\
\hline 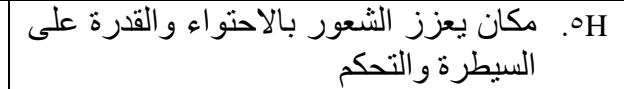 & $\underline{E}$ & 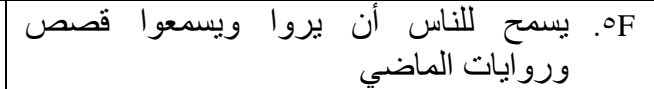 & $\frac{t^{3}}{2}$ \\
\hline 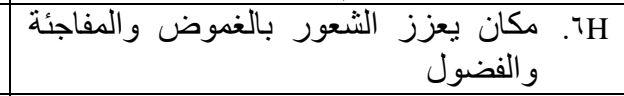 & & 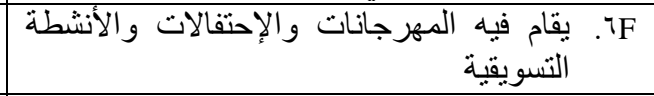 & $\underline{E}$ \\
\hline 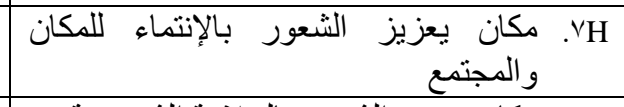 & & الحضاري الإحساس و الشعور بالفخر و التميز & \\
\hline مH مكان يعزيز الثعور بالسلامة الثخصية & & FF . يوفر للأفراد فرص الاجتماعية للمشاركة في الأنشطة & \\
\hline
\end{tabular}


هـ الاحساس بالمكان والحفاظ على التراث في المملكة العربية السعودية- (المدينة المنورة)

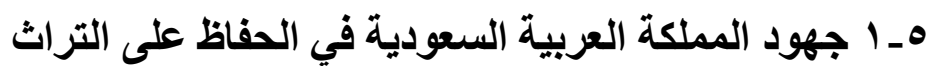

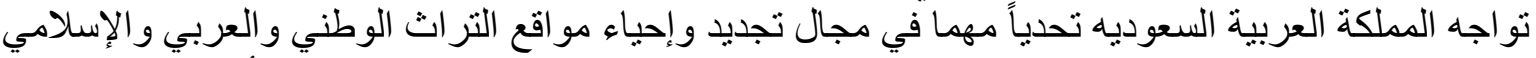

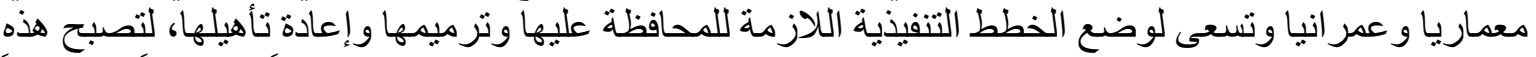

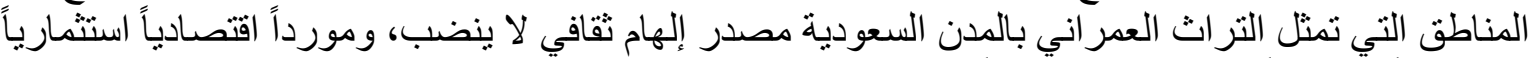

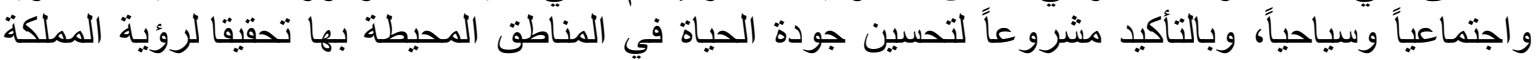

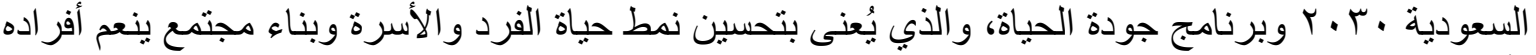

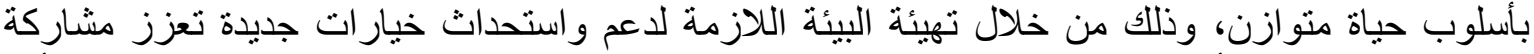

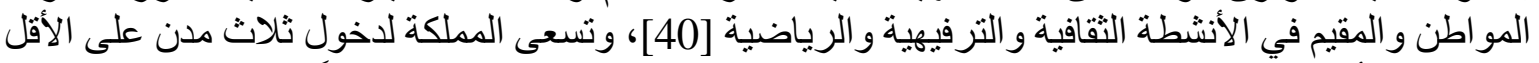

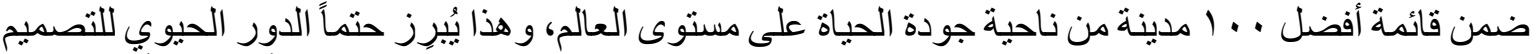

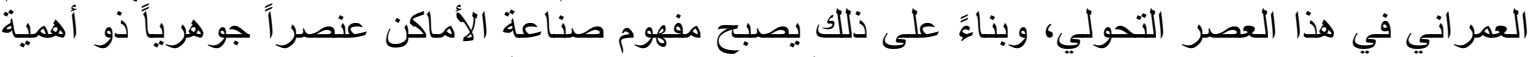

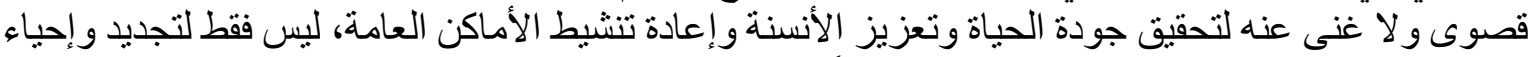

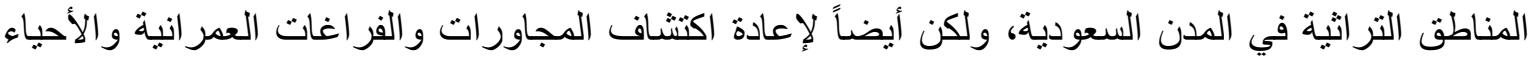
السكنية المحيطة بها والتي تعاني من التدهور ومن ضعن التهف العلاقات الاجتماعية [41].

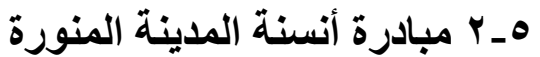

أفتقدت أحياء عشو ائية قديمة في المدينة المنورة لسنو المينة المئوة طويلة العديد من المقومات الخدمية لساكنيها بسبب قدمها

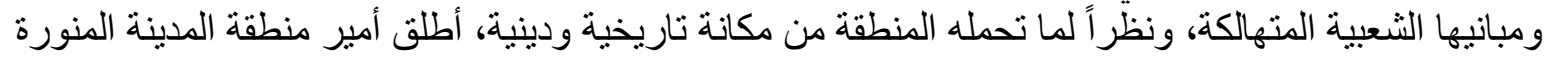

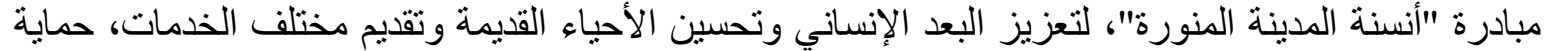

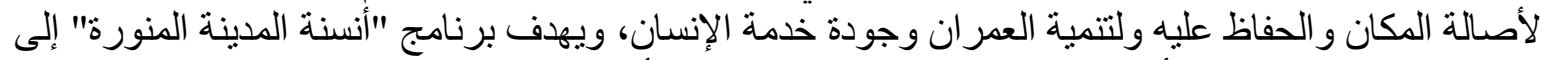

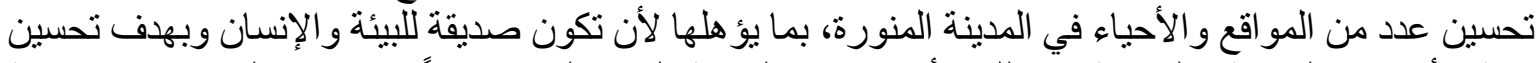

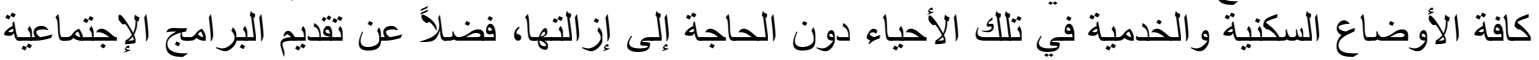

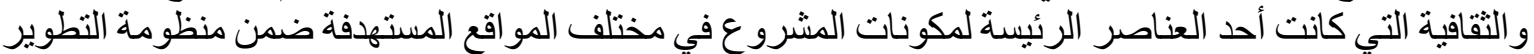

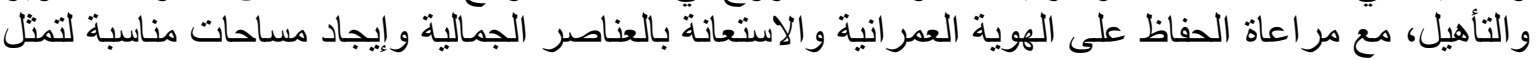

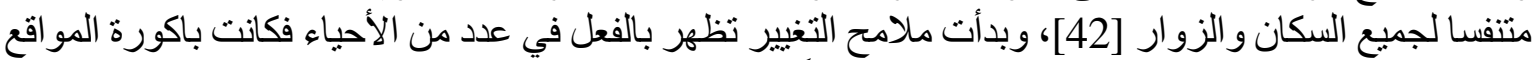

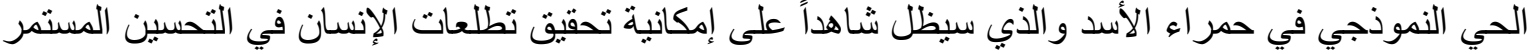

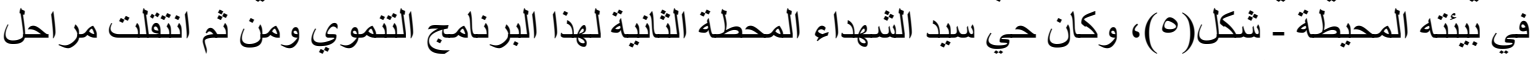

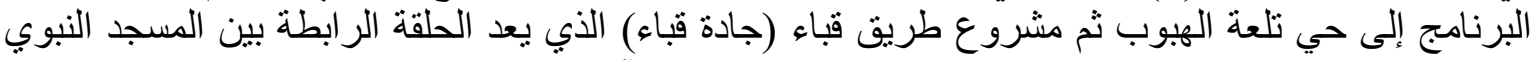

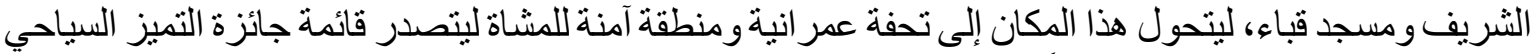

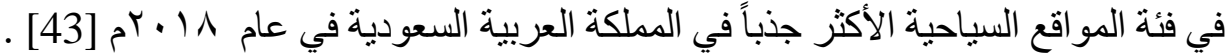
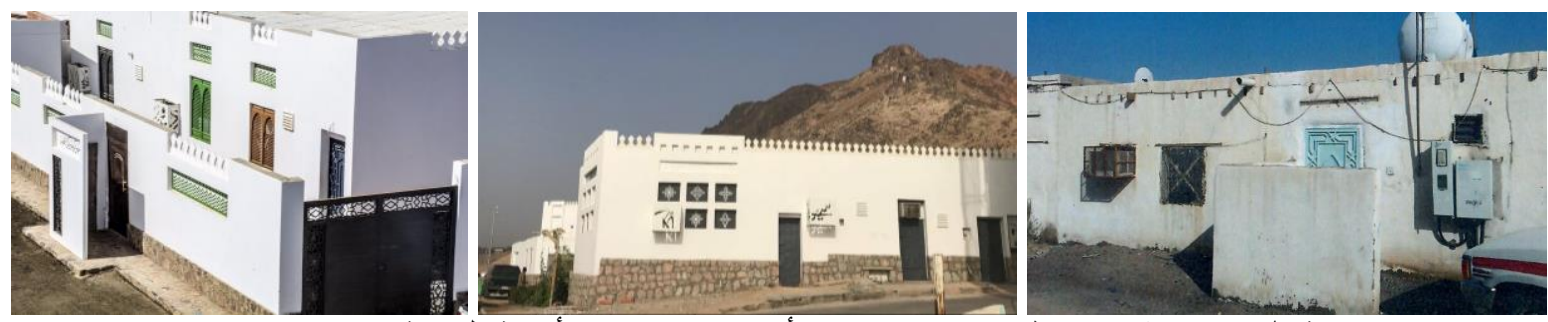

شكل (0): مشروع تطوير حي حمر اء الأسد ضمن مبادرة أنسنة المدينة [43] [42]

وفي هذا الجزء التالي من البحث يتم دراسة وتحليل أحد أهم و أبرز نماذج جهود التطوير و الحفاظ الحضري في

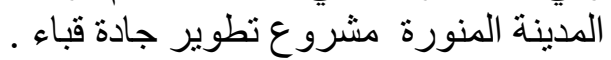

\section{7- دراسة تطبيقية لمشروع تطوير طريق قباء (جادة قباء)}

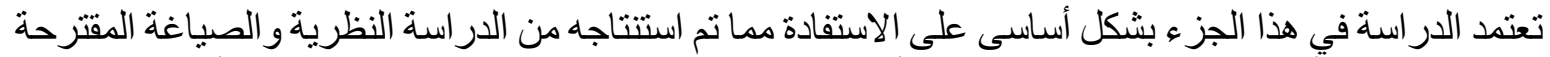

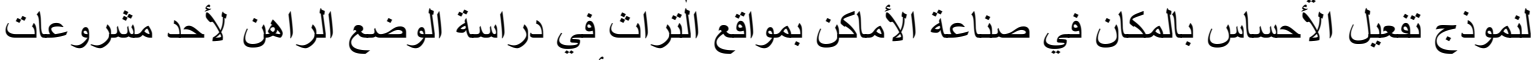

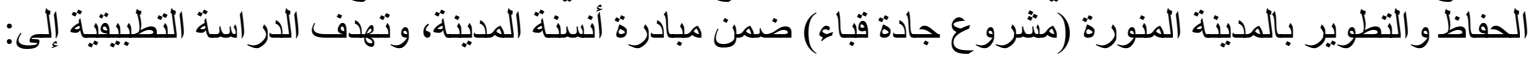




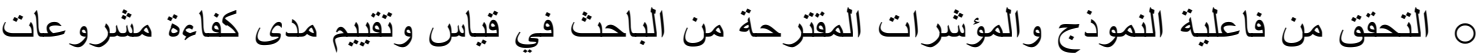

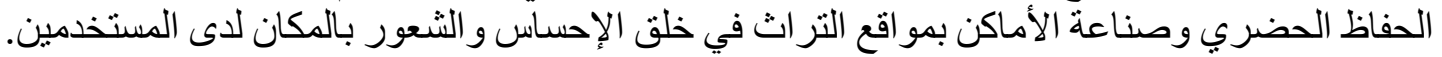

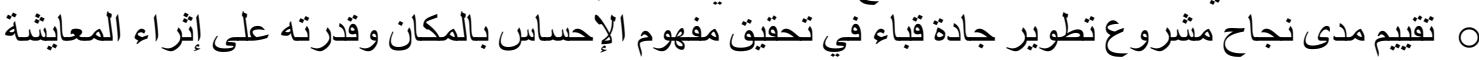

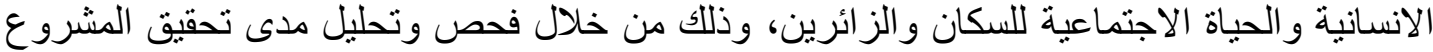

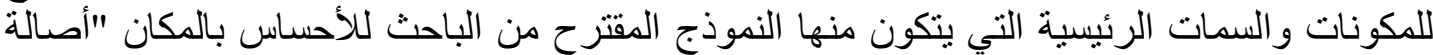

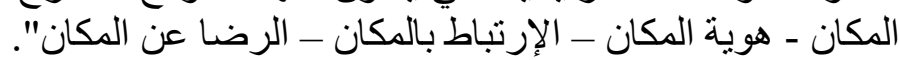
وتتقسم الدر اسة التطبيقية إلى قسمين رئيسن الإنيبين:

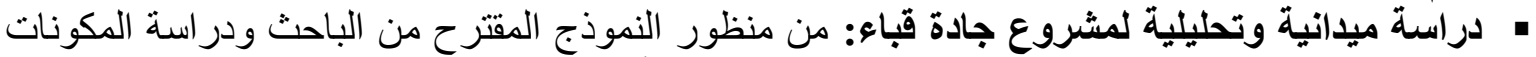

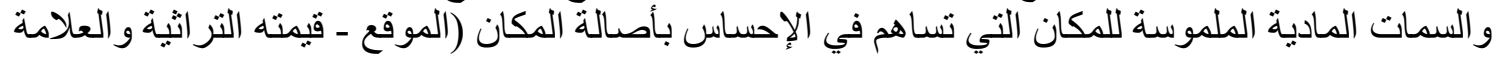

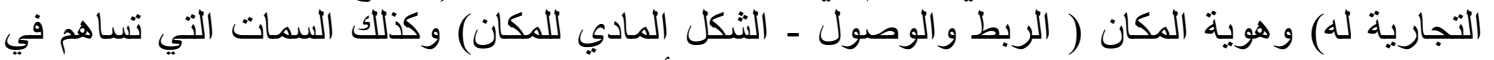

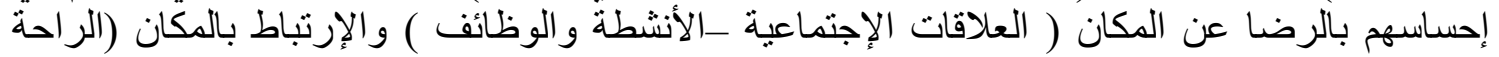

• دراسة إستطلاعية من خلال إستبيان للسكان والزوار للمشروع: لتقييم قدرة ونجاح المشروع في خلق

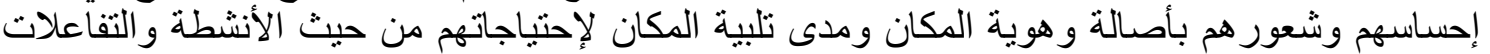

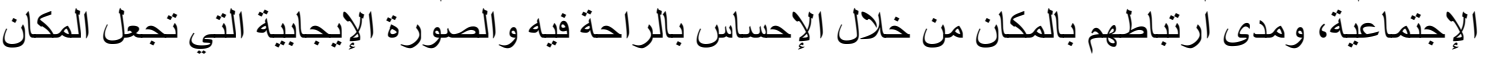

$$
\text { جذابا للهم و المعنى الذي يتكون من خلاعلاطل مشاعر هم و انطباعاتهم عنه. }
$$

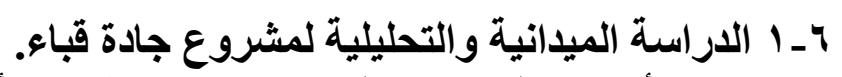

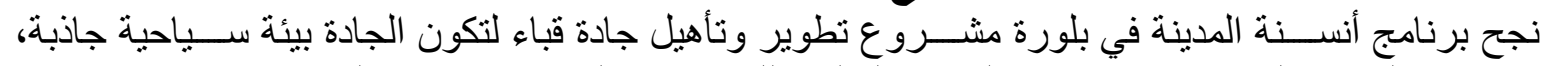

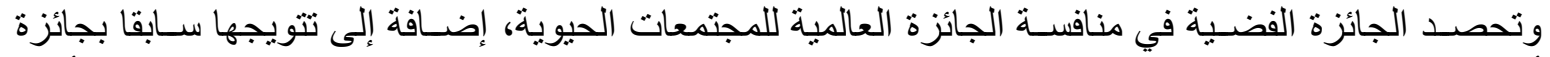

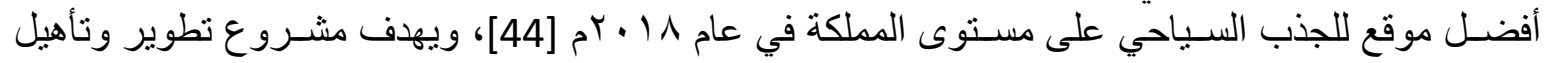

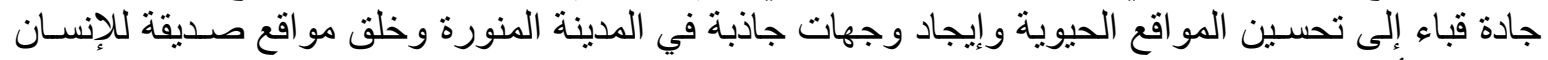

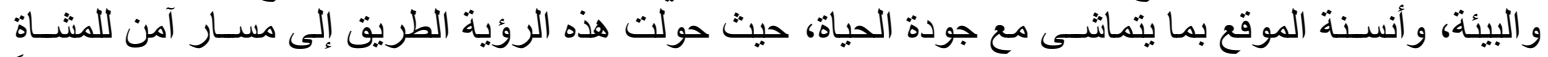

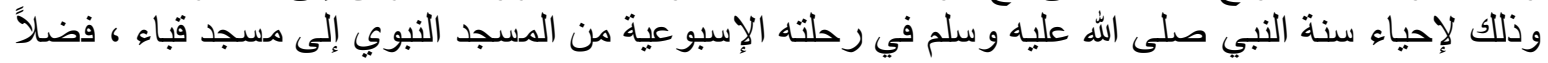

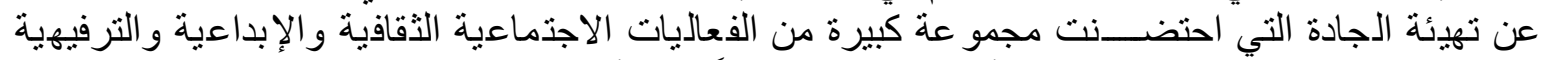

و السياحية خلال الفترة الماضية وبذلك أصبحت متنفس لكلاً من الأهالى و الزوار - شكل (T).

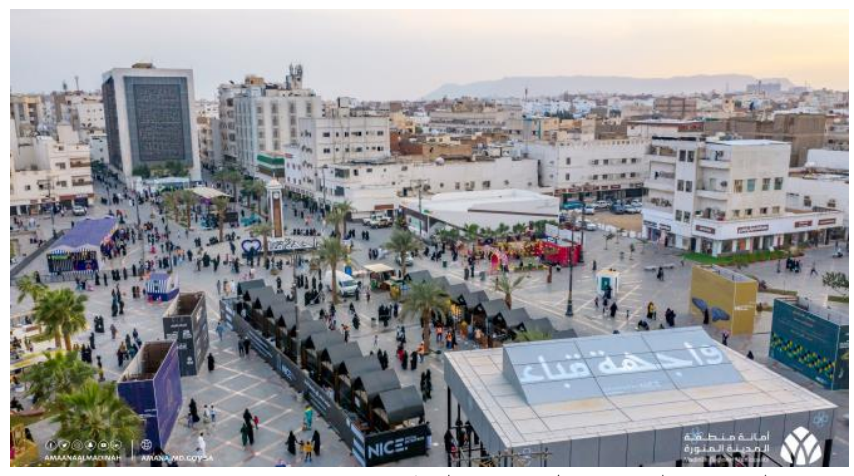

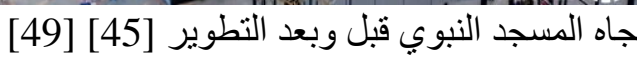

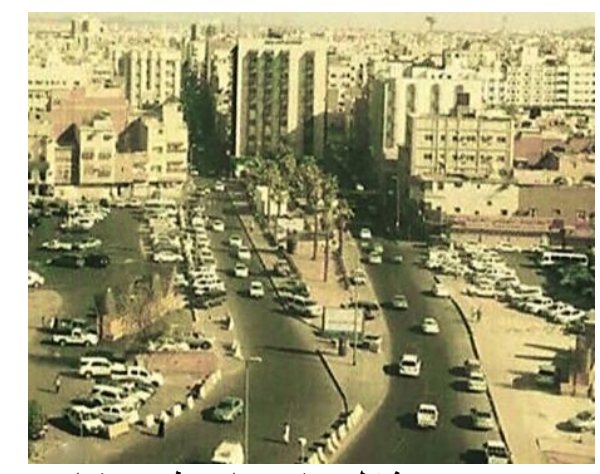

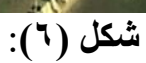

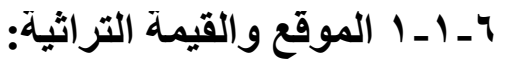

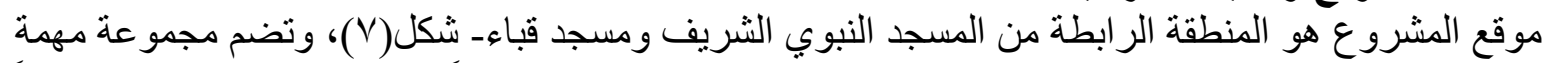

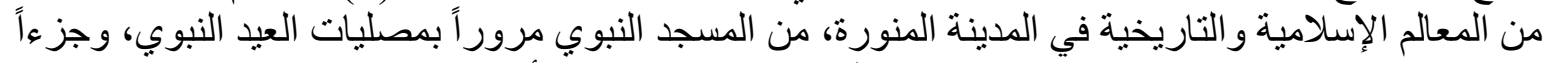

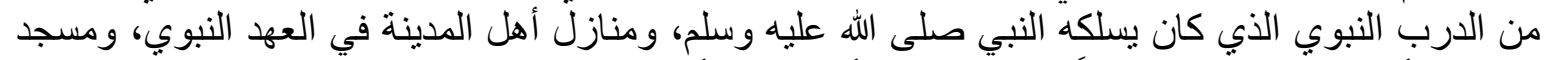

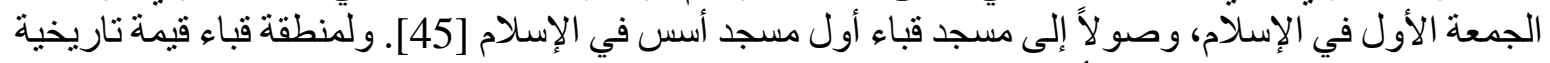

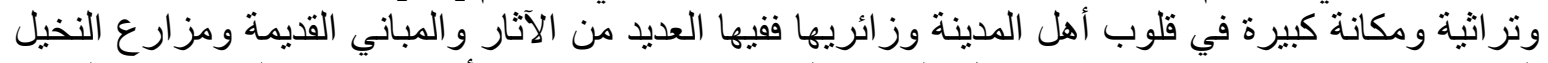

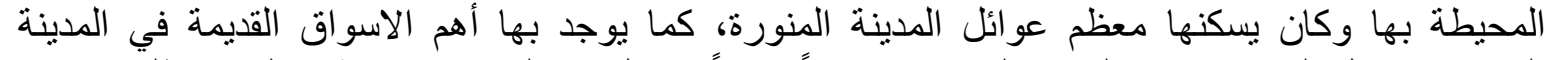

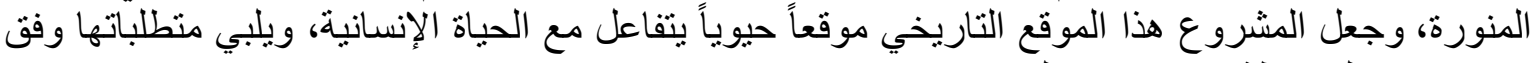
الاحتياجات المرتبطة مع مكون المونات الموقع. 


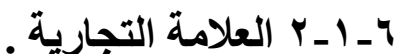

ساهم المشروع في تعزيز الحركة التجارية في المنطقة التي تحتضن أحد أهم الأسواق التجارية القديمة بالمدينة

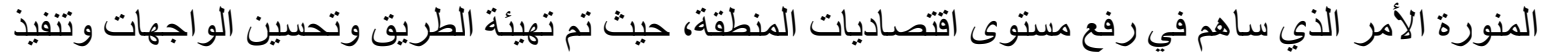

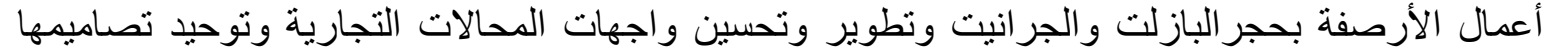

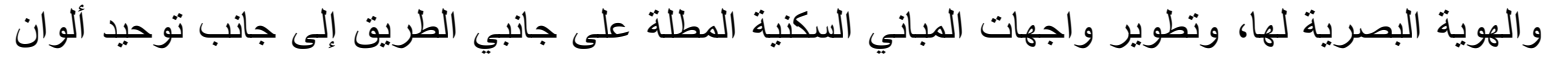

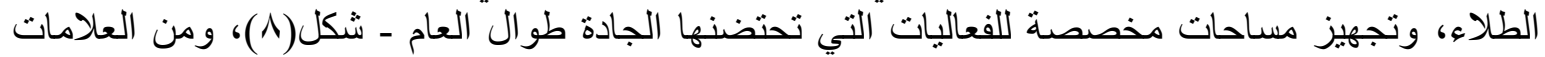

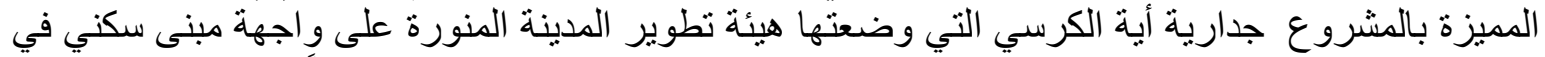

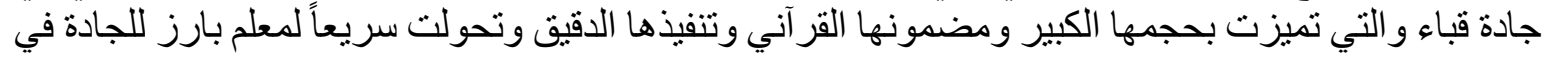

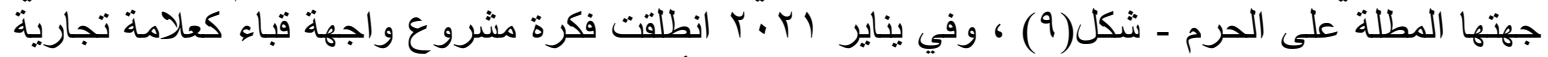

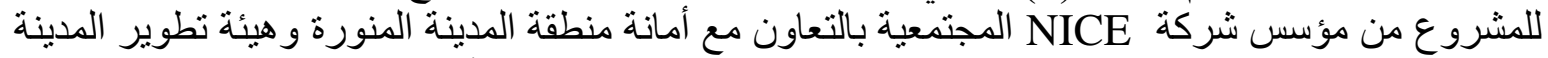

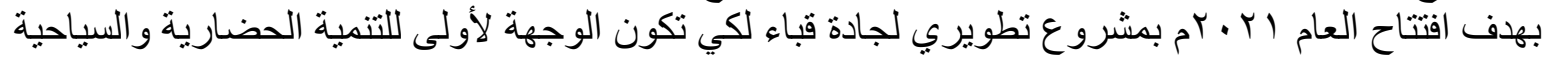

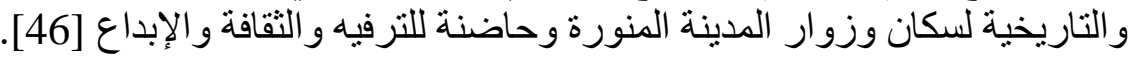

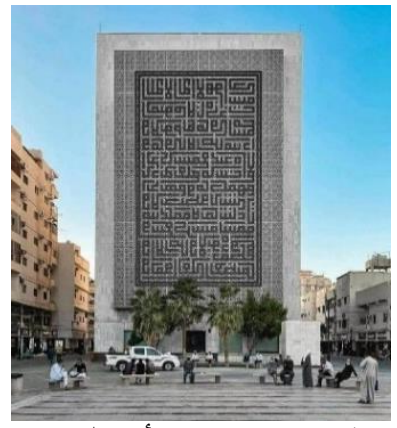

شكل (9): جدارية أية الكرسي

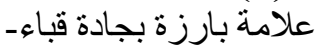
المصدر: الباحث بارن

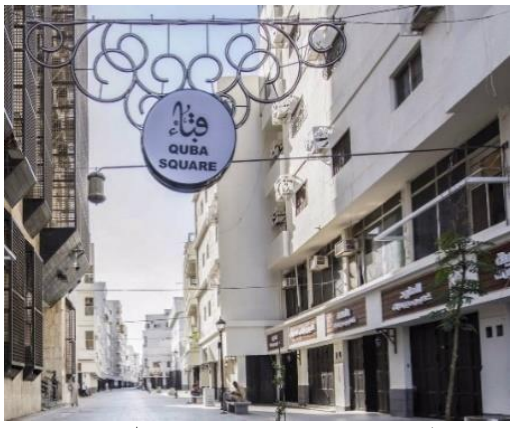

شكل (^): توحيد تصميم المحلات

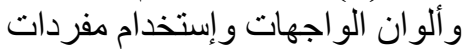

التراث الإسلامي و الخط المديني [42]

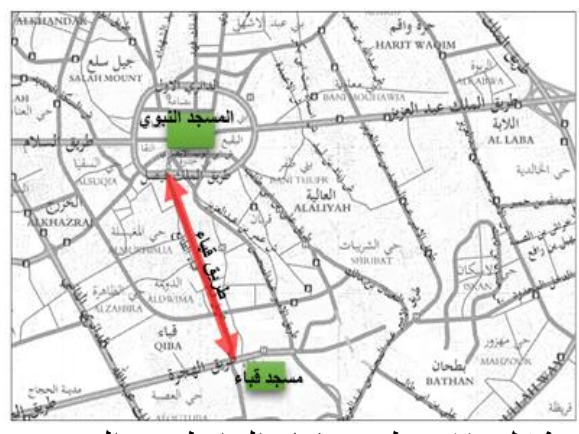

شكل (V): طريق قباء الر ابط بين المسجد

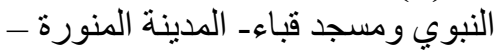
المصدر :الباحث المثنة المباء

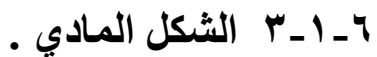

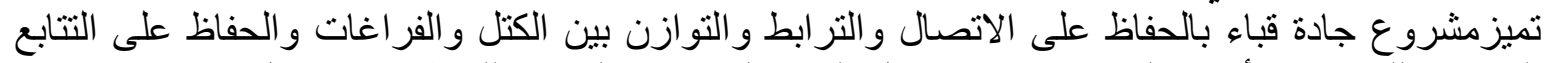

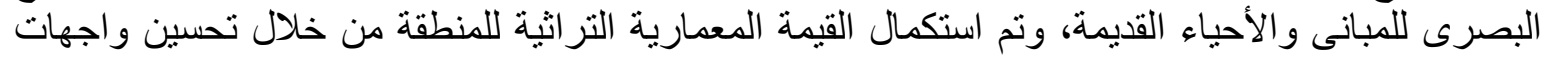

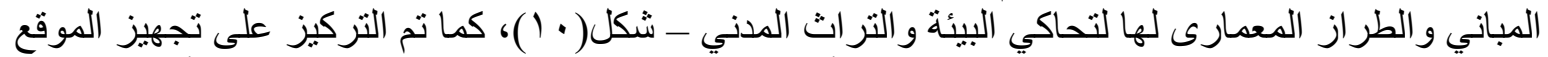

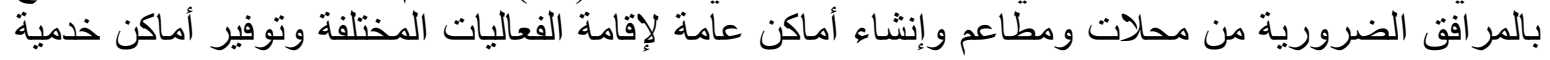

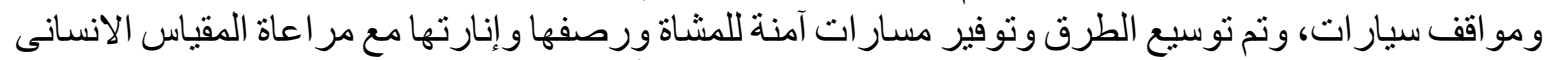

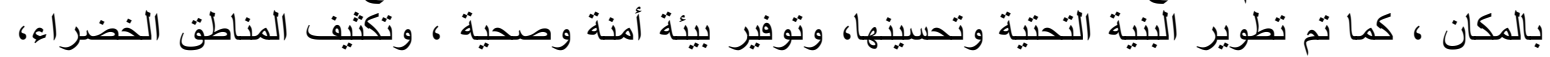

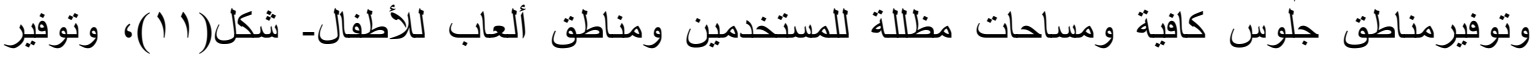

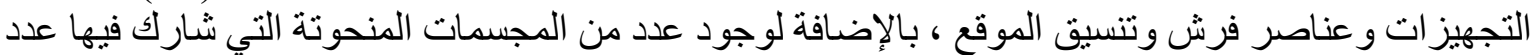
من النحاتين المميزين على مستوى العالمين العربي و الإسلامي.

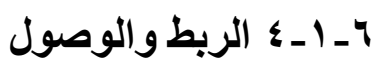

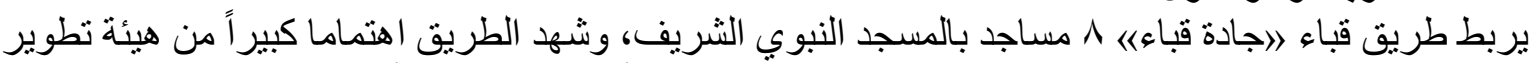

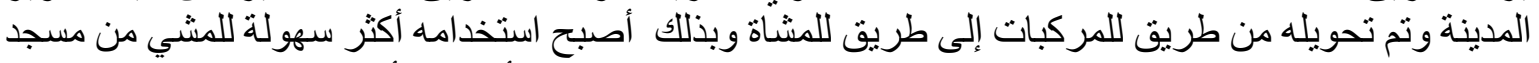

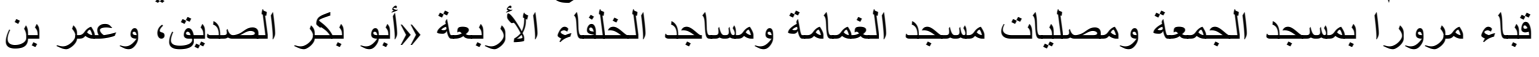

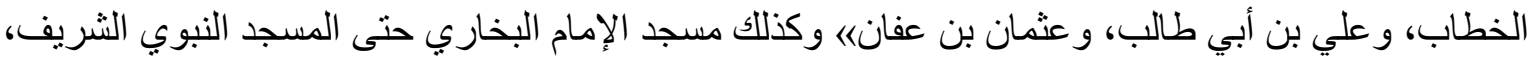

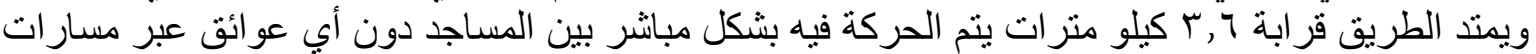

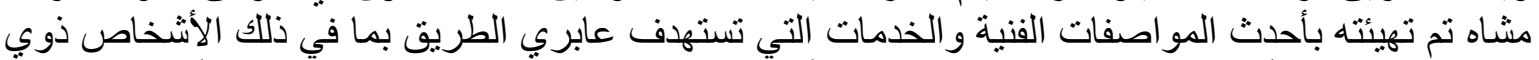

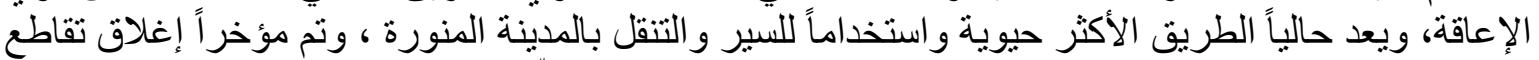

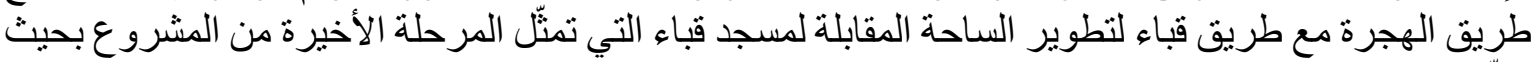

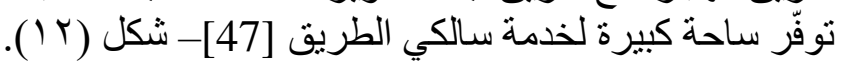




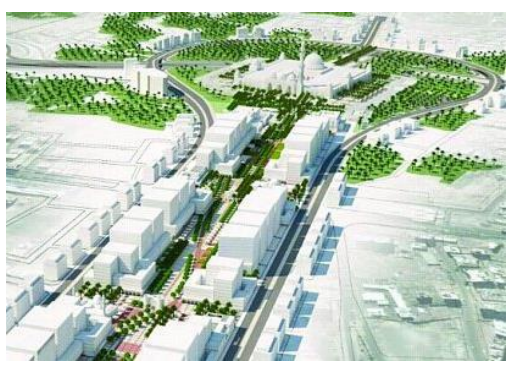

شكل (r ا I ): تصميم ساحة مسجد قباء

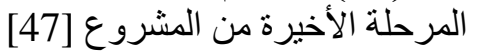

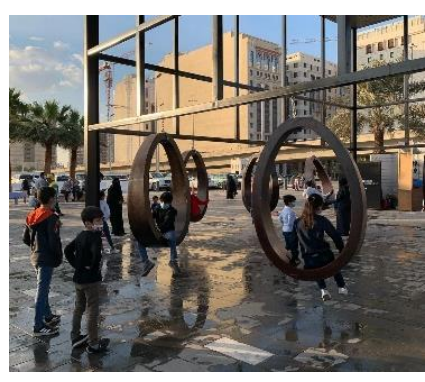

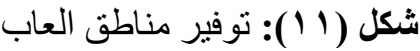
للأطفال - المصدر : الباحث

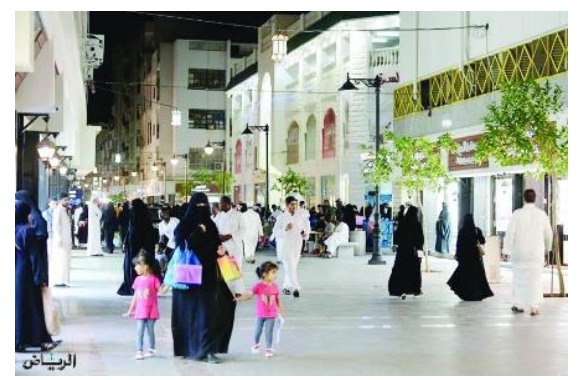

شكل( • (1): تحسين واجهات المباني

و المحلات التجارية [48] تصنية

تشهُ جادة قباء تجسيد للقيمة التاريخية للمنطقة عبر الفعاليات و الأنشطة المتنو عة و التي تحكي أصالة الماضي فئي

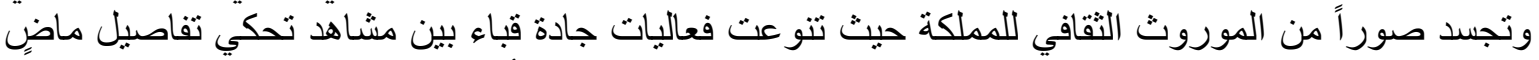

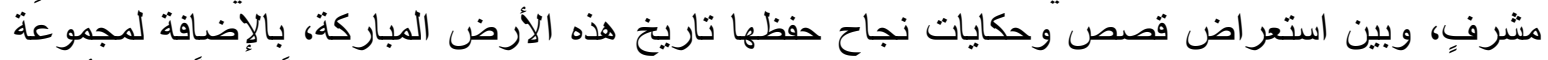

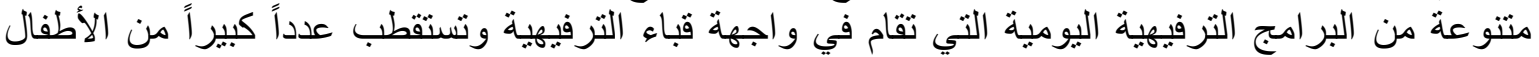

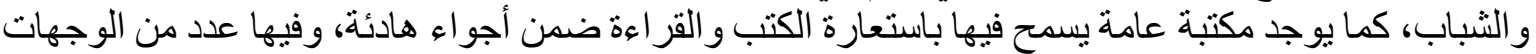

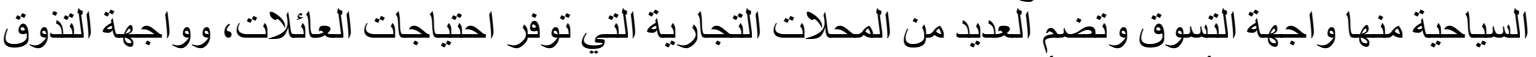

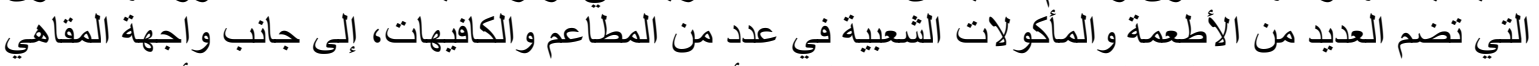

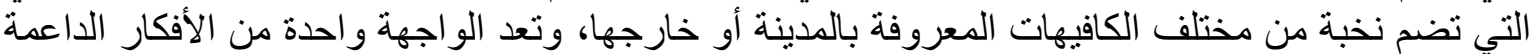

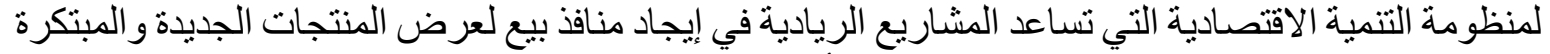

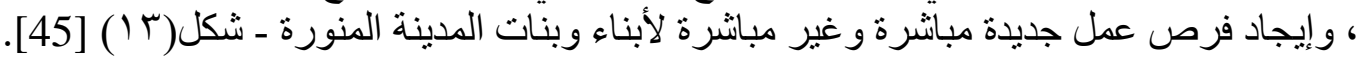

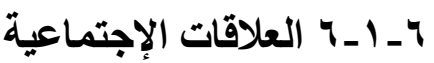

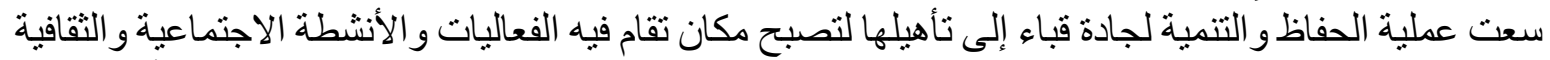

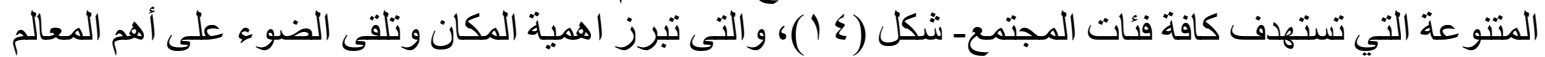

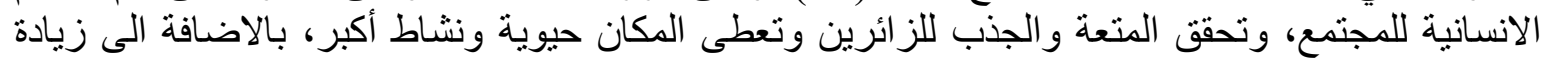

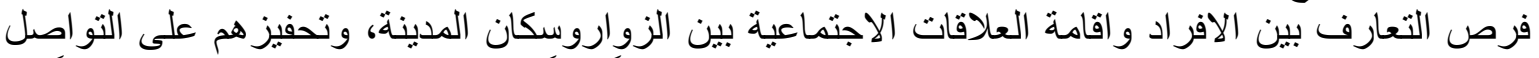

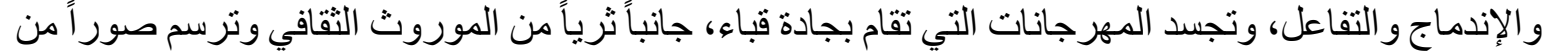

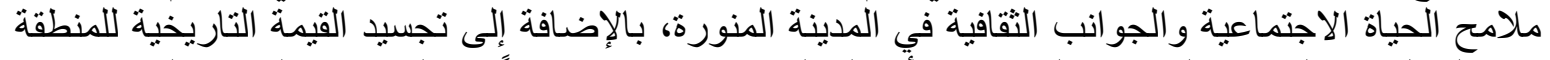

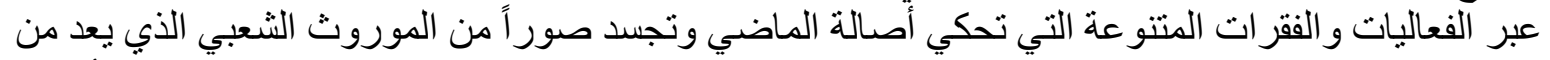

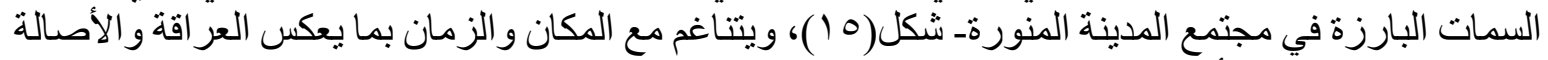

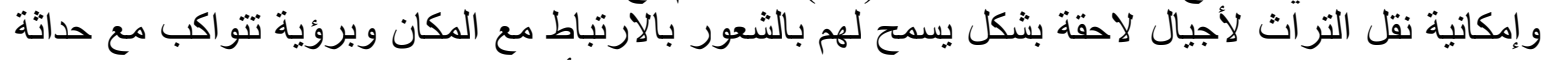

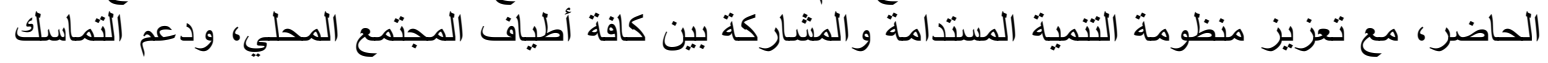

الاجتماعي والتميز الحضاري نعزيز منظومة [44].

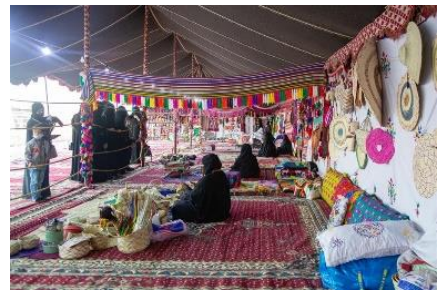

شكل (0) 10 ): صور من الموروث

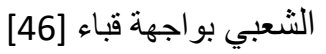

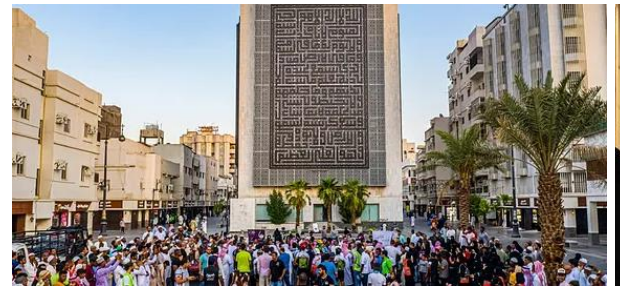

شكل (ع 1): التو اصل و الإندماج و التفاعل

الإجنماعي بجادة قباء [44]

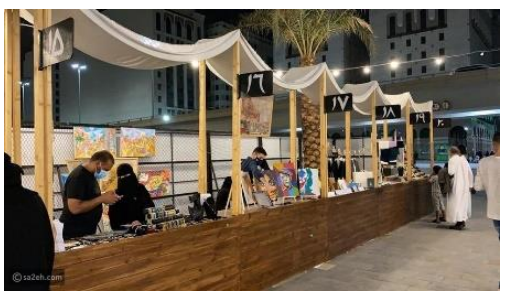

شكل (r آ ): نماذج من الأنشطة و الفعاليات التي تقام بو اجهة قباء [46] الأنة 
ا

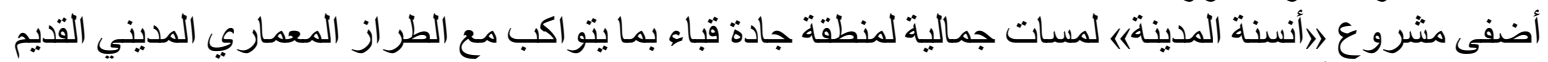

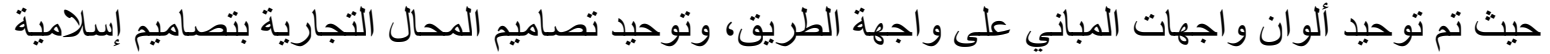

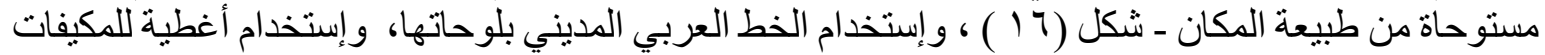

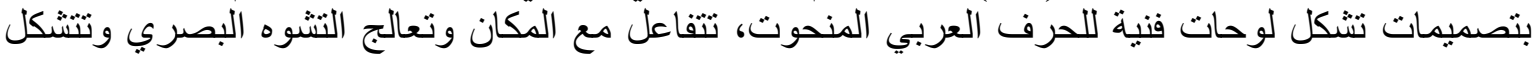

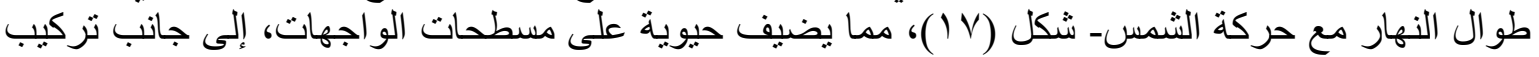

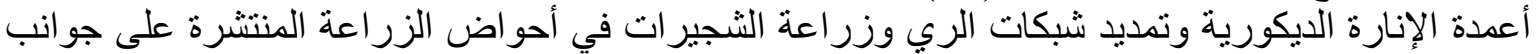

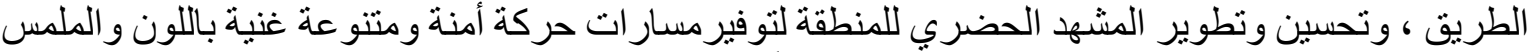

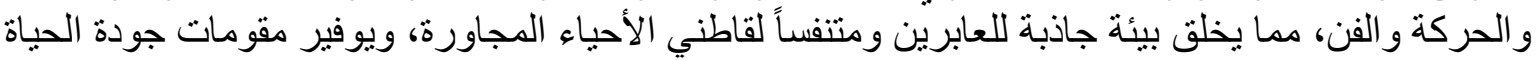

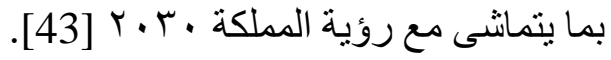

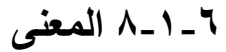

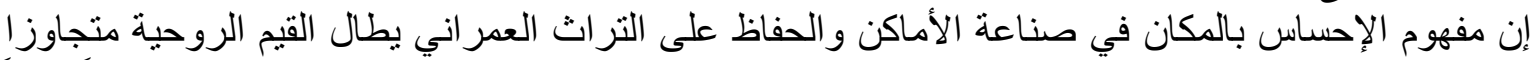

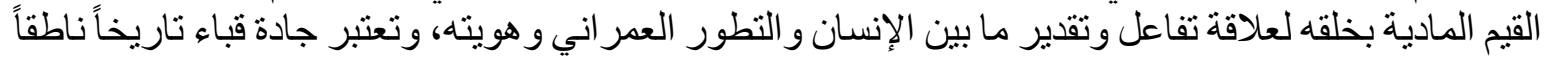

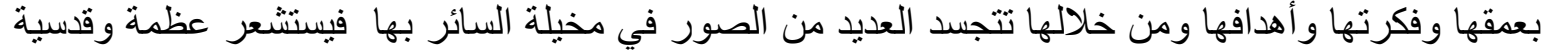

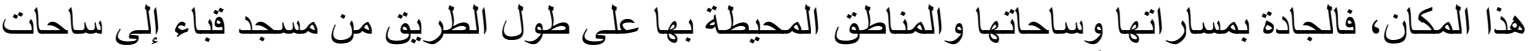

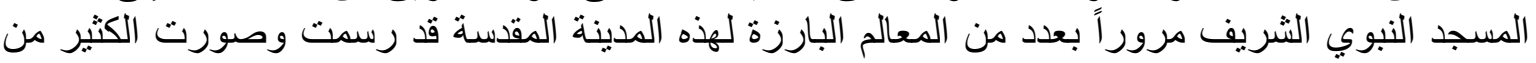

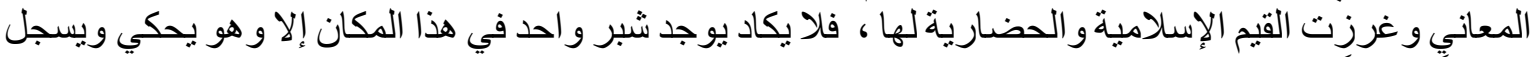
تاريخاً مشرقاً ويجسد الموروث الإيني و الثقافي والتراثي للمدينة المنورة - شكل (1) (1).

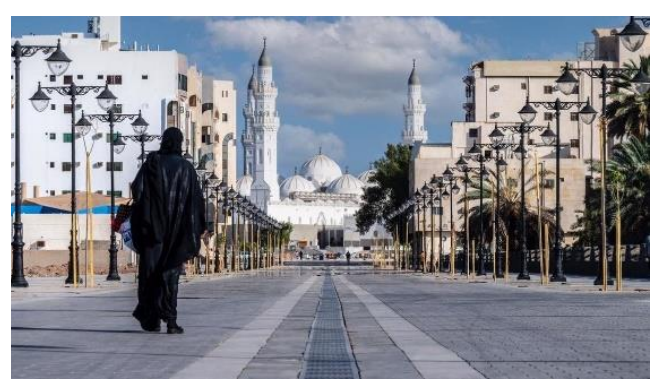

شكل (1 1 ) ): طريق جادة قباء بإتجاه مسجد قباء

[45]

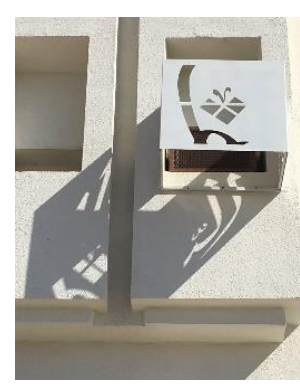

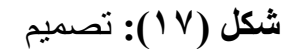

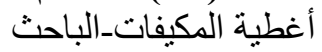

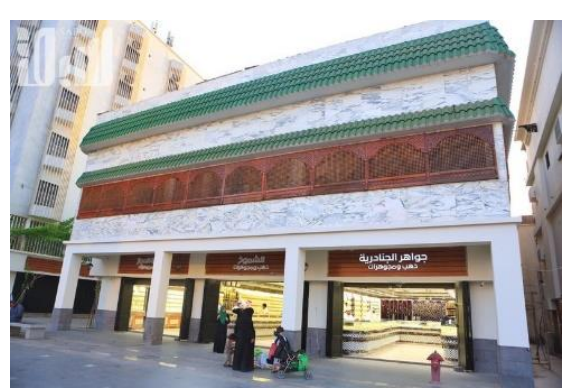

شكل (7 آ ): توحيد ألوان الو اجهات

وتصاميم المحلات_الباحث

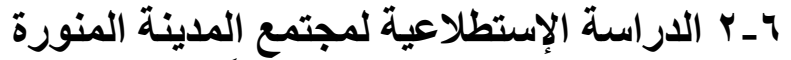

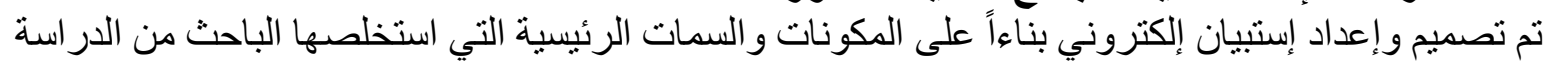

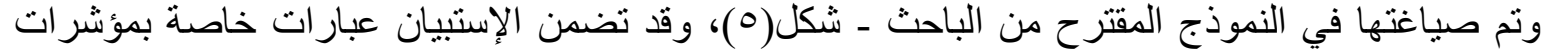

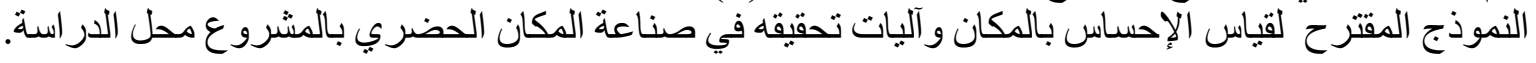

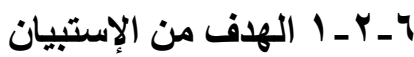

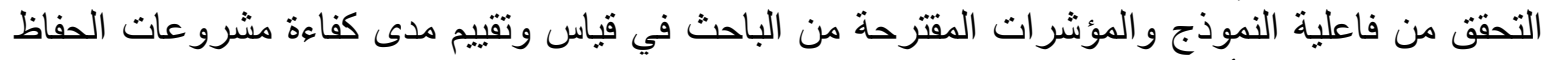

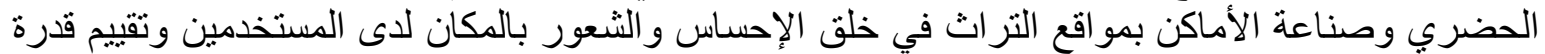

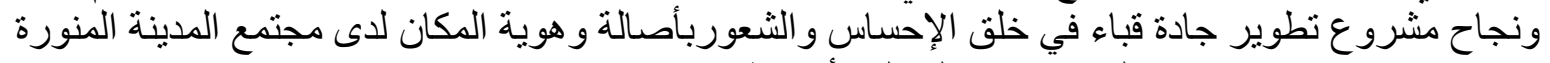

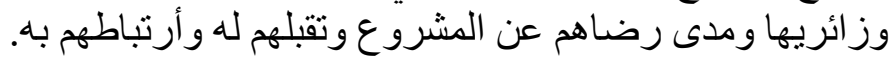

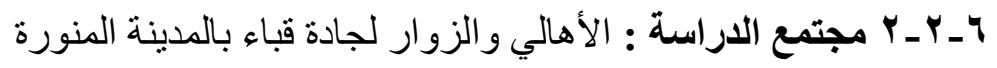

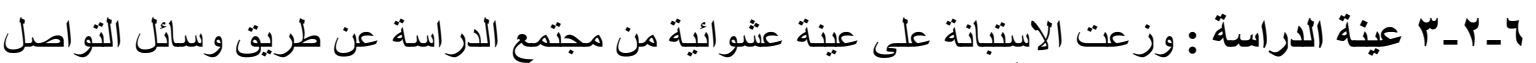

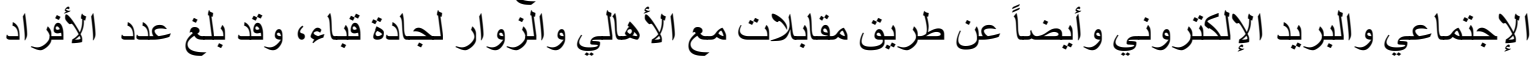

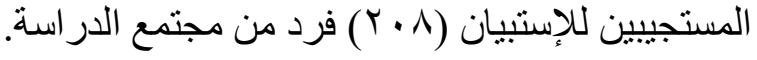




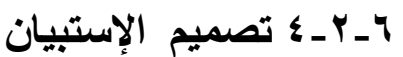

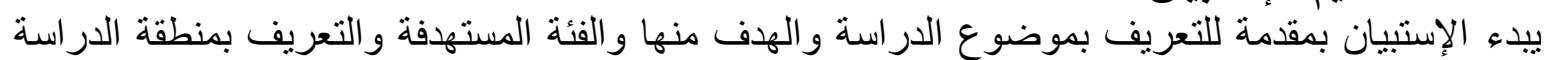
(جادة قباء) و الهدف من مشروع تطوير ها، و ويلي ذللك الأجز اء الرئيسية للإستبيان و هي كالتالي :

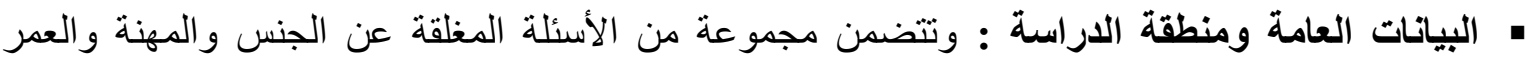

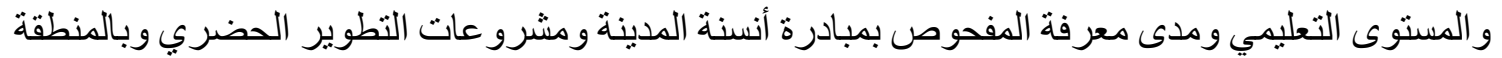

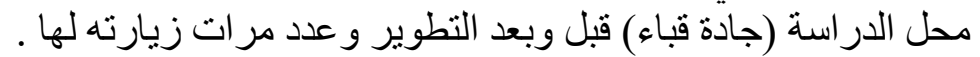
تقييم كفاعة المشروع في خلق الإحساس بالمكان : من خلال ع محاور رئيسية بالاستبيان تمثل المكونات

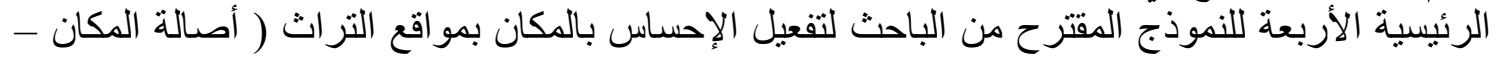

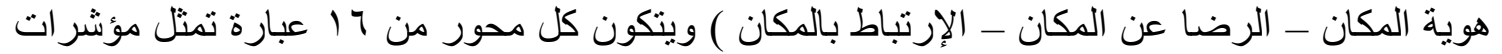

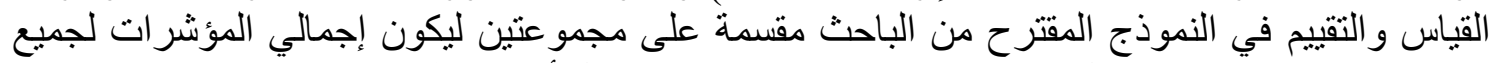

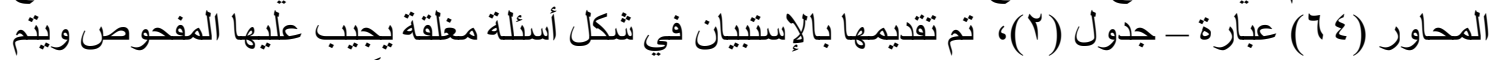

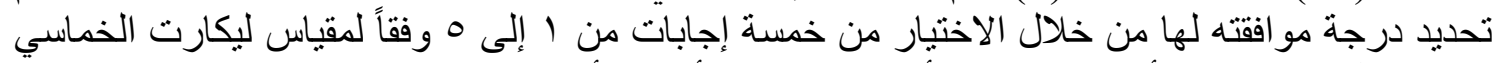

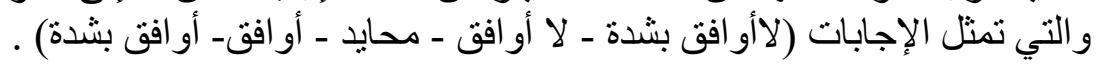

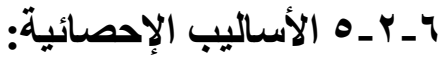

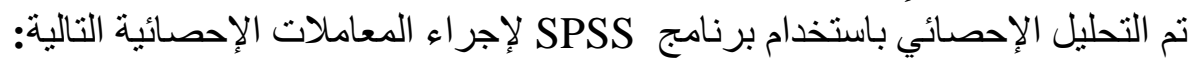

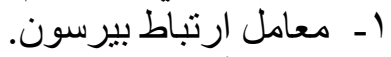

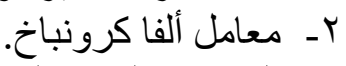

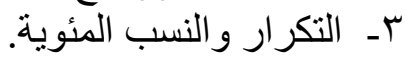
عـ ـ المتوسط الحسابى وذللك لترتيب المتغير ات لتوضيح أولوية تأثير ها، والدرجة النسبية لقوة الأبعاد.

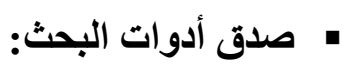

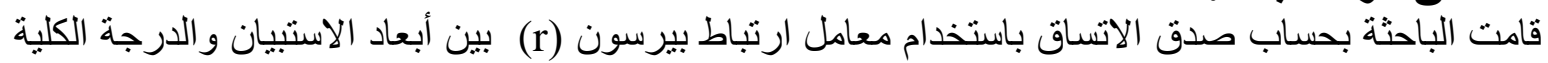

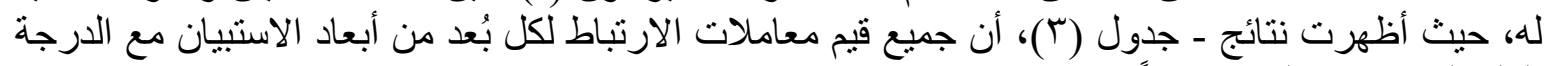

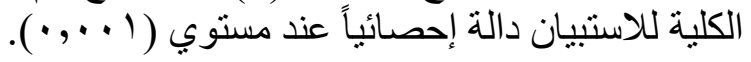

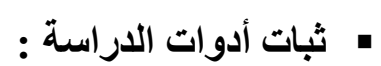

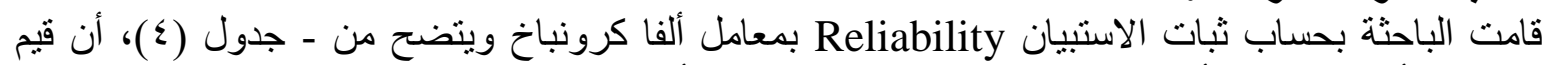

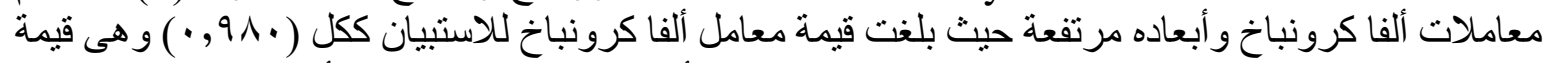

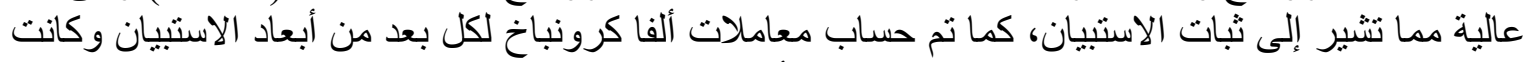
النتائج في الجدول التالي حيث كانت جميع قيم معامل ألفا كرونباخ مرتفعة مما يدل علي ثلي ثبات النات الاستبيان.

جدول ( \&): قيم معامل الثبات للاستبيان-

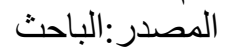

\begin{tabular}{|c|c|c|}
\hline كعامل ألفا & أبعاد الاستبيان & \\
\hline., $9 \ldots$ & القيمة التر اثية للمكان & \multirow{8}{*}{$\underline{\underline{z}}$} \\
\hline., $91 \pi$ & العلامة التجارية & \\
\hline$\cdot, \wedge \wedge 0$ & الشكل المادي & \\
\hline$\cdot, \wedge T Y$ & الوصول و الربط & \\
\hline$\cdot, \wedge \div \wedge$ & الوظائف و الأنشطة & \\
\hline., $9 Y Y$ & العلاقات الإجتماعية & \\
\hline$\cdot, 9 Y Y$ & الر احة و الصورة & \\
\hline$\cdot, 941$ & المعنى & \\
\hline
\end{tabular}

جدول (rّ): قيم معاملات الارتباط بين الدرجة الكلبة لكل بعد

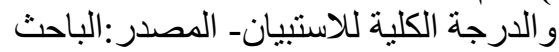

\begin{tabular}{|c|c|c|c|}
\hline الدلالة & الارتباط & \multicolumn{2}{|l|}{ أبعاد الاستبيان } \\
\hline$\cdot, \ldots 1$ & $\cdot, \lambda Y O$ & القيمة التر اثية للمكان & \\
\hline$\cdot, \ldots 1$ & $\cdot, \wedge \vee \neg$ & العلامة التجارية & \\
\hline$\cdot, \ldots 1$ & $\cdot, \wedge T V$ & الشكل المادى & \\
\hline.,$\ldots 1$ & $\cdot, \wedge \ldots$ & الوصول و الربط & \\
\hline$\cdot, \ldots 1$ & $\cdot, \wedge 9 \vee$ & الوظائف و الأنشطة & \\
\hline$\cdot, \ldots 1$ & $\cdot, \wedge 99$ & العلاقات الإجتماعية & \\
\hline$\cdot, \ldots 1$ & $\cdot, \wedge \wedge \vee$ & الر احة و الصورة & \\
\hline.,$\ldots 1$ & $\cdot, 9 \cdot \varepsilon$ & المعنى & \\
\hline
\end{tabular}




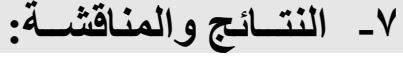 \\ V- إ وصف عينة البحث}

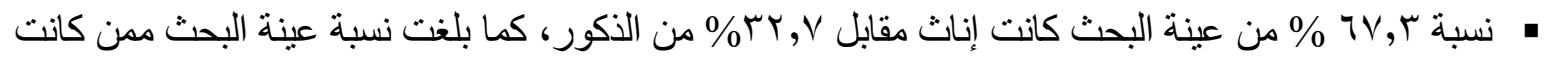

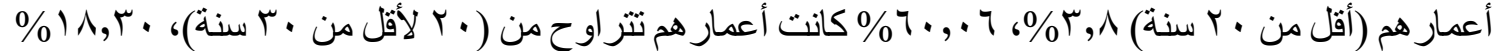

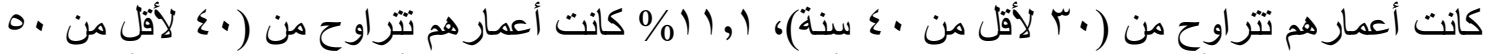

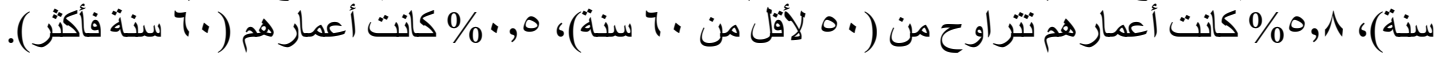

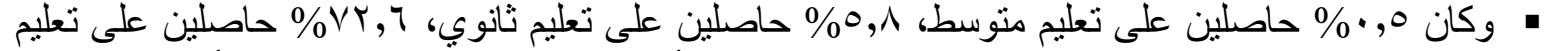

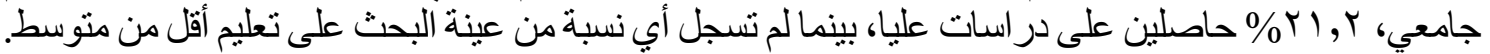

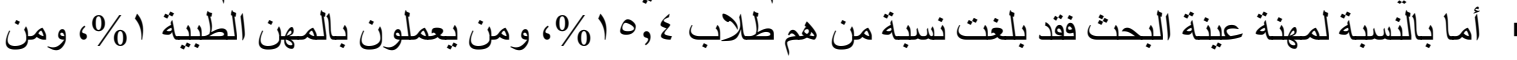

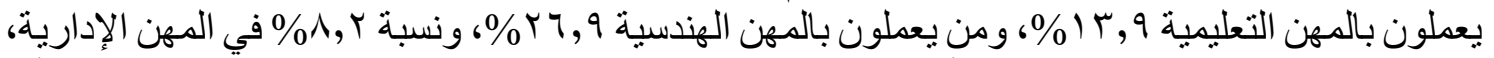

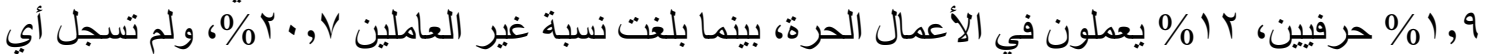
نسبة في المهن السياسية أو المتقاعدين في عينة البحث ، وكان وكان نسبة سكان المدينة المنورة من عينة البحث

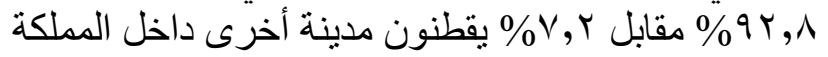

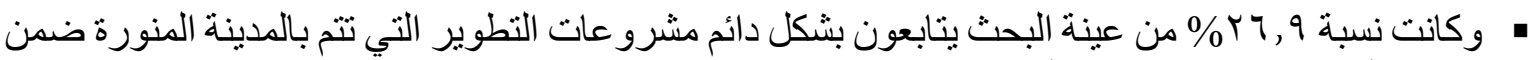

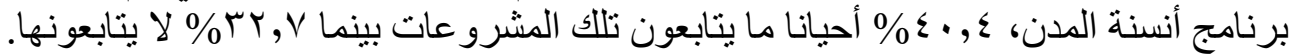

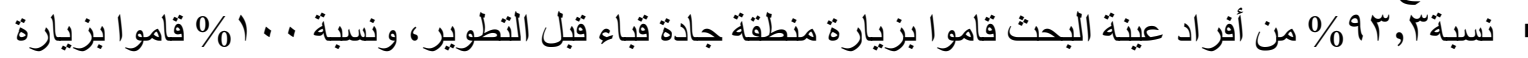

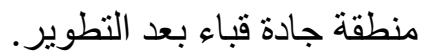

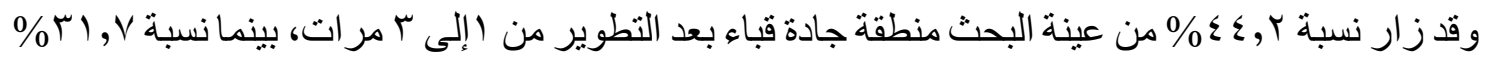

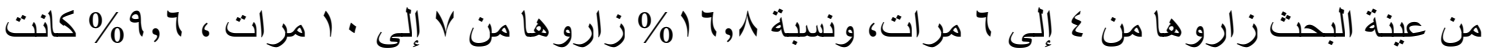

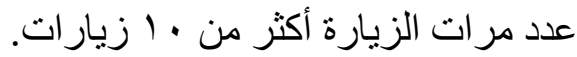

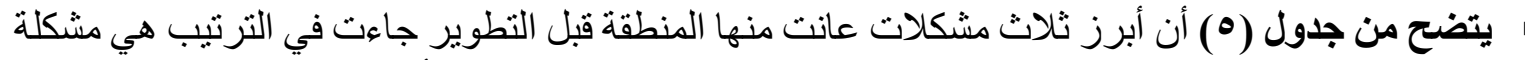

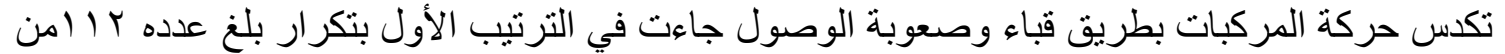

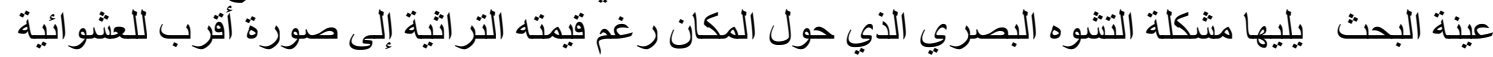

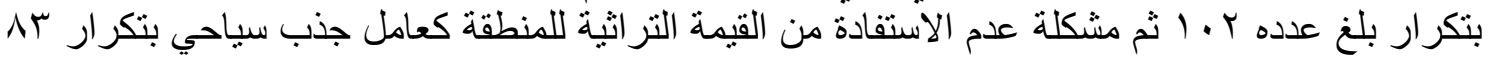
من عينة البحث، بينما جاءت مشكلة عدم وجود طابع موحد في التصميم لو اجهات المحلات التهات التجارية و المباني

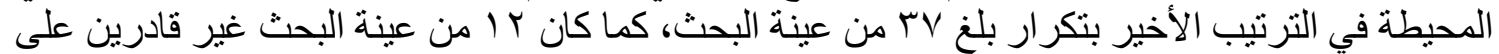

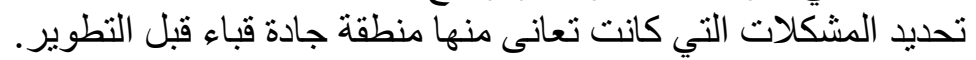

جدول (•): توزيع أفر اد عينة البحث وفقاً للمشكلات التي كانت تعاني منها قباء قبل التطوير ـ المصدر :الباحث

\begin{tabular}{|c|c|c|c|}
\hline الترتيب & المئويبة & التكرار & ماهي أبرز ثلاث مشكلات كانت تعاني منها المنطقة قبل التطوير \\
\hline 0 & r7,9 & 07 & صعوبة المشي و التسوق بطريق قباء \\
\hline$\varepsilon$ & $r \wedge, 0$ & A. & عدم وجود مناطق و أماكن للجلوس ومناطق خضر اء \\
\hline 7 & r,, r & $\varepsilon$ & ضجيج المركبات وروائح عو ادمها \\
\hline 1 & or,,$\Lambda$ & $11 \mathrm{~T}$ & تكسس حركة المركبات بطريق قباء وصعوبة الوصول \\
\hline V & r,, r & $\varepsilon \varepsilon$ & قلة الأنشطة الاجتماعية و الثقافية و الترفيهية \\
\hline r & rq, & NT & عدم الاستفادة من القيمة التر اثية للمنطقة كعامل جذب سياحي \\
\hline r & $\varepsilon q, \cdot$ & $1 \cdot r$ & التشوه البصرب الذي حول المكان رغم قيمته التراثية إلى صورة أقرب للعشو ائية \\
\hline$\Lambda$ & $i \vee, \Lambda$ & $r V$ & عدم وجود طابع موحد في التصميم لو اجهات المحلات التجارية و المباني المحيطة \\
\hline 9 & $0, \wedge$ & Ir & لا أعلم \\
\hline
\end{tabular}

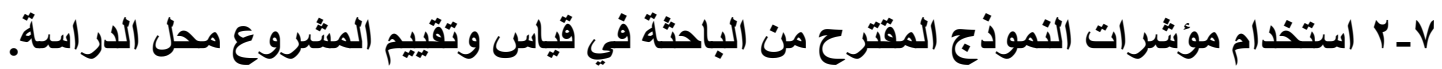

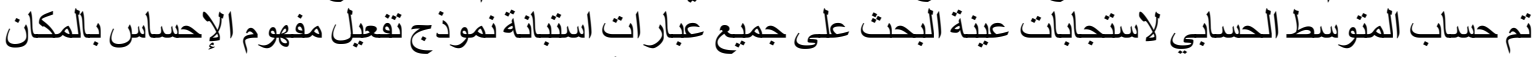

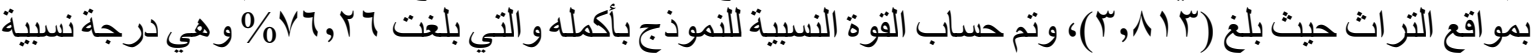
مرتفعة مما يشير إلى صلاحية النموذج لاستخدام الباحثين في تقييم مدى تفعيل الإحساس بالمكان بان بمو اقع التراث. 


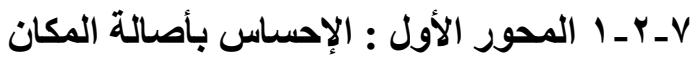

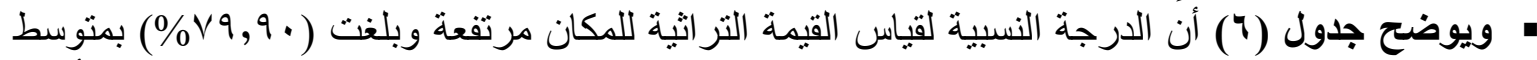

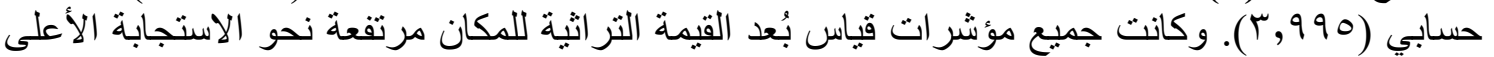

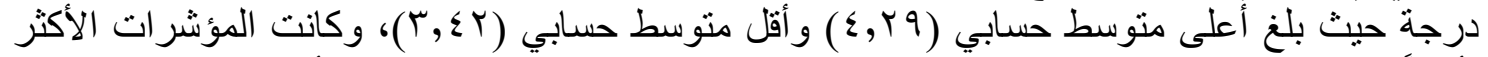
تأثثر اً لقياس القيمة التر اثثة للمكان المؤشر الخامس يلية الثيه المؤشر الثامن ثم السابع ثم الأول بمتوسطات حسابية

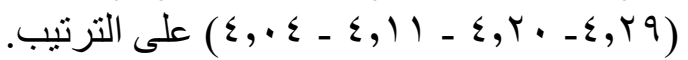

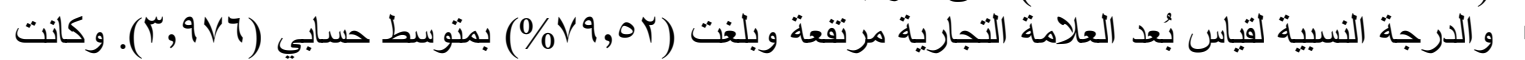

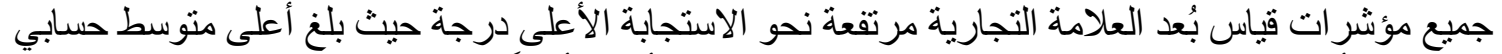

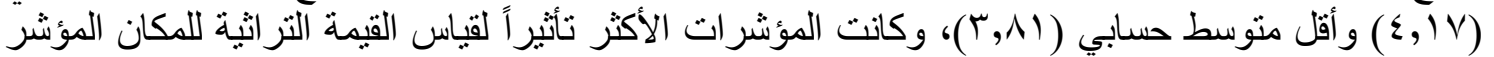

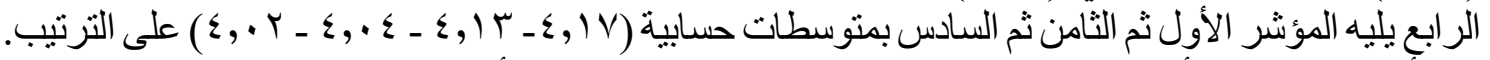

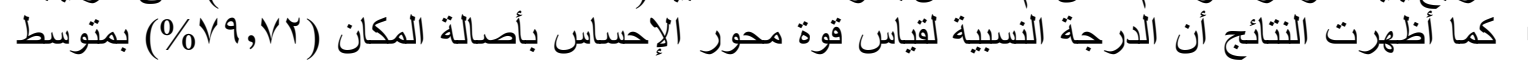

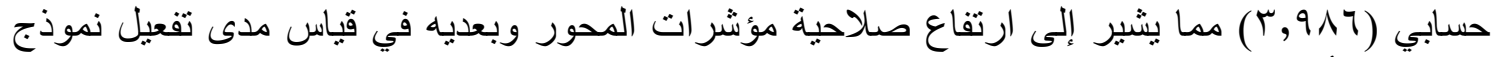
الإحسأس بأصالة المكان.

جدول (†) : استجابات أفر اد العينة على محور الإحساس بأصلالة المكان ــ المصدر :الباحث

\begin{tabular}{|c|c|c|c|c|c|c|c|c|}
\hline \multirow[b]{2}{*}{ 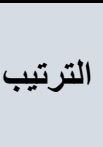 } & \multirow[b]{2}{*}{ المتوسط } & \multicolumn{5}{|c|}{ 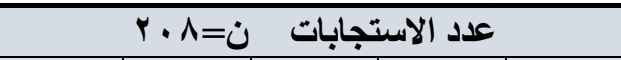 } & \multirow{2}{*}{\multicolumn{2}{|c|}{ 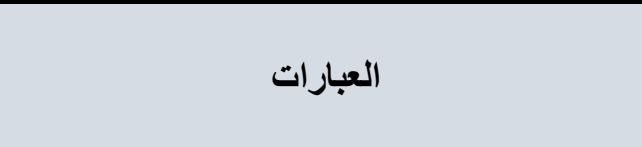 }} \\
\hline & & لا لأوافق & لا أوافق & 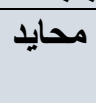 & أوافق & بشدة أو بق & & \\
\hline$\varepsilon$ & $\varepsilon, \cdot \varepsilon$ & V & 11 & rq & 1) & $\Lambda$. & \multicolumn{2}{|c|}{ '. تر مشي ناجح تطوير جادة قباء حقق صناعة مكان } \\
\hline 0 & ए,१q & $\wedge$ & $1 \pi$ & $\varepsilon \Lambda$ & $v$. & VI & \multicolumn{2}{|c|}{ 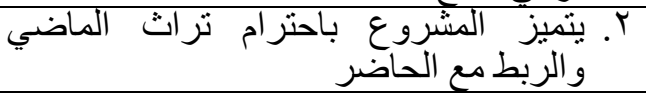 } \\
\hline$\wedge$ & $r, \Sigma T$ & 10 & ro & $\uparrow$ & 01 & $\varepsilon r$ & \multicolumn{2}{|c|}{ r. الققية التراثئة. إعادة تجليد للحرف والمهن ذات } \\
\hline 1 & $\varepsilon, \varphi_{q}$ & 7 & $1 \cdot$ & Ir & 79 & 111 & \multicolumn{2}{|c|}{ ع. حقق مشروع تطوير جادة قباء إحياء للمكان محليا } \\
\hline 7 & $r, 97$ & $\Lambda$ & TV & TV & $\Lambda$. & $V 7$ & \multirow{2}{*}{\multicolumn{2}{|c|}{ 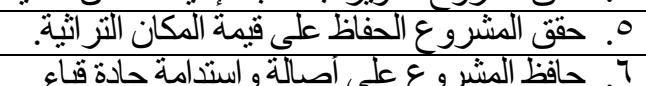 }} \\
\hline $\mathrm{V}$ & $r, 90$ & $\varepsilon$ & $1 \varepsilon$ & $\varepsilon \varepsilon$ & VY & $V \varepsilon$ & & \\
\hline$r$ & $\varepsilon, 11$ & $\mathrm{~V}$ & 10 & ro & $\pi$ & 91 & \multicolumn{2}{|c|}{ V. حقق المشرو ع صناعة مكان فريد ونادر } \\
\hline r & $\varepsilon, r_{.}$ & - & 14 & r. & $7 V$ & 91 & \multicolumn{2}{|c|}{ ^. الذقاكرة المشروع صناعة مكان اصيل يخلد في } \\
\hline \multicolumn{7}{|c|}{$r, 990$} & | المتوسط العام & القيمة التراثية \\
\hline \multicolumn{7}{|c|}{$\% \vee 9,9}$. & الارجة النسبية لقياس قوة البُعد & "للمكان \\
\hline r & $\varepsilon, 1 T$ & V & r & ro & $7 \varepsilon$ & 99 & \multicolumn{2}{|c|}{ ' جذاب ذشو روح جادة قباءة تجارية مميزة مكان سياحي } \\
\hline 0 & $\Gamma, \wedge q$ & 0 & 11 & rq & $\vee \wedge$ & 71 & \multicolumn{2}{|c|}{ r و حقق المشرو المرنبطة بِاء للمكانب و الرموز المادية } \\
\hline V & $\Gamma, \wedge)$ & $\wedge$ & TV & ד & זי & $V \varepsilon$ & \multicolumn{2}{|c|}{ r. جادة قباء المشروع على وضوح وتاكيد مداخل } \\
\hline T & IV & V & $\Lambda$ & Y & $\overline{\nabla \wedge}$ & $9 \varepsilon$ & \multicolumn{2}{|c|}{ ع. حقق المشروع وجود هوية بصرية مميزة } \\
\hline 7 & $\Gamma, \wedge \uparrow$ & V & IV & rq & 11 & $7 \varepsilon$ & \multicolumn{2}{|c|}{ •. ثر حافظة في جادوة قباءعلى وجود مفردات جمالية } \\
\hline$\varepsilon$ & $\varepsilon, \cdot r$ & 0 & $1 \pi$ & rq & TV & $\Lambda \varepsilon$ & \multicolumn{2}{|c|}{ 7. بالإيجقابية المشروع الحفاظ على تدعيم الإحساس } \\
\hline 0 & $r, \wedge q$ & 7 & 11 & 01 & V) & 79 & \multirow{2}{*}{\multicolumn{2}{|c|}{ 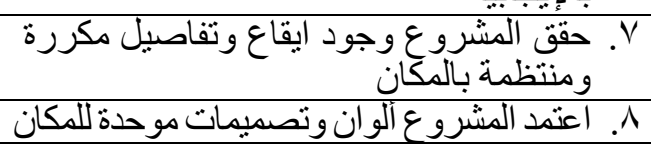 }} \\
\hline$\Gamma$ & $\varepsilon, \cdot \varepsilon$ & 9 & $\mathrm{~V}$ & ए纟 & V7 & $\lambda T$ & & \\
\hline \multicolumn{7}{|c|}{$r, 9 \vee q$} & المتوسط العام & العلامـة \\
\hline \multicolumn{7}{|c|}{$\% \vee q, 0 Y$} & \multirow{3}{*}{\multicolumn{2}{|c|}{ بأصألة المكاسن }} \\
\hline \multicolumn{7}{|c|}{$r, 9 \wedge \uparrow$} & & \\
\hline \multicolumn{7}{|c|}{$\% \vee q, \vee r$} & & \\
\hline
\end{tabular}




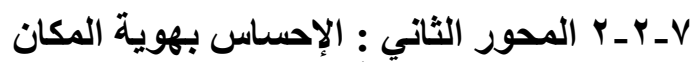

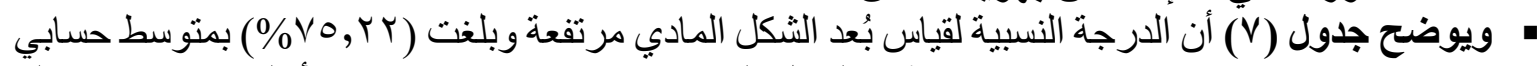

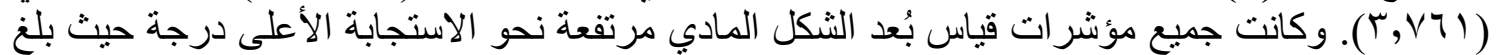

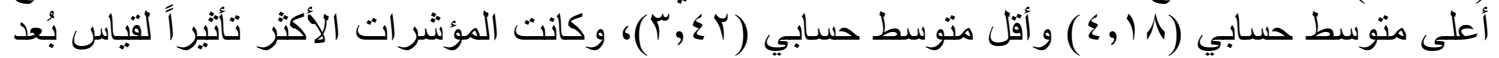

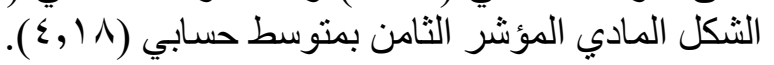

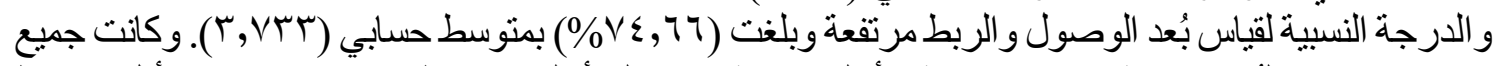

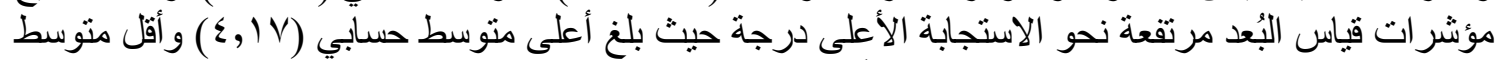

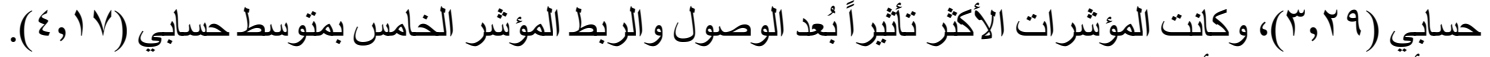

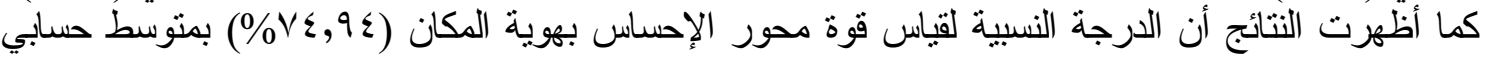
مما يثير إلى ارتفاع صلاحية مؤشر ات المحور وبعليه في قياس مدى تفعيل نموذج الإحساس بهوية المكان. (T, V ¿V)

جدول (V): استجابات آفر اد العينة على محور الإحساس بهوية المكان- المصدر:الباحث

\begin{tabular}{|c|c|c|c|c|c|c|c|}
\hline \multirow[b]{2}{*}{ الترتيب } & \multirow[b]{2}{*}{ | المتوسط } & \multicolumn{5}{|c|}{ 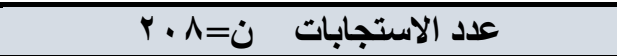 } & \multirow[b]{2}{*}{ 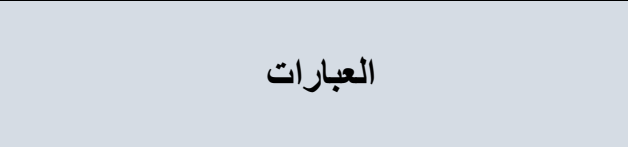 } \\
\hline & & | ل أشدافق & لا أوافق & محايد & أوافق & بشدة أو بق & \\
\hline 7 & $\Gamma, 70$ & $\mu$ & YI & $7 \leqslant$ & VA & $\varepsilon r$ & 1. تالتميز جادة قباء بالثفافية والقدرة على رؤية \\
\hline r & $r, \wedge r$ & r & 11 & $\varepsilon r$ & 94 & Or & r. يتحقق الاتصـال و التر ابط بين عناصره \\
\hline 0 & $r, V r$ & V & 11 & 00 & $V \varepsilon$ & $0 \leqslant$ & r. يحقق التو ازن بين الكتل و الفر اغات \\
\hline$\xi$ & $r, v \tau$ & $\Lambda$ & 11 & $\leqslant 0$ & NT & 00 & ــ ـ يتميز بنفاذية الممرات وحيويتها \\
\hline V & $r, \Sigma Y$ & 14 & r. & TV & or & $\leqslant 0$ & ๑. يتحقق بالمكان التدرج واختلاف المناسيب \\
\hline$\varepsilon$ & $r, V T$ & $\Lambda$ & 11 & $\leqslant 7$ & 11 & 00 & 7. ألتميز باضلملائمة للمكان. البصرية والمظهر التفصيلي \\
\hline r & $r, V V$ & $\Lambda$ & Y) & 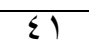 & $\overline{\nabla q}$ & 09 & V. يحقق تصميمه المقياس الإنساني المريح \\
\hline 1 & $\varepsilon, 1 \wedge$ & $\varepsilon$ & 1. & $r$ & Vq & 94 & ^. جكادة قباء مكان ثري ذو خصائص وهوية \\
\hline \multicolumn{7}{|c|}{$r, \vee \vee 1$} & \multirow{2}{*}{ ال الثنكل } \\
\hline \multicolumn{7}{|c|}{$\% \vee \vee, Y Y$} & \\
\hline 7 & $r, 7 \Gamma$ & $\pi$ & TO & 01 & $\pi$ & 01 & ا. ـ ترتبط جادة قباء بالمناطق المجاورة لها بشكل جيد. \\
\hline V & $r, 09$ & 17 & TV & $\varepsilon \pi$ & $7 \pi$ & 09 & \multirow{2}{*}{ 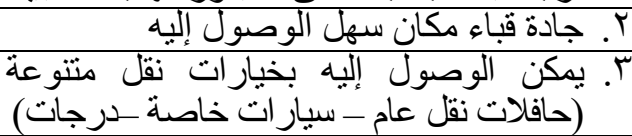 } \\
\hline 0 & r,TV & 11 & TY & $0 \leqslant$ & 09 & $7 r$ & \\
\hline$\varepsilon$ & $r, \vee q$ & 9 & T纟 & $\leqslant 0$ & $\overline{V T}$ & ov & ــ يتميز بإمكانية رؤيتها من مسافة بعيدة \\
\hline 1 & $\varepsilon, I V$ & 0 & 9 & YV & VY & 90 & \multirow{2}{*}{ 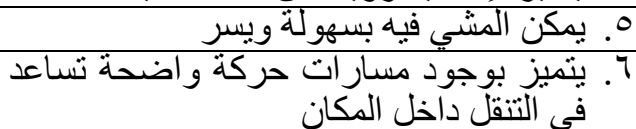 } \\
\hline r & $\Gamma, \wedge q$ & $\wedge$ & 19 & $r_{1}$ & A. & v. & \\
\hline$\wedge$ & $r, r q^{\prime}$ & 19 & rI & 10 & $\leqslant 7$ & rV & 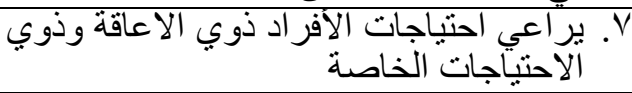 \\
\hline$r$ & $\Gamma, \Lambda \Gamma$ & V & 10 & $\sum 1$ & 19 & 07 & \\
\hline \multicolumn{7}{|c|}{$r, V \mu r$} & \multirow{2}{*}{ 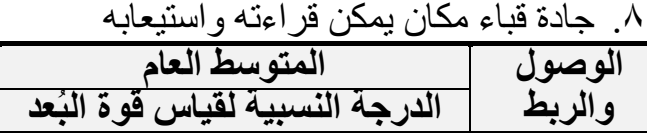 } \\
\hline \multicolumn{7}{|c|}{$\% \vee \vee, 77$} & \\
\hline \multicolumn{7}{|c|}{$r, V \leqslant V$} & المتوسط العام \\
\hline \multicolumn{7}{|c|}{$\% \vee \leq, q \leq$} & الإحسة النسبية لقياسي فوزة المكان محور \\
\hline
\end{tabular}

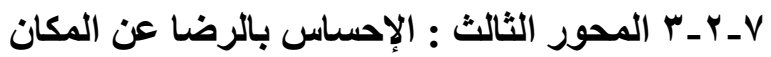

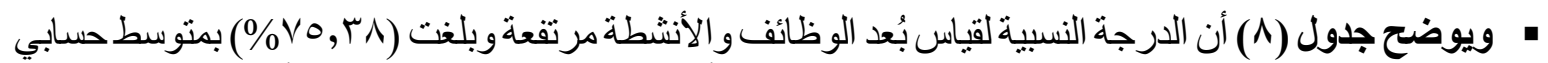

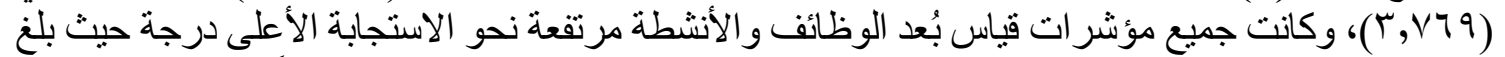

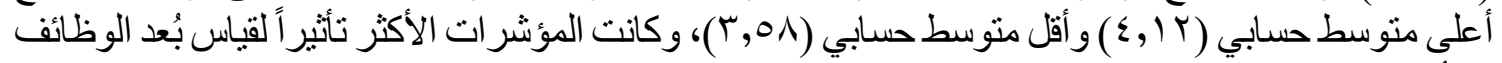




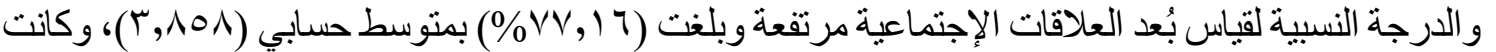

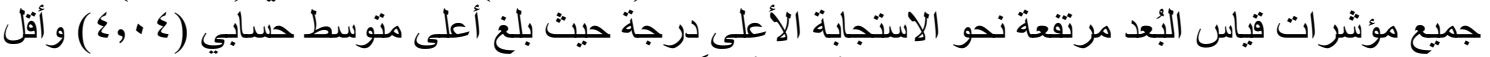

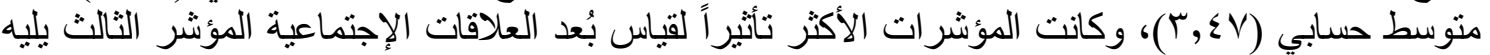

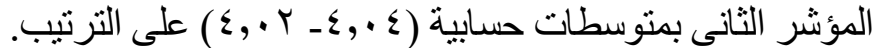

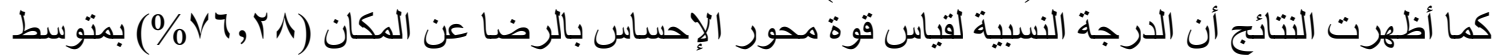

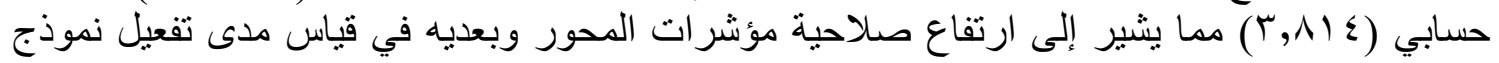

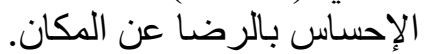
جدول (^): استجابات أفر اد العينة على محور الإحساس بالرضا عن المكانـ المصدر:الباحث

\begin{tabular}{|c|c|c|c|c|c|c|c|}
\hline \multirow[b]{2}{*}{ الترتيب } & \multirow[b]{2}{*}{ 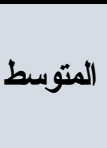 } & \multicolumn{5}{|c|}{ 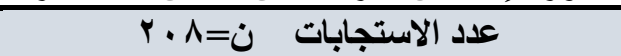 } & \multirow[b]{2}{*}{ 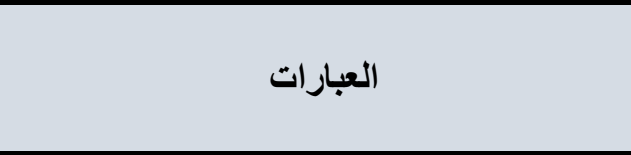 } \\
\hline & & لا لا أوافق & لا لا أوافق & 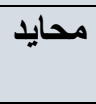 & أوافق أق & بشدافق & \\
\hline 1 & $r, 70$ & 1 . & MY & $0 \leqslant$ & TV & 00 & 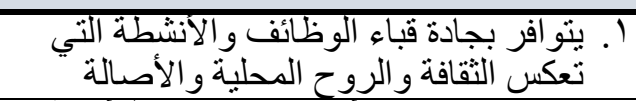 \\
\hline$\varepsilon$ & r,vo & 1 & r) & ov & VA & 01 & r. ألفردية و والجمأعية أماكن مخصصة للانشطة \\
\hline r & ץ,१^ & r & $1 \varepsilon$ & ד & ᄉ & 79 & 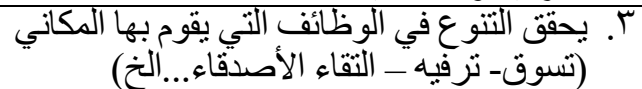 \\
\hline $\mathrm{V}$ & $\mu, 0 \wedge$ & 0 & TO & 70 & $\nabla \cdot$ & $\varepsilon \Gamma$ & ؛. يوفر فرص عمل متعددة لأفر اد المجتمع \\
\hline 1 & $\varepsilon, I Y$ & V & 7 & ro & $\Lambda \mathrm{V}$ & $\lambda \mu$ & ○. يحفز الاطفال على الانطلاق و الحركة. \\
\hline r & $r, \wedge r$ & 11 & Mr & rv & Tr & VT & 7. وركوب الدي داجات وتشجيع ممارسة الرياضة \\
\hline 0 & $r, 7 V$ & 9 & IV & 09 & V) & OY & V. جادة قباء مكان صحي يحافظ على البيئة \\
\hline $\mathrm{V}$ & $r, 0 \wedge$ & $\pi$ & YI & $0 \leqslant$ & $\overline{V Y}$ & $\varepsilon \wedge$ & ^. . يمكن للناس وضع طابعهم الخاص على المكان \\
\hline \multicolumn{7}{|c|}{$r, v 7 q$} & المتوسط العام \\
\hline \multicolumn{7}{|c|}{$\% \vee \bullet, r \wedge$} & و الأنشطة الدرجة النسبية لقياس قُوة البُعد \\
\hline$r$ & $r, 9 \Lambda$ & $\varepsilon$ & ir & ro & 9 . & TV & ' إنساني إجنماعى نظاجح جادة قباء صناعة مكان \\
\hline Y & $\varepsilon, \cdot Y$ & $r$ & 9 & $\sum 1$ & $\lambda \Gamma$ & VY & ب. يحفز ألناس على التو أصل و الإندماج و التفاعل. \\
\hline T & $\varepsilon, \cdot \varepsilon$ & 0 & $\Lambda$ & $\varepsilon \cdot$ & $\nabla V$ & $\overline{\nabla \wedge}$ & r. يحقق المشروع إثراء جودة الحياة للمجتمع \\
\hline 0 & r,q & ○ & 10 & $\varepsilon$. & Vฯ & VY & 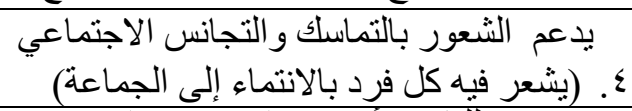 \\
\hline$\Lambda$ & $r, \Sigma V$ & 10 & rq & 00 & $7)$ & $\leqslant \wedge$ & •. وروايحح للناس الماضي ان يروا ويسعوا قصص \\
\hline $\mathrm{v}$ & $r\rceil)$, & $1 \varepsilon$ & TY & 01 & 77 & 00 & 7. يقام فيَهة المهرجأنات و الاحتفالات و الانشطة \\
\hline$\varepsilon$ & 90 & 0 & Y. & ए乏 & $\nabla \cdot$ & $\mathrm{Vq}$ & \multirow{2}{*}{ 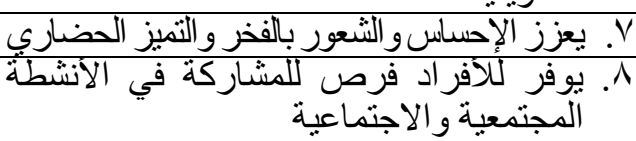 } \\
\hline 1 & $r, \wedge 0$ & r & r) & $\leqslant 7$ & $V_{7}$ & ז & \\
\hline \multicolumn{7}{|c|}{$r, \wedge \otimes \wedge$} & آلمتوسط العام \\
\hline \multicolumn{7}{|c|}{$\% \vee V, 17$} & الارجة النسبية لقياس قُوة البُعد \\
\hline \multicolumn{7}{|c|}{$r, \Lambda \backslash \varepsilon$} & المتوسط العام \\
\hline \multicolumn{7}{|c|}{$\% \vee \neg, \nvdash \wedge$} & 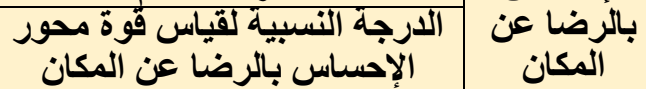 \\
\hline
\end{tabular}

المحور الرابع : الإحساس بالارتباط بالمكان r-V

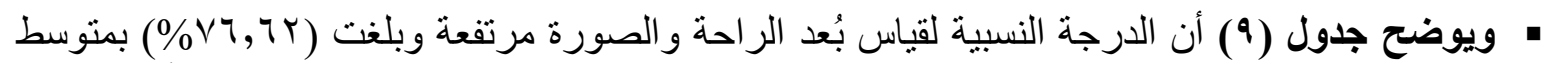

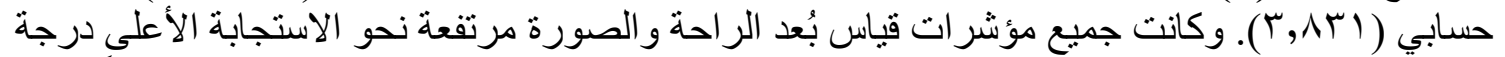

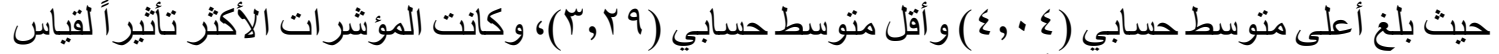

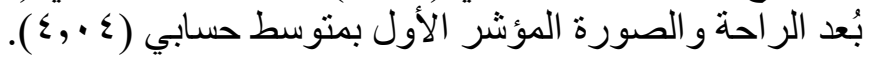




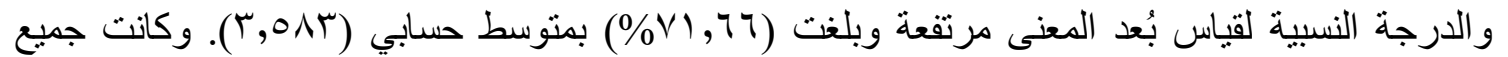

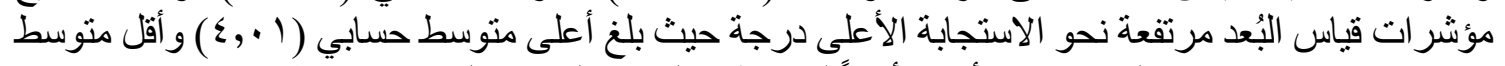

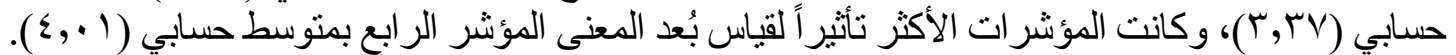

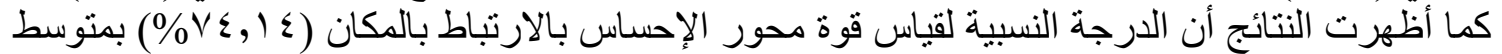

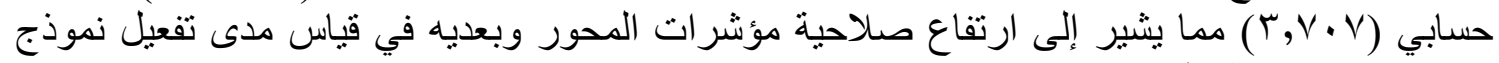
الإحساس بالارنباط بالمكان.

جدول (9): استجابات أفر اد العينة على محور الإحساس بالارتباط بالمكانـ المصدر :الباحث

\begin{tabular}{|c|c|c|c|c|c|c|c|}
\hline \multirow[b]{2}{*}{ الترتيب } & \multirow[b]{2}{*}{ المتوسط } & \multicolumn{5}{|c|}{ 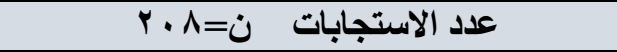 } & \multirow[b]{2}{*}{ 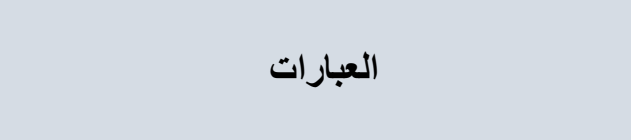 } \\
\hline & & ل الأوافق & لا أوافق & 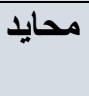 & أوافق & 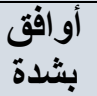 & \\
\hline T & $\varepsilon, \cdot \varepsilon$ & 7 & 9 & $r \cdot$ & $\Lambda V$ & VT & 1. جادة قباء مكان يعطي انطباع أولي جيد. \\
\hline$\varepsilon$ & r,q. & 0 & 10 & «1 & $\Lambda$. & $7 V$ & Y. جالأمان قباء مكان يعزز الإحساس و الَّشعور \\
\hline$\Gamma$ & $r, q 1$ & 0 & 17 & $\varepsilon$. & $V V$ & $V \cdot$ & r. ينو افر فيه مساحات نظيفة و مناطق خضر اء \\
\hline$\Lambda$ & $r, r q$ & 19 & rV & 00 & ov & $\varepsilon$. & ع. يعزز الشعور بالر احة. \\
\hline 0 & $r, \wedge q$ & 0 & $1 \leq$ & $\sum \Gamma$ & NT & $7 \varepsilon$ & هـ يعزز الإحساس بالمتعة البصرية. \\
\hline V & $r, \wedge)$ & 9 & 17 & $r v$ & $\Lambda \wedge$ & $0 \wedge$ & 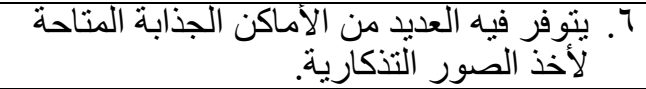 \\
\hline r & $r, 90$ & $\varepsilon$ & 11 & $\varepsilon \cdot$ & $\Lambda \wedge$ & 70 & V. يعزيز الشعور بالجمال (الشكلي و المعنوي) \\
\hline 7 & $\Gamma, \wedge T$ & $\Lambda$ & YI & TV & $\Lambda \mathrm{V}$ & 70 & ^. يعزيز الثعور بتاريخ وتراث آلمكان. \\
\hline \multicolumn{7}{|c|}{$r, \wedge \Psi_{1}$} & آلمتوسط العام \\
\hline \multicolumn{7}{|c|}{$\% \vee 7,7 Y$} & الارجة النسبية لقياس قوة البُعد \\
\hline r & ५,११ & 0 & 14 & Tr & $\wedge 7$ & VI & 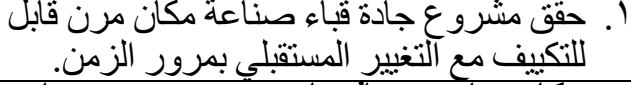 \\
\hline 1 & $\uparrow, \wedge q$ & V & 14 & «1 & (1) & 77 & 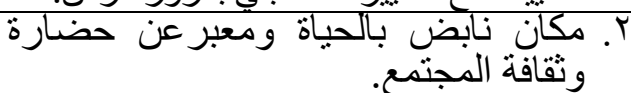 \\
\hline$\Gamma$ & r,q६ & 7 & 11 & $r v$ & 19 & 70 & r. مكان يعزز المعاني والعو اطف الإيجابية \\
\hline 1 & $\varepsilon,+1$ & 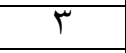 & $1 \leq$ & ry & $\Lambda$. & Vo & ـ. يعزز ألثعور بالرحابة والإتساع \\
\hline$\varepsilon$ & $r$ & $r$ & 11 & $\varepsilon \varepsilon$ & 19 & 71 & \multirow{2}{*}{ 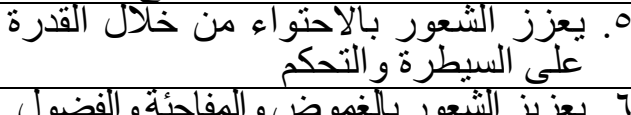 } \\
\hline$\Lambda$ & $T, r V$ & 11 & rq & 70 & $\sum 9$ & ¿ई & \\
\hline 0 & $r, q 1$ & 0 & $1 \varepsilon$ & $\varepsilon$. & $\Lambda \varepsilon$ & 70 & 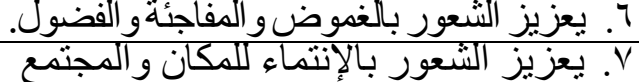 \\
\hline $\mathrm{V}$ & $r, \mathrm{r} \wedge$ & $\mathrm{V}$ & IV & $\varepsilon \varepsilon$ & AV & Or & ^. يعزيز الشعور بالسلامة الشخصية \\
\hline \multicolumn{7}{|c|}{$r, O \wedge \mu$} & المتوسط العام \\
\hline \multicolumn{7}{|c|}{$\% \vee 1,77$} & الارجة النسبية لقياس قوة البُعد \\
\hline \multicolumn{7}{|c|}{$r, V \cdot V$} & المتوسط العام \\
\hline \multicolumn{7}{|c|}{$\% \vee \leq, 1 \leq$} & الأرجة النسبية لقياس قُّباط بالمكان محور \\
\hline
\end{tabular}

r r-V

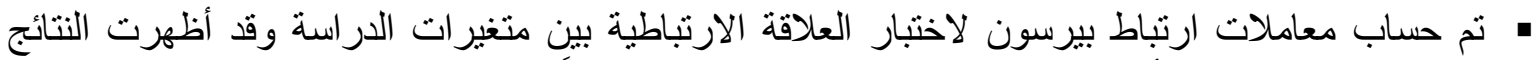

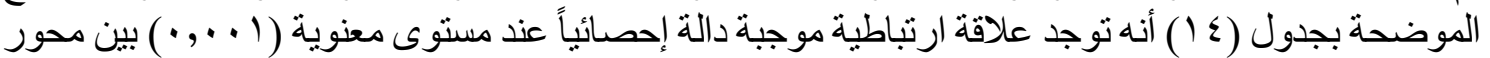

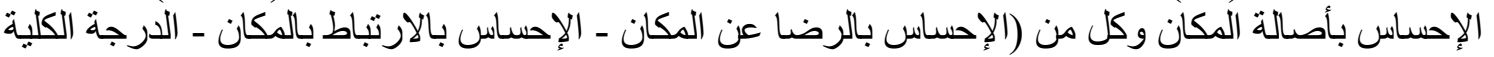

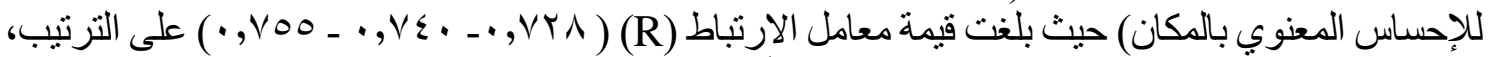

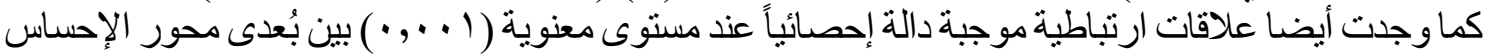

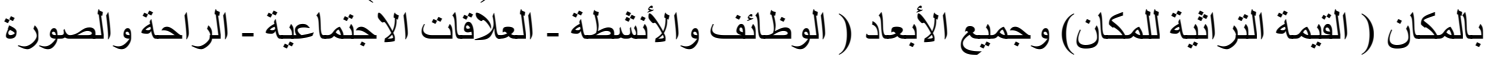

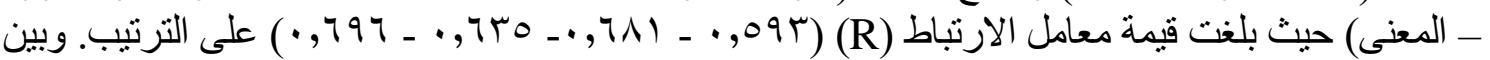

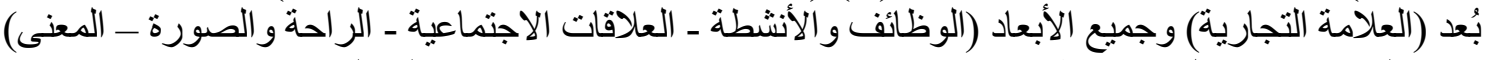

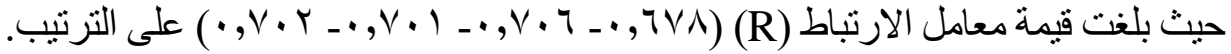




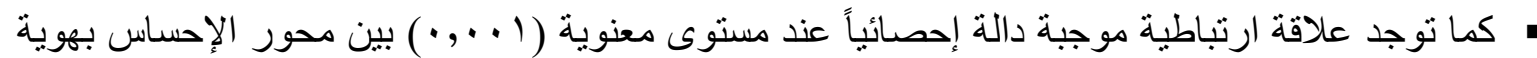

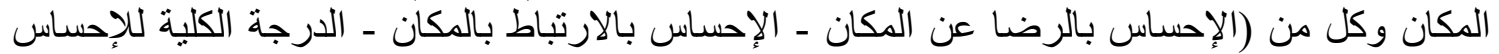

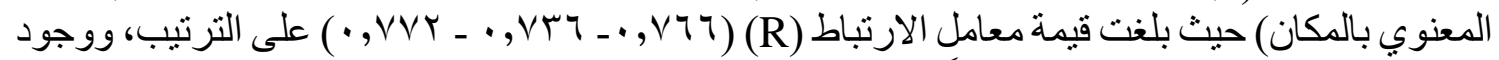

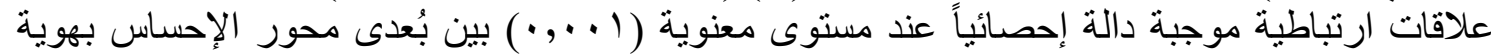

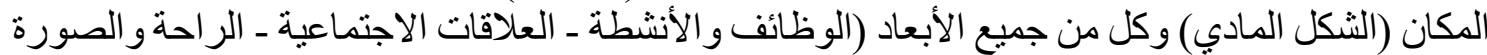

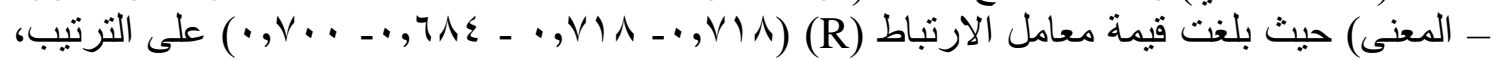

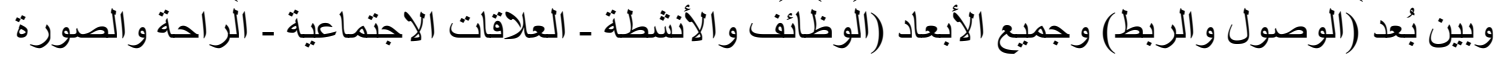

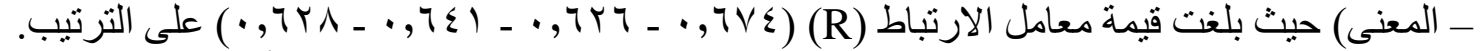

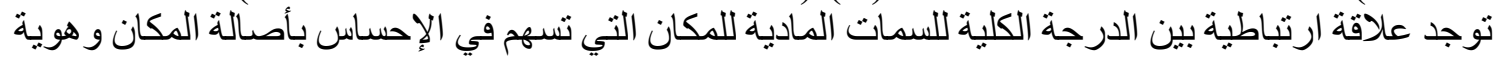

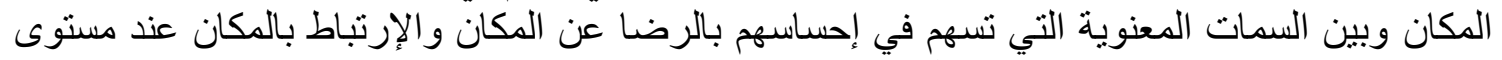

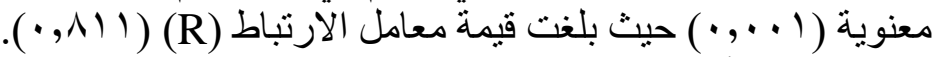

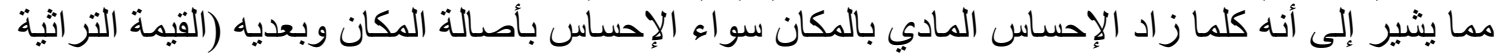

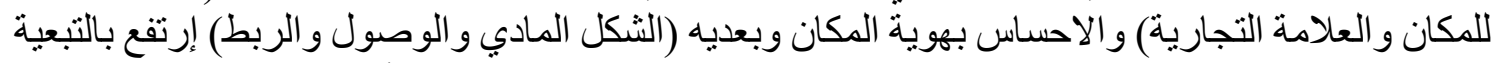

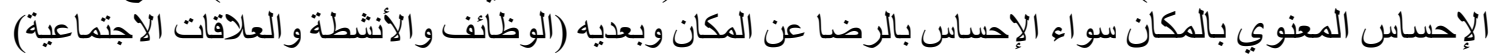

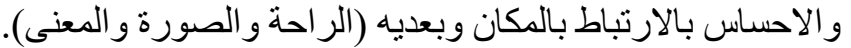

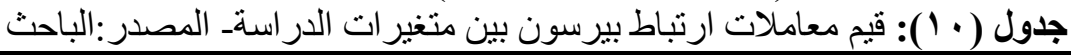

\begin{tabular}{|c|c|c|c|c|c|c|c|}
\hline اللإجهات الكليهات & بالإحساس & المعنى & والصورة الرة & بالإلإضاساس عن & الإجتماعلاتية & والوظتشطة & متغيرات الدراسة \\
\hline$* * * ., 799$ & $* * *,, 7 \wedge 9$ & $* * * ., 797$ & ***., тro & $* * *,, 74 \wedge$ & $* * *,, 7 \wedge 1$ & $* * *, 094$ & القيمة التراثية للمكان \\
\hline$* * *,, \vee \leq 0$ & $* * *,, \vee Y O$ & $* * * \cdot, V \cdot r$ & $v \cdot 1$ &,$V Y \leq$ & $* * *,, \vee \cdot\urcorner$ & $* * *,,\rceil \vee \wedge$ & العلامة التجارية \\
\hline$* * *,, \vee 00$ & $v \varepsilon$. & $* * *,, V \mu 1$ & 799 & NYA & , YYO & 970 & الإحساس بأصالة المكان \\
\hline ***., vor & $* * *,, \vee>0$ & $* * *,, \vee \ldots$ & $* * *,, \uparrow \wedge \varepsilon$ & $* * *,, \vee 0$. & $* * * ., \vee \backslash \wedge$ & $* * *,, \vee \backslash \wedge$ & الشكل المـادي \\
\hline$* * *$, , \^० & $* * *,, 707$ & ***.,Tr^ & $* * *,, 7 \leq 1$ & $* * *,, T \vee \wedge$ & ***.,TYT & $* * *,, 7 \vee \leq$ & الوصول والربط \\
\hline$* * *,, \vee \vee r$ & $* * *,, \vee r u$ & $* * *,, \vee \backslash r$ & $* * *,, \vee \backslash 1$ & 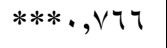 & $* * *,, \vee Y I$ & $* * *,, V \leq V$ & الإحساس بهوية المكان \\
\hline$* * *,, \wedge \backslash 1$ & $* * * ., \vee \wedge \varepsilon$ & $* * *,, \vee \neg \vee V$ & $* * *,, \vee \leq 9$ & $* * *,, \vee \vee \varepsilon$ & $* * *,, \vee \vee 9$ & $* * *,, \vee \leqslant 9$ & الارجة الكلية للسمات \\
\hline
\end{tabular}

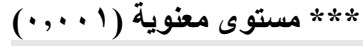

النتائج العامـة والتوصيات

• الإحساس بالمكان هو عبارة عن مجموعة من المعاني و المعتقدات والرموز والقيم و المشاعر التي يربطها

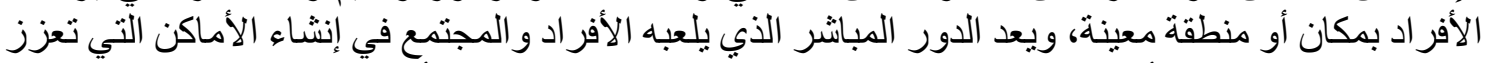

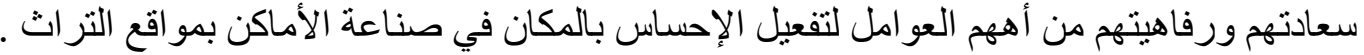

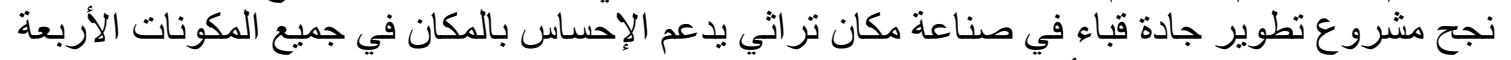

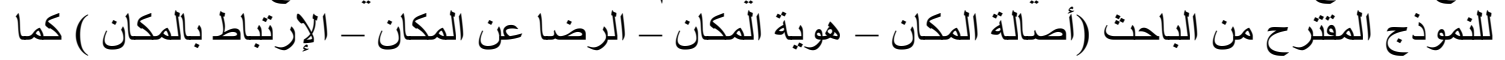

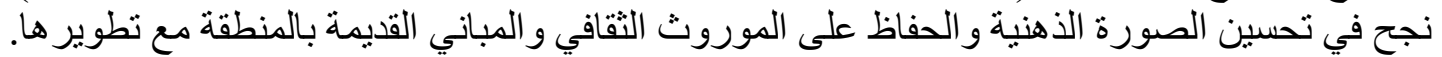

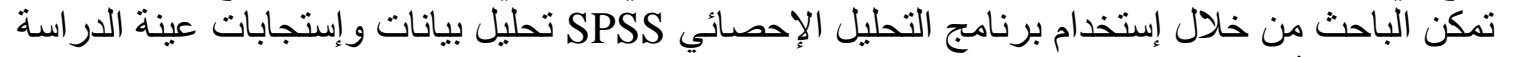

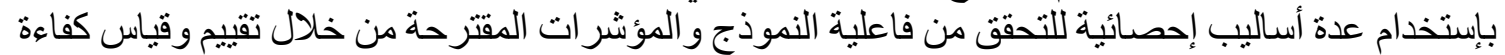

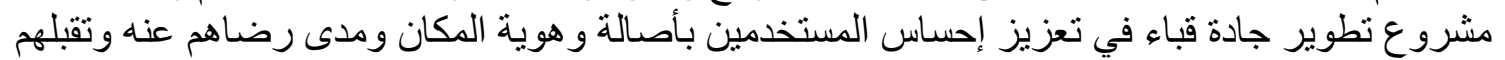

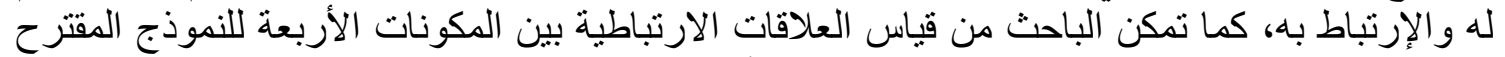

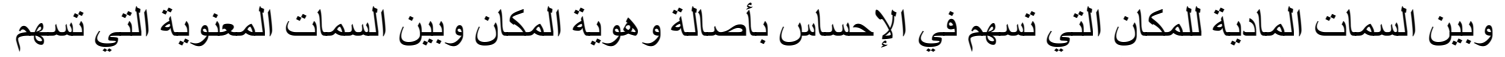

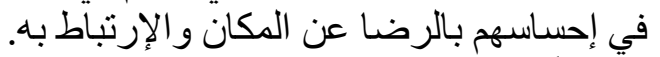

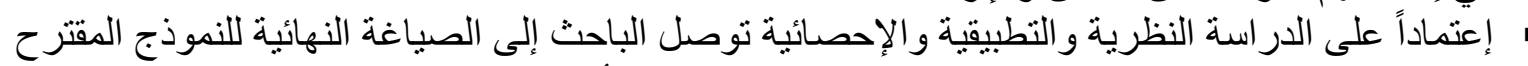

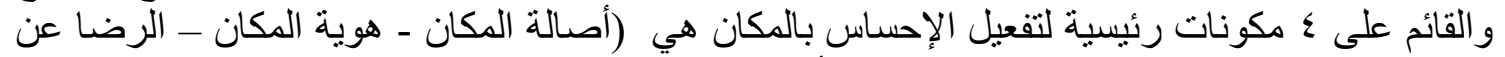

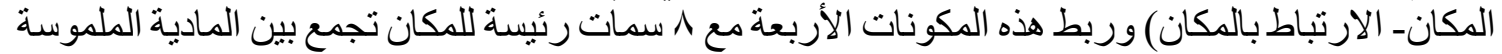

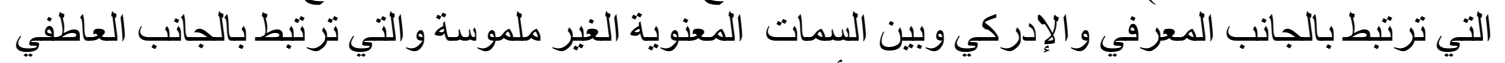

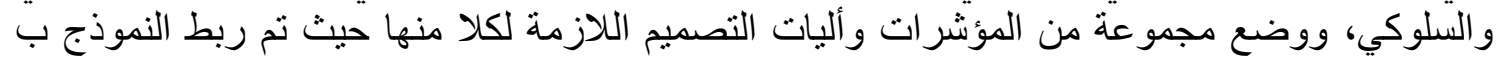




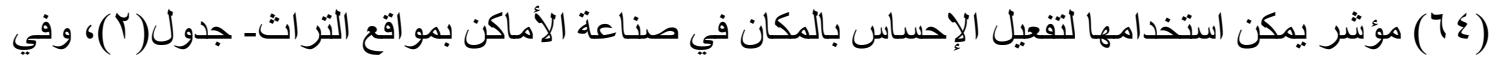

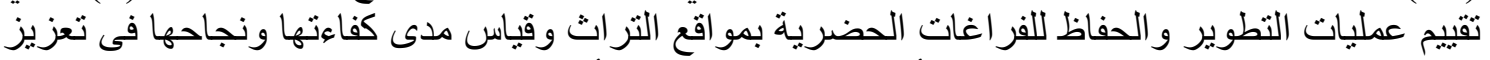

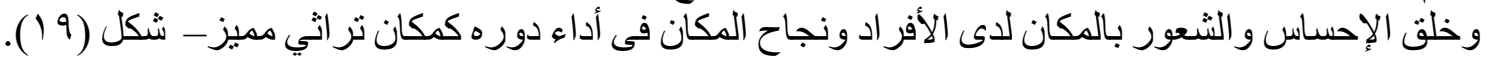

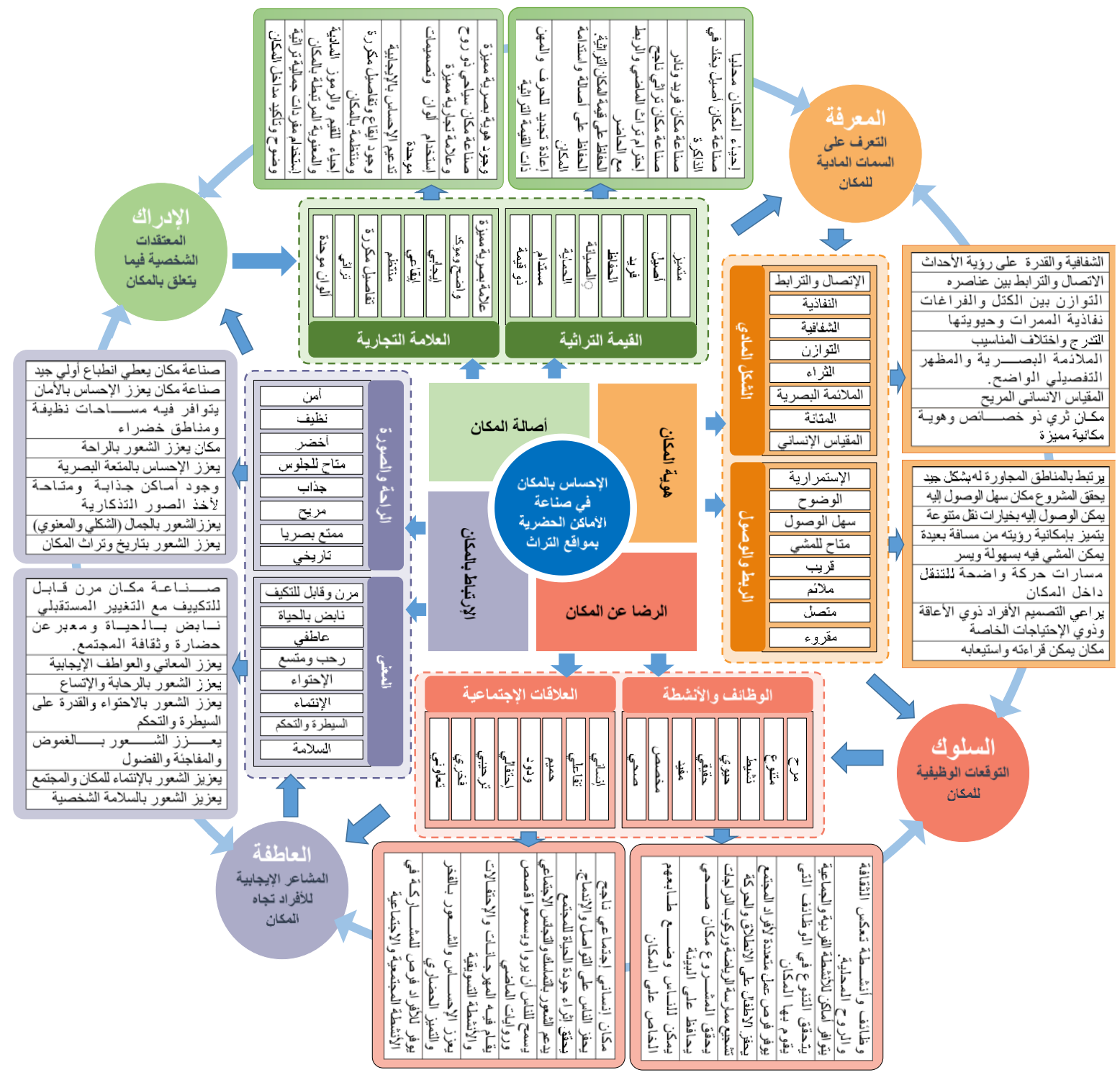

شكل (9 (1): الصياغة النهائية للنموذج المقتر ح لتفعيل الإحساس بالمكان فى صناعة الأماكن بمو اقع التراث ـ المصدر :الباحث

\section{ومن أهم توصيات الدراسة:}

• يعد تحقيق النموذج المقترح لصناعة الأماكن بمواقع التراث من أهم التوصيات الرئيسية للبحث مع تفعيل

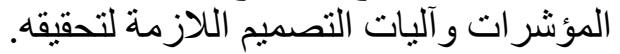

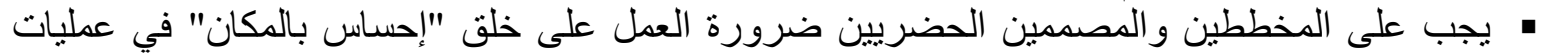

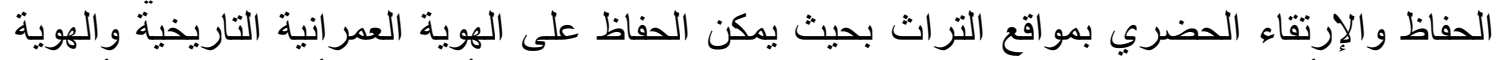

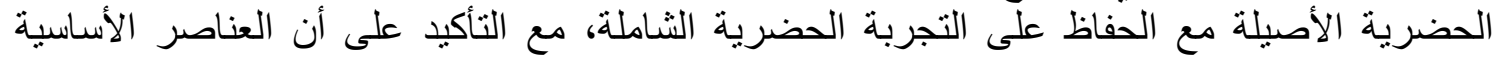

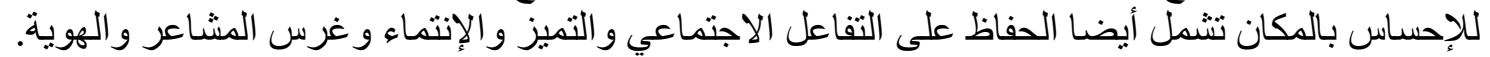

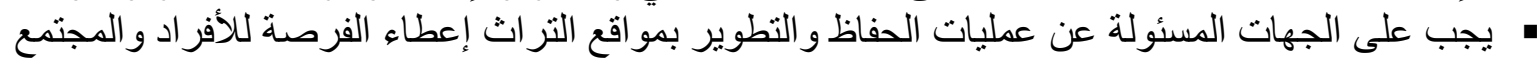

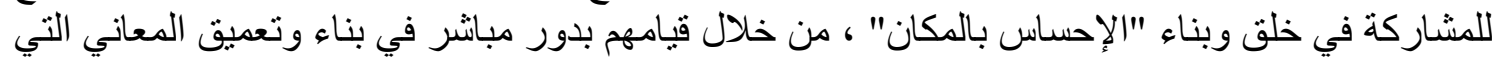




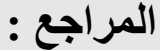

[1] Grantham, C., \& Tuan, Y. (1978). Space and Place: The Perspective of Experience. Contemporary Sociology, 7, 513.

[2] Yeung, H. L. (2013). Rethinking the role of sense of place in heritage conservation: a case study of Cattle Depot Artist Village. HKU Theses Online (HKUTO).

[3] Couclelis, H. (1992). Location, Place, Region, and Space. Geography's Inner Worlds, R. F. Abler, MG Marcus, and JM Olson, Eds..

[4] Oldenburg, R. (2007). The character of third places . Routledge.

[5] Madden, K. (2011). Placemaking in urban design. In Companion to urban design . Routledge.

[6] Ujang, N., \& Zakariya, K. (2015). The notion of place, place meaning and identity in urban regeneration. Procedia-social and behavioral sciences, 170, 709-717.

[7] "Lew, A. A. (2017). Tourism planning and place making: place-making or placemaking?. Tourism Geographies, 19(3), 448-466".

[8] "Project for Public Spaces (PPS)," 2018. [Online]. Available: https://assets-global.websitefiles.com/5810e16fbe876cec6bcbd86e/5a6a1c930a6e6500019faf5d_Oct-2016-placemaking-booklet.pdf.

[9] Lynch, K. (1960). The image of the city (Vol. 11). MIT press..

[10] Hes, D., \& Hernandez-Santin, C. (Eds.). (2020). Placemaking fundamentals for the built environment. Palgrave Macmillan..

[11] "Ross, C. (2016). Exploring the Ways Arts and Culture Intersect with Public Safety. Report for ArtPlace America."

[12] "Placemaking: What if we Built our Cities Around Places?," Project for public spaces, 2018. [Online]. Available: https://uploadsssl.webflow.com/5810e16fbe876cec6bcbd86e/5b71f88ec6f4726edfe3857d_2018\%20placem aking\%20booklet.pdf. [Accessed 117 2021].

[13] M. Al-boush, "the concept of placemaking," twentytwo Architectural Magajine, 2016. [Online]. Available: http://www.twentytwo-group.org/. [Accessed 107 2021].

[14] Corsane, G., Davis, P., \& Convery, I. (2012). Introduction: Making Sense of Place. Making Sense of Place: Multidisciplinary Perspectives.

[15] "Clark, M. (2012). Achieving Memorable Places,'Urban Sense of Place'for successful urban planning and renewal?.

[16] Mullendore, N. D., Ulrich-Schad, J. D., \& Prokopy, L. S. (2015). US farmers' sense of place and its relation to conservation behavior. Landscape and Urban Planning, 140, 67-75.

[17] Jorgensen, B. S., \& Stedman, R. C. (2001). Sense of place as an attitude: Lakeshore owners attitudes toward their properties. Journal of environmental psychology, 21(3), 233-248.

[18] Southworth, M., \& Ruggeri, D. (2011). Beyond placelessness: place identity and the global city. Companion to Urban Design, London: Routledge, 495-509..

[19] Lim, M., \& Barton, A. C. (2010). Exploring insideness in urban children's sense of place. Journal of Environmental Psychology, 30(3), 328-337.

[20] Cresswell, T. (2004). Place: A short introduction. Oxford: Blackwell.

[21] Hu, M., \& Chen, R. (2018). A framework for understanding sense of place in an urban design context. Urban Science, 2(2), 34.

[22] Krupat, E. (1985). People in cities: The urban environment and its effects (No. 6). Cambridge Univ. Press.

[23] Najafi, M., \& Shariff, M. K. B. M. (2011). The concept of place and sense of place in architectural studies. International Journal of Human and Social Sciences, 6(3), 187-193.

[24] Sebastien, L. (2020). The power of place in understanding place attachments and meanings. Geoforum, 108, 204-216. 
[25] Cymru, C.D. (2020).Placemaking Guide 2020,Design Commission for Wales Ltd.

[26] Punter, J. (1991). Participation in the design of urban space. Landscape design, 200(1), 24-27.

[27] Salah Ouf, A. M. (2001). Authenticity and the sense of place in urban design. Journal of Urban Design, 6(1), 73-86.

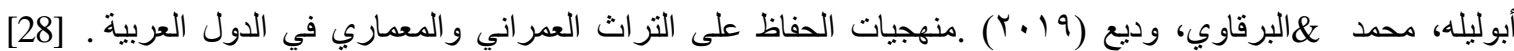
Baheth. 2. 127. 10.21625/baheth.v2i1.422..

[29] "Heath, T., Oc, T., \& Tiesdell, S. (2013). Revitalising Historic Urban Quarters. Routledge.".

[30] "Elhefnawy, M., \& Mohamed, A. (2017, November). A Proposed Methodology for'Placemaking'in the Conservation on the Heritage Areas in Egypt. In 1st International Conference on Towards a Better Quality of Life.".

[31] "Dameria, C., Akbar, R., \& Indradjati, P. N. (2018, May). Whose sense of place? Re-thinking place concept and urban heritage conservation in social media era. In IOP conference series: Earth and environmental science (Vol. 158, No. 1). IOP Publishing".

[32] "Falahatkar, H., \& Aminzadeh, B. (2020). The sense of place and its influence on place branding: a case study of Sanandaj natural landscape in Iran. Landscape Research, 45(1), 123-136.".

[33] Evans, G. (2015). Rethinking place branding and place making through creative and cultural quarters. In Rethinking place branding (pp. 135-158). Springer, Cham.

[34] Al-Duji, M. H., Taha, S. I., \& Al-Sanjari, H. A. R. (2010). الهوية المكانية لبيئة السكن في توجهات العمارة العر اقية المعاصرة و إنعكاسها على النتاج المعماري. Iraqi Journal of Architecture and Planning, 9(1)..

[35] Erfani, G. (2020). Sense of place as an investigative method for the evaluation of participatory urban redevelopment. Cities, 99, 102648.

[36] Al-Kodmany, K. (2013). Placemaking in the High-Rise City: Architectural and urban design analyses. International Journal of High-Rise Buildings, 2(2), 153-169.

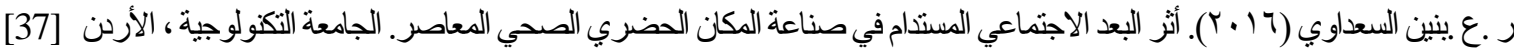

[38] Friedman, A. (2021). Sense of Place, Human Scale, and Vistas. In Fundamentals of Sustainable Urban Design (pp. 75-83). Springer, Cham..

[39] Dousti, F., \& Mostafa Behzadfar, A. V. K. (2018). A new reading of sociable public spaces: The Nexus between urban design and microsociology. Armanshahr Architecture \& Urban Development, 11(22), 39-49

2030," [Online]. Available: برنامج جودة الحياة -رؤية المملكة https://www.vision2030.gov.sa/ar/v2030/vrps/qol/. [Accessed 287 2021].

و .إ بخيت" ,اتجاهات وتحدِيّات التخطيط العمر اني في إطار السعي نحو رؤية المملكة ",2030مركز الإدارة المحلية , [41] 2021. [Online]. Available: http://www.ksclg.org/publication-project/english-urban-planningtrends-and-challenges-in-the-pursuit-of-saudi-vision-2030/. [Accessed 287 2021].

[42] , 2019. [Online]. Available:القرشي" , أنسنة المدينة ..الأحياء العشو ائية تتحول تحفاً معمارية ",العربية نت http://ara.tv/ybcx6. [Accessed 48 2021].

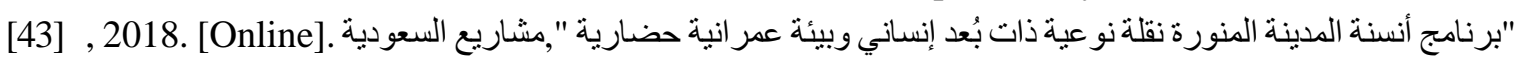
Available: http://bit.ly/2P6gUyB. [Accessed 48 2021].

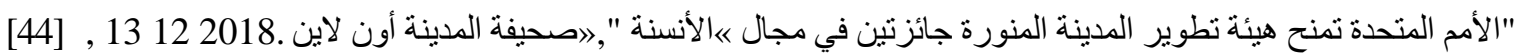
[Online]. Available: https://www.al-madina.com/article/604742. [Accessed 1308 2021]. ح .القرشي" ,جادة قباء قصة أشهر شار ع تاريخي في المدينة المنورة ",العربية نت . Available: https://ara.tv/g6gdg. [Accessed 1308 2021].

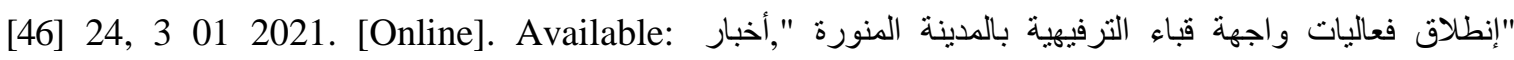
https://akhbaar24.argaam.com/article/detail/526076. [Accessed 1608 2021].

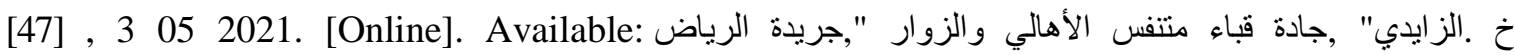
https://www.alriyadh.com/1883563. [Accessed 2908 2021].

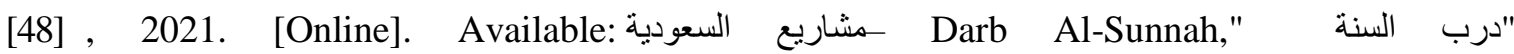
http://bit.ly/2qHbH2E. [Accessed 1608 2021]. 


\title{
The Role Of Sense Of Place In Place-Making And Urban Conservation for Heritage Sites: Al-Madinah Al-Munawara Case Study
}

\begin{abstract}
:
In the age of rapid urban development and globalization, historical cities face many challenges, the most important of which is the missing of their urban spaces for their heritage value and specific landmarks that gave it its own spirit and meaning as a vital urban element, to be replaced by the so-called lost space or no place, and thus the challenge of place-making of of heritage value and that can be recognized and felt is an urgent necessity for distinctive urban environments that enhance and maintain social, economic and cultural relations, which requires a reformulation of the basic principles in the creation of places and the concept of preservation and development of heritage sites beyond the relationship of buildings with spaces and axes that connect areas to each other to change in a way Gradually becoming more socially and psychologically oriented through the application of other elements of equal importance, which are the elements of social and psychological human needs, in order to achieve the spirit and meaning of the place derived from its natural, heritage and cultural components. Based on this problem, the researcher assumes that the sense of place is an integral part of the philosophy of placemaking and is one of the main quality indicators for cities with heritage values. The study relies on 3 main parts, starting with a theoretical study to examine the close relationship between the concept of a sense of place, placemaking and Urban Conservation, then devising, developing and formulating a model to enhance and activate the role of a sense of place in placemaking and Urban Conservation in heritage sites in a way that increases their architectural and urban efficiency And building measurable indicators for the proposed model that can be adopted in examining the existence of the concept of a sense of place in the projects of upgrading and Urban Conservation in heritage sites and their surroundings areas. The researcher chose the Quba Avenue project in Madinah as a case study, which is one of the projects of the "Humanizing Madinah" program. A field and analytical study were conducted for the project in addition to an exploratory study of the population and visitors and the analysis of the results of the questionnaire by descriptive and statistical methods, with the aim of verifying the effectiveness of the model and the indicators proposed by the researcher and evaluating the extent of success Quba Avenue development project in achieving the concept of a sense of place, , the most important conclusions of this study was the final formulation of the proposed model and the recommendation to activate it in evaluating the development and Conservation processes of urban spaces in heritage sites and measuring their efficiency and success in creating a successful urban heritage environment and place in which individuals can sense and feel a place.
\end{abstract}

\section{KEYWORDS:}

Sense of Place - Placemaking - Urban Conservation - Heritage Sites 